\title{
TOWARD THE USE OF HIGH VOLUME COARSE RECYCLED CONCRETE AGGREGATE IN NEW CONCRETE PRODUCTION
}

\section{BY}

\author{
Anto Sucic, B.Eng \\ Ryerson University \\ $2006-2010$
}

\begin{abstract}
A Thesis Presented To Ryerson University
In Partial Fulfillment of the

Requirements for the Degree of

Master of Applied Science

In The Program of

Civil Engineering
\end{abstract}

Toronto, Ontario, Canada, 2013

(C)Anto Sucic 2013 


\section{Declaration of Authorship}

I hereby declare that I am the sole author of this thesis.

I authorize Ryerson University to lend this thesis to other institutions or individuals for the purpose of scholarly research.

Author's Signature

Date

I further authorize Ryerson University to reproduce this thesis by photocopying or by other means, in total or in part, at the request of other institutions or individuals for the purpose of scholarly research.

Author's Signature Date 


\title{
TOWARD THE USE OF HIGH VOLUME RECYCLED CONCRETE AGGREGATE IN NEW CONCRETE PRODUCTION
}

\author{
Master of Applied Science, 2013 \\ Anto Sucic \\ Department of Civil Engineering \\ Ryerson University
}

This thesis reports the findings of a study carried out to determine the feasibility of using Recycled Concrete Aggregate (RCA) in the production of newly made concrete at high replacement levels of conventional coarse Virgin Aggregates (VA). The study evaluated the properties of new concrete produced with coarse RCA, in order to address the issues typically associated with the characteristics of the recycled material. Concrete specimens were tested for fresh properties, hardened properties, as well as overall durability of mixes. Making minor modifications in mix design, the drawbacks typically associated with the use of RCA were successfully mitigated at high replacement levels, making up to a full $100 \%$ replacement feasible. Through the use of higher replacement levels of RCA in the production of concrete, the environmental impacts of VA harvesting may be significantly reduced, as well as providing a more economical means of waste concrete disposal for ready mix producers. 


\section{Acknowledgements}

I would like to first and foremost express my deepest gratitude and appreciation to my mentor throughout these many wonderful years at Ryerson University, Dr. Medhat Shehata. His continuous passion for the subject and dedication to his students have been the driving inspiration and encouragement towards achieving great things, as he has always believed we could.

My continuous gratitude goes on to my Mum, who has continually strived to allow me to pursue my ambitions and get me through the toughest of times. She is truly my inspiration to strive for my achievements.

My gratitude extends to the wonderful faculty and staff of the Ryerson University Department of Civil Engineering. For the many years I have been here, I was proud to call this department my home away from home. The opportunities that were provided and support that we had received as the students in this department have shaped us to be the proud future engineers we were inspired to be.

Finally, my appreciation goes to my friends throughout these many years who have endured the struggles and shared the laughter with me during my time at Ryerson. Special thanks go out to Kirllos Wahba and Dan Hughi, whose friendship and support have kept us going. A special thanks also goes out to Min Yao, Domenic Valle, and Nidal Jaalouk for their support over the years. 


\section{Dedication}

\section{Mum}

My Inspiration 


\section{Table of Contents}

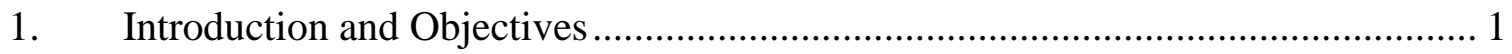

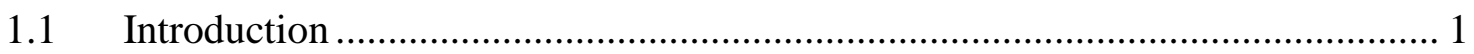

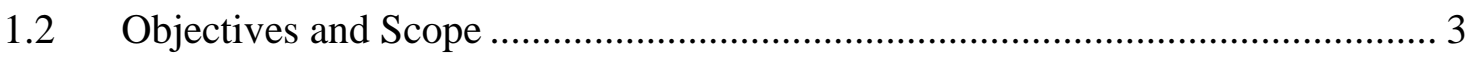

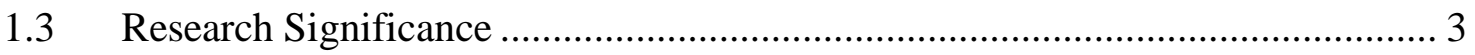

1.4 Research Objectives ............................................................................ 4

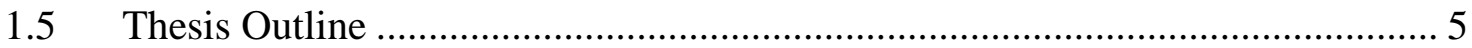

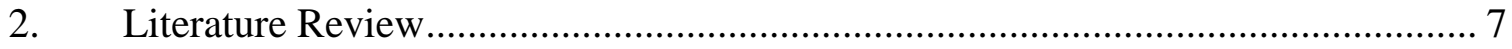

2.1 Residential (Class-R) Concrete .......................................................... 7

2.2 Recycled/Reclaimed Concrete Aggregate (RCA) ..................................... 8

2.2.1 Origins and Properties of Recycled Concrete Aggregate ........................... 9

2.2.2 Properties of Concrete made with Recycled Concrete Aggregate.............. 11

2.3 Alkali Silica Reaction (ASR) in Concrete...................................................... 21

2.3.1 Mitigation of Alkali Silica Reaction ................................................. 22

2.4 Alkali Silica Reaction and Recycled Concrete Aggregate ............................. 24

3. Materials and Experimental Methods ............................................................. 25

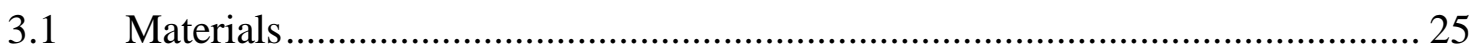

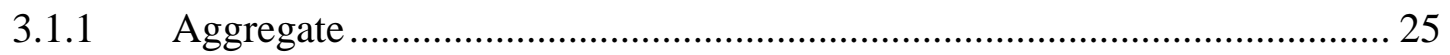


3.1.2 Cementing Materials .............................................................................. 27

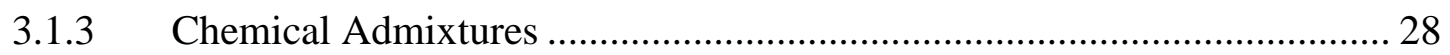

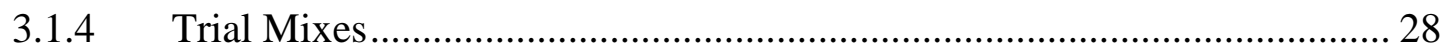

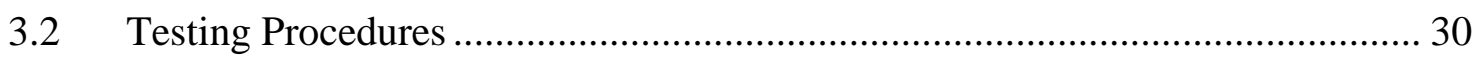

3.2.1 Batching Sequence and Fresh Properties .................................................... 30

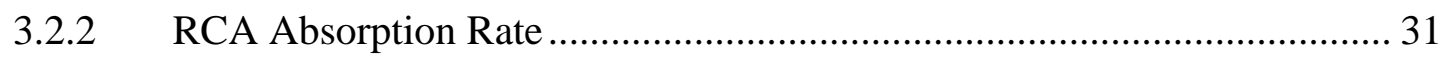

3.2.3 Compressive Strength Testing ……………….................................... 32

3.2.4 Drying Shrinkage Testing .................................................................... 32

3.2.5 Alkali Silica Reaction (ASR) Testing ......................................................... 33

3.2.6 Alkali Leaching Test .......................................................................... 34

3.2.7 Paste Testing - Shrinkage Reducing Admixture (SRA) ............................. 38

3.2.8 Rapid Chloride Permeability Testing (RCPT) ............................................. 40

3.2.9 Freezing and Thawing Resistance Testing …………….......................... 41

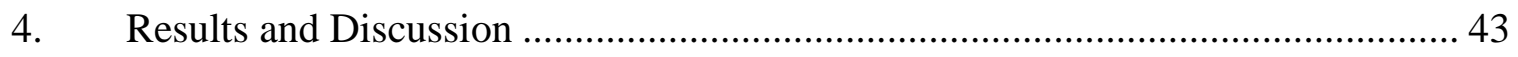

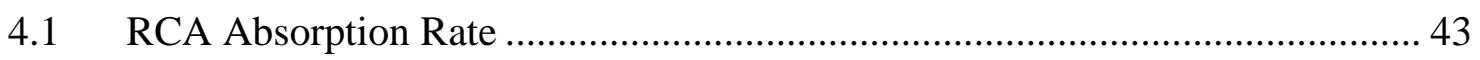

4.2 Batching Procedure and Fresh Properties .......................................................... 46

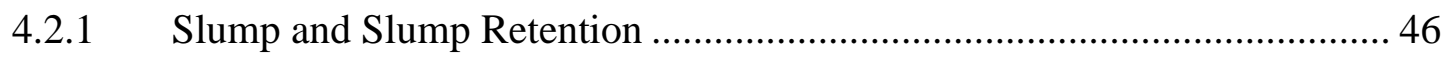

4.2.2 Air Content.......................................................................................... 49

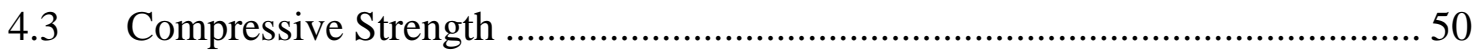

4.4 Drying Shrinkage Evaluation of RCA Concrete ............................................ 53 
4.4.1 Drying Shrinkage of Conventional VA vs. RCA Concrete ....................... 53

4.4.2 Effect of GGBS Addition to VA Concrete ............................................ 54

4.4.3 Effect of Chemical Admixtures on VA Concrete Shrinkage ...................... 56

4.4.4 Effect of 100\% RCA replacement of Coarse Aggregate .......................... 58

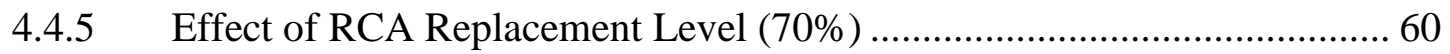

4.4.6 Effect of 70\% RCA Replacement and GGBS Addition ........................... 61

4.4.7 Effect of Shrinkage Reducing Admixture (SRA) Dosage .........................63

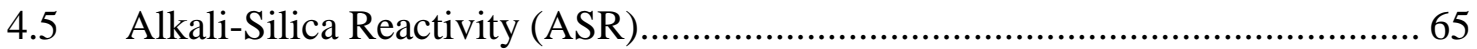

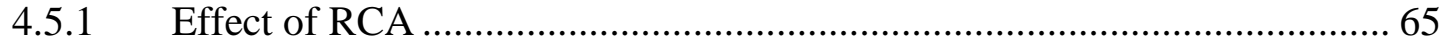

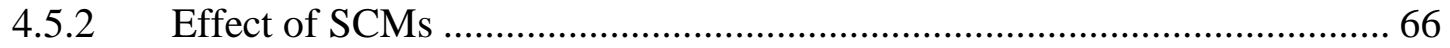

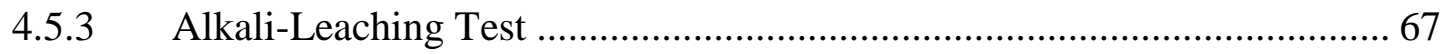

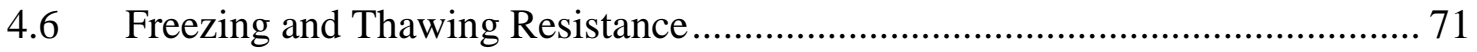

4.6.1 Virgin Aggregate Control Mix (V-CTR-FT) ......................................... 71

4.6.2 100\% Recycled Concrete Aggregate Mix (R-CTR-FT) .......................... 73

4.6.3 100\% Recycled Concrete Aggregate Mix with 30\% Slag Replacement .... 75

4.6.4 Relative Behaviour of Freeze/Thaw Specimens ..................................... 78

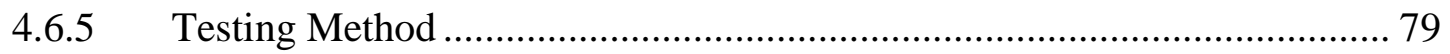

4.7 Rapid-Chloride Permeability Testing (RCPT) .............................................. 80

4.8 Hydration Rate Testing of SRA Paste Samples using Loss on Ignition ............ 82

5. Summary, Conclusions and Recommendations for Future Work ....................... 84 
5.1 Batching and Fresh Properties of RCA Concrete........................................... 84

5.1.1 Conclusions for Batching and Fresh Properties of RCA .......................... 84

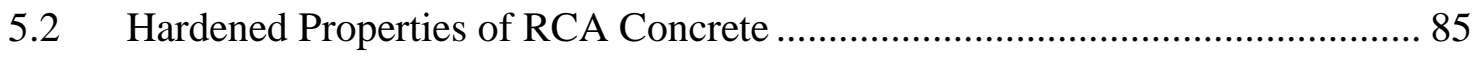

5.2.1 Conclusions for Hardened Properties of RCA Concrete ........................... 85

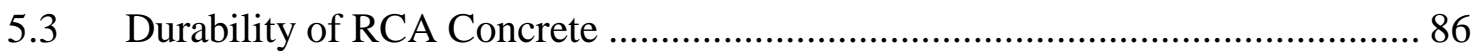

5.3.1 Conclusions for Durability of RCA Concrete........................................... 86

5.4 Recommendations for Future Research .................................................. 88

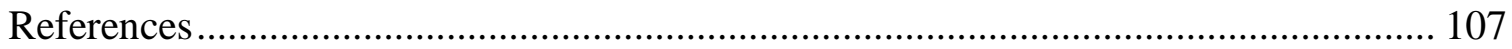




\section{List of Tables}

Table 2-1- CSA Class-R exposure criteria (Canadian Standards Association, 2009) ........ 7

Table 2-2 Properties of virgin aggregate vs. RCA (American Concrete Pavement

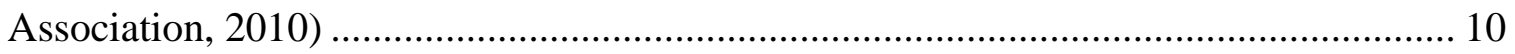

Table 2-3 Two-Stage Mixing Approach (TSMA) (Tam, Gao, \& Tam, 2005) ................ 14

Table 2-4 Effect of RCA on fresh properties of concrete (American Concrete Pavement

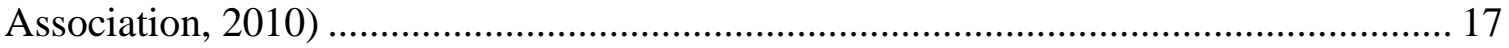

Table 2-5 Effect of RCA on hardened properties of concrete (American Concrete

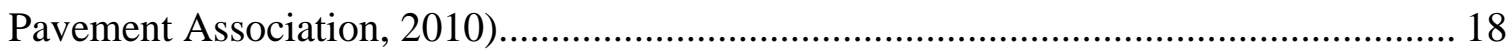

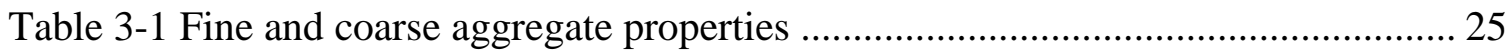

Table 3-2 Chemical composition of cementing materials ........................................ 27

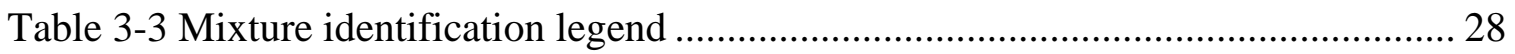

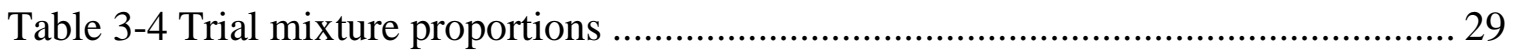

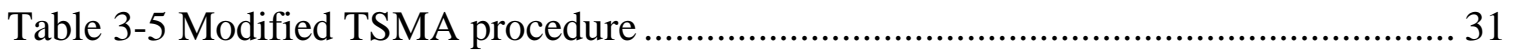

Table 3-6 - Summary of concrete prism test specimens ............................................. 34

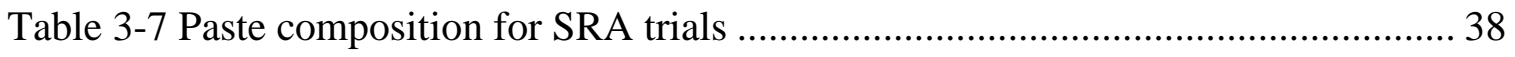

Table 4-1 - Compressive strength and standard deviation of trial mixtures ...................52

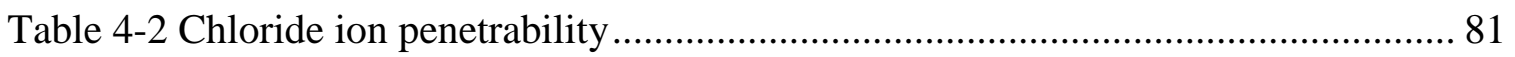

Table D-1 Absorption Rate of 14 mm - 19 mm RCA ........................................... 102

Table D-2 Absorption Rate of 10 mm- 14 mm RCA................................................ 103

Table D-3 Absorption Rate of 5 mm - 10 mm RCA.................................................. 104 
Table D-4 Absorption Rate of Graded Mixture.

Table E-1 Loss on Ignition (LOI) of Paste Samples................................................ 106 


\section{List of Figures}

Figure 2.2-1 Interfacial Transition Zones (ITZs) locations on RCA concrete 12

Figure 2.2-2 - Interfacial transition zones in RCA concrete (Ryu, 2002)

Figure 2.2-3 Interfacial transition zone (ITZ) composition (Mehta \& Monteiro, 1993) .. 13

Figure 2.2-4 - RCA concrete using TSMA (Ryu, 2002). 15

Figure 2.2-5 - Preferential path of water in VA concrete (left) and RCA concrete (right) (Konin \& Kouadio, 2011)

Figure 2.3-1 - Map cracking in concrete experiencing ASR (Fontana, 2013).....

Figure 3.1-1 Coarse RCA gradation 26

Figure 3.2-1 RCPT specimen preparation 40

Figure 4.1-1 Absorption rate of coarse RCA.... 44

Figure 4.2-1 Virgin aggregate mixure slump retention 47

Figure 4.2-2 RCA mix slump monitoring with additional water tampering throughout retention cycle. 48

Figure 4.3-1 Compressive strength (100\% VA) 50

Figure 4.3-2 Compressive strength (100\% RCA). 51

Figure 4.4-1 Drying shrinkage of conventional VA concrete and experimental RCAconcrete 54

Figure 4.4-2 Drying shrinkage of mixes with virgin aggregates and GGBS replacement 55 Figure 4.4-3 Ultimate 180-day drying shrinkage of class R virgin aggregate mixtures... 55 Figure 4.4-4 Drying shrinkage of mixes with virgin aggregates \& chemical admixtures 57 
Figure 4.4-5 Ultimate drying shrinkage of VA mixtures containing chemical admixtures

Figure 4.4-6 Drying shrinkage of mixes with 100\% RCA replacement and 30\% GGBS 58

Figure 4.4-7 Ultimate drying shrinkage of mixtures containing 100\% RCA 59

Figure 4.4-8 Drying shrinkage of mixtures containing varying RCA replacement levels 60

Figure 4.4-9 Ultimate drying shrinkage of mixes containing both VA and RCA 61

Figure 4.4-10 Drying shrinkage of mixes containing both 70\% RCA \& 30\% GGBS ..... 62

Figure 4.4-11 Ultimate drying shrinkage of mixes with VA, RCA, and 30\% GGBS ..... 63

Figure 4.4-12 Drying shrinkage of mixtures with varying SRA dosages ....................... 64

Figure 4.4-13 Ultimate drying shrinkage of VA and RCA mixtures containing SRA ..... 64

Figure 4.5-1 Reactivity of marginally reactive sand with $100 \%$ coarse RCA ................. 66

Figure 4.5-2 Reactivity of marginally reactive sand and 100\% coarse RCA with SCMs 67

Figure 4.5-3 Released alkalis from paste specimen results in DW 68

Figure 4.5-4 Released alkalis from paste specimens results in solution (\% of CTR mix) 69

Figure 4.5-5 90-week expansion versus available alkalis for tested paste samples......... 70

Figure 4.6-1 Adequate (left) and poor (right) performance freezing and thawing test specimens (Wang \& Steffes, 2009) 71

Figure 4.6-2 Durability factor of VA class R mixes cast at $0.7 \mathrm{w} / \mathrm{cm}$ 72

Figure 4.6-3 Freezing/thawing specimens - VA control mix at $0.7 \mathrm{w} / \mathrm{cm}$ ratio 73

Figure 4.6-4 Durability factor of $100 \%$ coarse RCA mixes cast at $0.62 \mathrm{w} / \mathrm{cm}$ ratio 74 
Figure 4.6-5 Freezing/thawing specimens $-100 \%$ Coarse RCA at $0.62 \mathrm{w} / \mathrm{cm}$ ratio ...... 75

Figure 4.6-6 Durability factor of $100 \%$ RCA mixes \& 30\% GGBS at $0.62 \mathrm{w} / \mathrm{cm}$ ratio .76

Figure 4.6-7 - Freezing/thawing specimens of 100\% RCA \& 30\% GGBS at 0.62 w/cm 77

Figure 4.6-8 Average durability factors for all freezing/thawing specimens ................. 78

Figure 4.6-9 Freezing/thawing specimens - general observations ............................... 78

Figure 4.6-10 Pulse-velocity testing method - direct (The Constructor, 2012) .............. 79

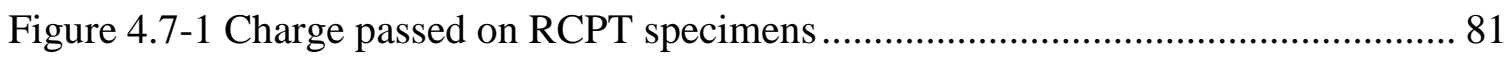

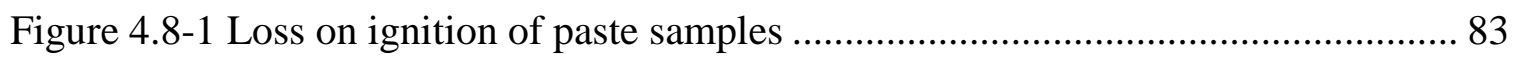




\section{List of Appendices}

Appendix A - Alkali Leaching Test Calculations and Results................................... 90

Appendix B - Drying Shrinkage Prism Results ....................................................... 96

Appendix C - Freeze/Thaw Durability Results ................................................. 100

Appendix D - RCA Absorption Rate Results..................................................... 102

Appendix E - LOI Testing Results ..................................................................... 106 


\section{Chapter 1}

\section{Introduction and Objectives}

Though we commonly take for granted the built environment in which we live, one would hardly realize the major role that this man-made conglomerate of nature's raw phenomenon plays in the daily lives of people. Much like the people that design and produce it, concrete undergoes its own extensive and rigorous life cycle. From the moment the first light hits the stone at the quarry, through the heat, pressures, and diversity of the cement plant, to forming bonds with the aggregate that originally shaped the cement into what it has become, holding strong through the years and challenges faced, and ultimately, when all else fails, we pick ourselves up and rise to the occasion once again. These are the fundamental principles to which we pride ourselves as engineers, and our work should strive be a clear reflection of these values.

\subsection{Introduction}

Rising to the occasion once again is where the greatest untapped potential in the ready mix concrete production industry lies. Around the globe, ready mix producers consume a vast quantity of raw natural resources to produce the constituents and concrete that is immensely used every day. This is a necessary step in order to produce the concrete used in the construction of various structures that make up the nature of our modern day society. With such practice however, comes great scrutiny on the environmental effects associated with such actions.

Concrete waste products, and by-products, have been dumped into landfill sites as a 'means of disposal' for many years, and thus consumed invaluable space that is already very limited. Becoming more aware of our actions, people have adapted a belief in sustainable development and thus promoting interest in making better use of what was once referred to as waste. 
Recycling concrete of any nature has become a popular topic around the globe and, though the hesitation exists and the progress is slow, research continues on the Recycled Concrete Aggregate (RCA), in order to promote its use in the development of new concrete.

The hesitation stems from the fact that RCA has such an unpredictable nature and experiences many of the drawbacks that concrete is initially designed to avoid. RCA's physical properties create many challenges in performance, but from research and better understanding, and being willing to accept the negatives as new challenges, we can ultimately work towards a positive sustainable development practice through maximizing the use of these materials.

Among the vast quantity of concrete supplied by ready mix producers each year, aggregate yards contain heaps of virgin aggregate used in the production, but are also filled with a large amount of hardened concrete awaiting proper processing and disposal. While some of this concrete is currently re-processed into RCA, and sold as granular base material, ready mix producers are reluctant to implement RCA into their concrete mixes, and thus are not able to take full advantage of these materials. The reluctance to incorporate RCA into their mix designs stems from the drawbacks of the properties of RCA, among which reduced strength (Hansen, 1986), increased drying shrinkage (SagoeCrentsil, Brown, \& Taylor, 2001), and the possibility of promoting of Alkali-Silica Reactivity (ASR), are major potential concerns which this study focused to address.

Depending on the type of RCA used, it is thus apparent that the deciding factor on the properties of the aggregate becomes the composition of the residual mortar. A diluted paste matrix reduces the overall density of the material (Limbachiya, Koulouris, Roberts, \& Fried, 2004), and also lowers the compressive strength. The workability of RCA concrete mixes is reduced by the increased absorption rate of the RCA (Rahman, Hamdam, \& Ahmad Zaidi, 2009). By replacing the virgin aggregate with RCA, the overall paste volume (including both residual and new paste) is increased significantly, 
and thus contributes to significant increases in drying shrinkage (Tavakoli \& Soroushian, 1996). Finally, the residual paste may contribute to alkali-aggregate reactivity due to its alkali and calcium hydroxide contents. These are three of the main parameters evaluated in this study.

\subsection{Objectives and Scope}

The study aims at developing more concrete applications that can safely incorporate a large volume of coarse RCA. One of such applications is concrete of moderate strength (15-20 MPa), which can be used in residential (Class $\mathrm{R}$ ) concrete. The experimental program evaluates a full range of parameters associated with the production of RCA concrete.

To further reduce the carbon footprint of the mixes, and relate to current practices of concrete production in Ontario, the use of Ground, Granulated Blast Furnace Slag (GGBS) is also incorporated and evaluated in the mixes. The use of common chemical admixtures such as Water Reducing Admixture (WRA), and Shrinkage Reducing Admixture (SRA) to reduce drying shrinkage, was also evaluated. By better understanding the performance of incorporating large volumes of RCA into concrete production, the ultimate goal of this project is to produce a feasible approach for production of RCA concrete that would minimize both economic and environmental impacts.

\subsection{Research Significance}

This research is among the few to evaluate the use of high volume RCA implementation in structural concrete, according to current Canadian standards in North America. The focus of this research is to assess the use of high volumes of RCA in new concrete production. This is done in order to contribute towards a sustainable industry design by implementing a highly environmentally friendly, and economically feasible, approach to structural concrete design in the ready mix industry. This research hopes to further 
contribute towards raising the interest in testing and implementing the use of RCA in the ready mix and construction industry.

\subsection{Research Objectives}

The project looks at developing construction applications for coarse RCA. It has been found that concrete with RCA, despite achieving relatively high strength, suffers other negative impacts on long term performance, especially drying shrinkage. The research looks at ways of controlling fresh properties, and mitigating the effects of long term durability issues in moderate strength concrete containing coarse RCA.

The principle objectives of this project are to evaluate all parameters associated with the production of high-volume RCA concrete. The ultimate goal of this research; the use of coarse RCA in concrete production, is to achieve equivalent (or better) fresh and hardened properties than its virgin aggregate counterparts. Research has shown that, through proper mixture design, such a goal is possible. The effects of implementing RCA into concrete are highly dependent on the nature, composition, and gradation of the RCA (American Concrete Pavement Association, 2010).

Initial steps included a look into the physical properties of the material to better understand the possible drawbacks by evaluating the moisture behaviour of the aggregate and its constituents.

Once the behaviour of the aggregate was understood, a proper batching procedure needed to be developed accordingly, and the production parameters needed to be redefined. The fresh properties of all concrete batches were thoroughly monitored throughout the production process and care was taken to ensure field-like conditions were simulated to best represent real-world applications. The stability of the concrete's fresh properties, mainly slump and air retention, were the major focus in production.

Hardened properties of the mixes were tested to ensure the design criteria are satisfied in terms of meeting the compressive strength requirements for the production of Class $\mathrm{R}$ 
concrete. Ultimately, various parameters of long-term durability were evaluated to provide a focal point for future research development in other mixes. The long-term durability focused on monitoring some primary concrete concerns including drying shrinkage, the freezing and thawing durability, chloride ion penetration, and alkali-silica reaction.

As this topic is of great interest to the industry, industry-favourable conditions were maintained throughout the study. All mixtures were made with a high water-to-cementing materials $(\mathrm{w} / \mathrm{cm})$ ratio, and relatively low cementing materials content, in order to minimize the overall cost of the application. The use of GGBS is also incorporated to reduce the carbon footprint of the project and better reflect current industry practices. The effects of common and specialty chemical admixtures, such as Water Reducing Admixture (WRA) and Shrinkage Reducing Admixture (SRA), respectively were also evaluated.

Ultimately, the goal of the project is to produce a feasible approach of incorporating RCA in the large-scale use of concrete to minimize costs and impact on the environment. Furthermore, favourable results of the study may provide a basis for further future research in higher risk/performance applications for specialty concrete.

\subsection{Thesis Outline}

Chapter 1 sets the train of thought for the importance of sustainable material production and introduces the role RCA can play towards achieving this goal. Further emphasis is put on the topic's importance to the ready mix concrete and construction industry, as well as outlining the significance of this research and respective parameters investigated.

Chapter 2 includes a comprehensive overview of the major research previously performed on the topic of RCA concrete, as well as the fundamental concepts behind the research. Specific focus is maintained on the origins and properties of RCA, the challenges associated with its use in concrete production, as well as the principles behind 
the various durability testing parameters. By thoroughly understanding the concepts addressed in this chapter, one may obtain the necessary circumstantial understanding to interpret these results.

Chapter 3 outlines a complete overview of the specifics involved in the research process. Details including the experimental procedures, as well as properties of the raw materials used in this study are covered. It is important to understand the detailed approaches taken in the testing process, as outlined in this chapter, in order to realize the full potential of the material in application.

Chapter 4 analyzes the findings obtained throughout the research process and discusses their significance. The various evaluation parameters are outlined in chronological order and discuss the important findings in order to find conclusions for implementation of the tested techniques.

Chapter 5 presents the conclusions of the study and their relevance to further potential research in the development of high-volume RCA concrete. 


\section{Chapter 2}

\section{Literature Review}

\subsection{Residential (Class-R) Concrete}

Residential (or otherwise referred to as 'Class-R') concrete is defined by CSA A23.1-09 as represented in Table 2-1, below. As seen, this class of concrete comprises of very high maximum w/cm ratios (0.7) and relatively low requirements in terms of compressive strength (15-20 MPa at 28 days).

Mixes designed to conform to this exposure class are typically produced by ready mix producers in the most economical means possible, by minimizing on the cementing material content, maximizing the $\mathrm{w} / \mathrm{cm}$ ratio, and eliminating the need for expensive admixtures. As Supplementary Cementing Materials (SCMs) are typically cheaper alternatives to Portland Cement (PC), and decrease the environmental impact of concrete production, their use is highly encouraged in the production of all mixes, and is common practice throughout the province of Ontario, and various other provinces in Canada.

Table 2-1- CSA Class-R exposure criteria (Canadian Standards Association, 2009)

\begin{tabular}{ccccc}
\hline $\begin{array}{c}\text { Class of } \\
\text { exposure }\end{array}$ & Description & $\begin{array}{c}\text { Maximum } \\
\text { W/CM Ratio }\end{array}$ & $\begin{array}{c}\text { Minimum Compressive } \\
\text { Strength } \\
(\mathrm{MPa} @ \text { @ 28 Days })\end{array}$ & $\begin{array}{c}\text { Air } \\
\text { Content }\end{array}$ \\
\hline R-1 & $\begin{array}{c}\text { Residential concrete: } \\
\text { footings, columns, } \\
\text { fireplaces, and chimneys }\end{array}$ & 0.7 & 15 & $3-6 \%$ \\
\hline R-2 & $\begin{array}{c}\text { Residential concrete: } \\
\text { foundation walls, grade } \\
\text { beams, piers, etc. }\end{array}$ & 0.7 & 15 & $4-7 \%$ \\
\hline R-3 & $\begin{array}{c}\text { Residential concrete: } \\
\text { interior slabs on ground not } \\
\text { exposed to freeze-thaw }\end{array}$ & 0.65 & 20 & - \\
\hline
\end{tabular}


This type of concrete application is also amongst the highest volume applications in the market, and thus even small reductions in production costs (i.e. material costs, transport, etc.) would significantly impact the value of these mixes to ready mix producers throughout the province. As such mixtures are considered both high volume, and low risk applications, they become the optimal potential applications for evaluation of using a high volume of coarse recycled materials in their production. From a technical perspective, their design parameters also perfectly simulate some worst-case scenarios in terms of concrete properties for performance considering the high $w / \mathrm{cm}$ ratio and relatively low strength.

\subsection{Recycled/Reclaimed Concrete Aggregate (RCA)}

The construction industry relies heavily on the production of concrete to continue maintaining and developing our cities and societies. Producing two of concrete's primary constituents (aggregate and cement) requires the use of large amounts of raw materials and decreases the availability of natural resources, while at the same time increasing energy consumption for their processing and transportation (Oikonomou, 2005). As highquality virgin aggregate sources are being rapidly depleted, costs of virgin aggregates and raw materials are rising. Consequently, cost effective and sustainable alternatives had to be implemented, and with such a demand, gave rise to the wider-scale application of RCA. Interest and research led to the many current (and proposed) uses of RCA. Some of these would include, but are not limited to: Unstabilized (Granular) Subbase/Backfill, Cement-Stabilized Subbases, Concrete Mixtures, water treatment filters, and many more (American Concrete Pavement Association, 2010).

Concrete, and other building and demolition waste, are typically processed and taken to landfills when not re-used. Upon demolition of an existing structure, the claimed concrete could be recycled into new construction rather than being taken to landfill sites for disposal. This action reduces the use of landfills and natural virgin aggregate (Tam \& Tam, 2007). 
In regards to sustainable development, the use of Recycled Aggregate Concrete (RAC) is acquiring particular interest in civil construction. The use of coarse RCA has already been accounted for in many countries, in fact, Italy definitively allows for the use of $30 \%$ coarse RCA replacement of virgin aggregate for producing structural concrete since 2009 (Corinaldesi V. , 2011). Similarly, recycling of building and demolition waste has been set at $40 \%$ in Germany since 1991. In 1994, Holland used approximately 78,000 tons of RCA in the production of new concrete, as a $20 \%$ replacement for coarse aggregate, without differentiation in fresh and hardened properties of the concrete (Oikonomou, 2005).

The European Code EN 206 (Annex E) had actually incorporated the use of coarse recycled material as part of their general practices and allows up to a $50 \%$ replacement level, depending on the exposure class (European Committee for Standardization, 2012). It further subdivides the RCA in various categories based on sources, gradations, and properties. Further considerations are even implemented to account for ASR risks and measures.

\subsubsection{Origins and Properties of Recycled Concrete Aggregate}

The properties of RCA are contingent upon its original source. There are two main types of RCA, each with their own distinct features; Reclaimed "Municipal" RCA and Returnto-Plant "Clean" RCA.

Reclaimed RCA originates from the demolition of existing structures, and is processed back into aggregate. This variant of RCA has typically undergone proper curing and placement procedures, required in order to satisfy the criteria specified for its original purpose, but has also been exposed to different degrading conditions over its service life, and thus may leave undesired residuals inside the mortar of the aggregate such as chlorides. The material typically also contains a certain level of particulate contaminants; such are asphalt chunks, wood chips, corroded steel slivers, or others, collected from the demolition site, and brought back to the processing plant. 
Return-to-Plant RCA, or otherwise known as "Clean" RCA, is the end product of processing the hardened washout concrete from trucks into granular material. Though this 'clean' material is typically free of (or contains minimal) contaminants, it also suffers from a lack of proper placement and curing, and is unable to form a strong paste matrix due to the excessive water added into the mix to wash it out of the truck's drum.

Both types of RCA are typically stored in separate location within the same aggregate yard. The piles start as larger waste sections of hardened concrete and are then processed through using a portable crushing plant in order to dispose of the hardened material. Much of this processed material is stored and re-used as a granular product wherever the application is feasible.

American Concrete Pavement Association (2010) has prepared an overview of the fundamental properties of RCA (relative to VA), as displayed in Table 2-2. Due to the crushing process associated with the production of RCA, the shape and texture of RCA particles has been found to typically be angular with a rougher surface, as well as more porous (Limbachiya, Koulouris, Roberts, \& Fried, 2004). In fact, some studies have suggested that the crushing process of the RCA will actually impact the reactivity of the material when used in the production of new concrete.

Table 2-2 Properties of virgin aggregate vs. RCA (American Concrete Pavement Association, 2010)

\begin{tabular}{ccc}
\hline Property & Virgin Aggregate & RCA \\
\hline Shape and Texture & Well-rounded \& smooth to angular \& rough & Angular with rough surface \\
\hline Absorption Capacity & $0.8 \%-3.7 \%$ & $3.7 \%-8.7 \%$ \\
\hline Specific Gravity & $2.4-2.9$ & $2.1-2.4$ \\
\hline L.A. Abrasion Mass Loss & $15 \%-30 \%$ & $20 \%-45 \%$ \\
\hline Sodium Sulfate Soundness & $7 \%-21 \%$ & $18 \%-59 \%$ \\
\hline Mass Loss & & $1-12 \mathrm{lb} / \mathrm{yd}\left(0.6-7.1 \mathrm{~kg} / \mathrm{m}^{3}\right)$ \\
\hline Chloride Content & $0-2 \mathrm{lb} / \mathrm{yd}^{3}\left(0-1.2 \mathrm{~kg} / \mathrm{m}^{3}\right)$ & 10.6 \\
\hline
\end{tabular}


Other typical physical properties, including absorption, specific gravity, abrasion resistance, soundness and chloride content, are predominantly impacted by the presence of residual mortar on the RCA aggregate. The porous nature of the residual mortar reduces the overall specific gravity of the material, while creating increased absorptive properties, due to the presence of cementing materials and potential intrusion paths created in the fractured aggregate.

The hardness of concrete paste (making up the majority of the residual mortar) is typically lower than that of virgin aggregate, and thus lowering the aggregate's abrasive resistance. It is thus extremely important that the density and absorptive properties of the RCA are carefully determined prior to implementation in new concrete (Limbachiya, Koulouris, Roberts, \& Fried, 2004).

\subsubsection{Properties of Concrete made with Recycled Concrete Aggregate}

The use of RCA in concrete can impact both the fresh and hardened properties of the concrete, regardless of coarse or fine constituents, and thus requires the typical mix designs to be modified in order to mitigate the drawbacks associated with the use of RCA in higher volumes (Hansen, 1986).

Concrete produced with RCA essentially comprises of not only the Interfacial Transition Zone (ITZ) between the original aggregate, and residual mortar of the RCA, but also that between the RCA and fresh paste (Ryu, 2002), as shown in Figure 2.2-1. It is thus necessary to ensure a stronger ITZ formation with the new paste, in order to achieve comparable compressive strength results, as the strength is usually dictated by the weaker of the two ITZ's (Zhang \& Ingham, 2010). 


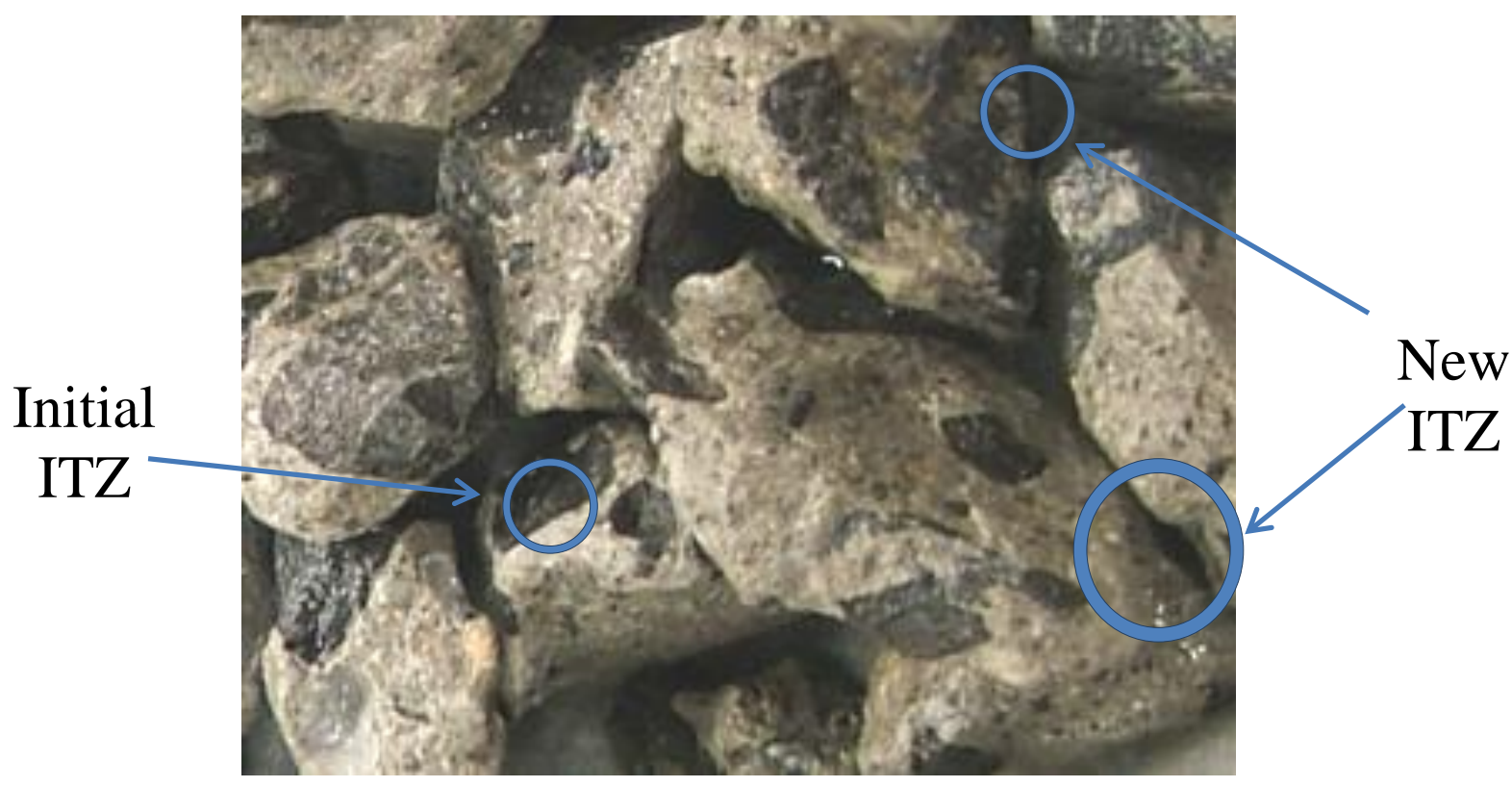

Figure 2.2-1 Interfacial Transition Zones (ITZs) locations on RCA concrete

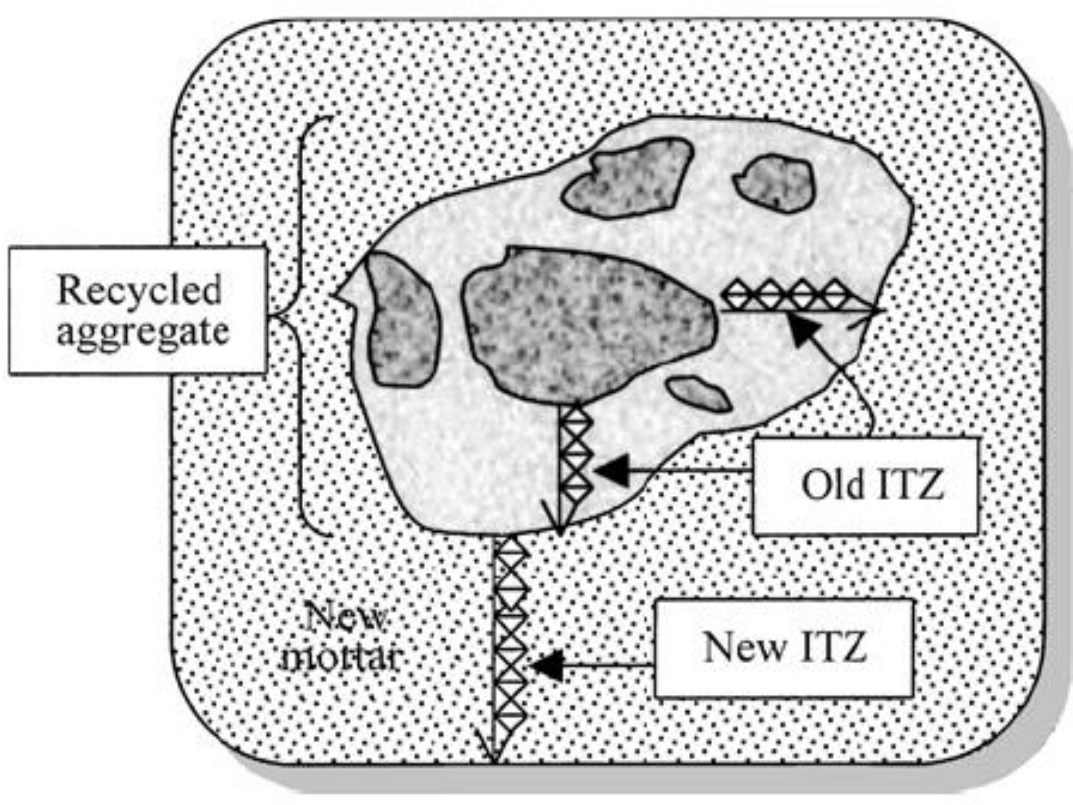

Figure 2.2-2 - Interfacial transition zones in RCA concrete (Ryu, 2002)

Figure 2.2-2 displays the various ITZ's that occur within concrete made with RCA. The initial ITZ occurs at the interface between the original virgin aggregate and mortar used 
to produce the RCA's concrete of origin. This ITZ is essentially a highly influential factor in determining the performance of the concrete produced. The new ITZ occurs at the interface between the old and new mortar. The ITZ, by nature, is a porous zone of crystallized Ettringite and Calcium Silicate Hydrate $(\mathrm{CSH})$ as seen in Figure 2.2-3 (Mehta \& Monteiro, 1993). These zones are typically around 10-15 $\mu \mathrm{m}$ in thickness at the edges of the virgin aggregate, residual mortar, and new mortar thicknesses depicted in Figure 2.2-2.

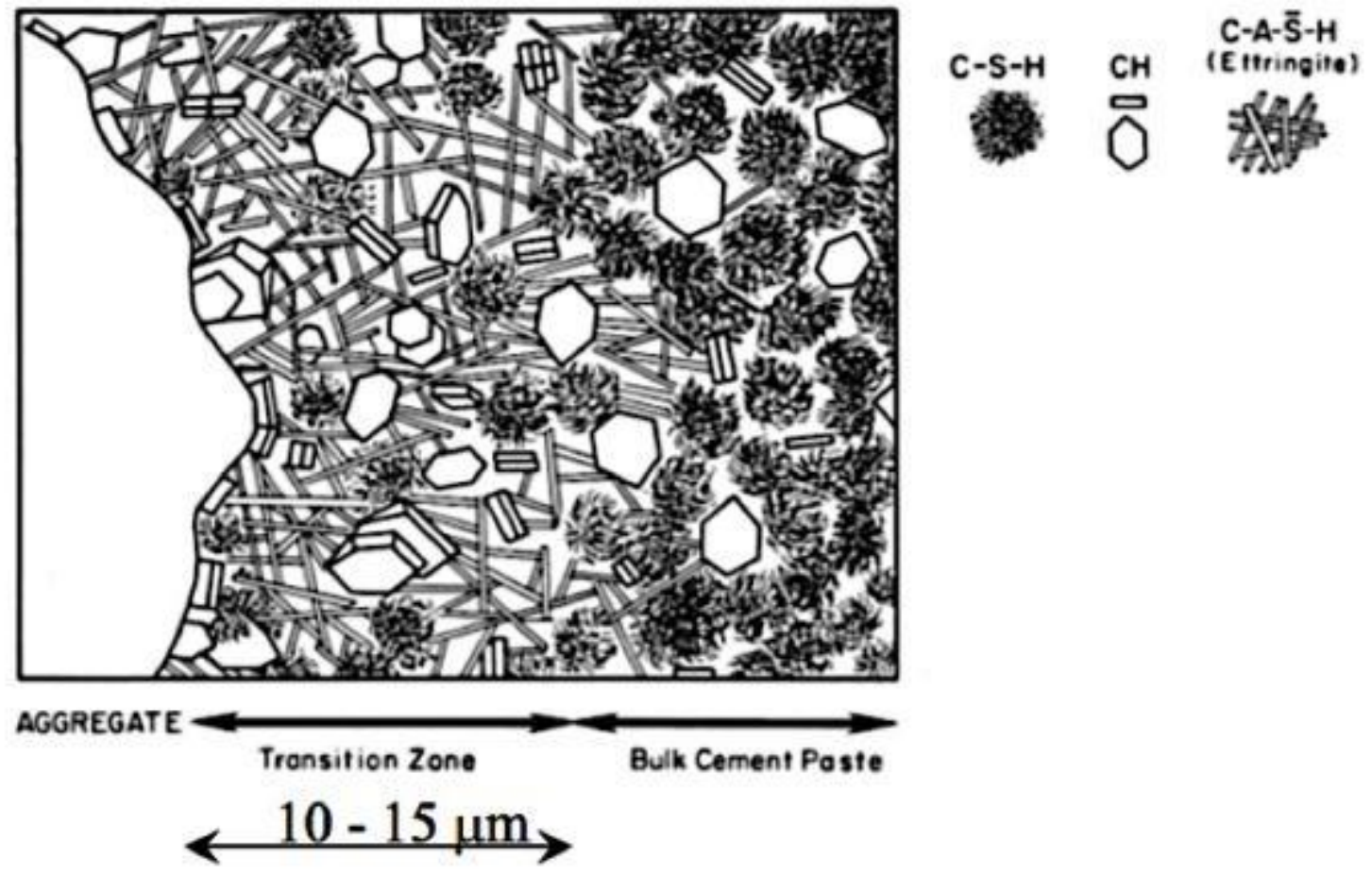

Figure 2.2-3 Interfacial transition zone (ITZ) composition (Mehta \& Monteiro, 1993)

In order to address the inferior compressive strength, and higher variability in behaviour of RCA-concrete, Tam et al. (2005) proposed the Two-Stage Mixing Approach (TSMA) as shown in Table 2-3. 
The initial half of the mixing water would coat and absorb into the aggregate, and thus leading to the formation of a thin layer of cement slurry. The slurry is then able to permeate into the porous residual mortar of the RCA, thus filling up any cracks and voids, to provide a stronger ITZ between the residual mortar and fresh paste (Tam, Gao, \& Tam, 2005). The TSMA has been reported to increase the compressive strength of concrete up to approximately $20 \%$ with greater effectiveness as the replacement level of RCA increases (Tam, Gao, \& Tam, 2005).

Table 2-3 Two-Stage Mixing Approach (TSMA) (Tam, Gao, \& Tam, 2005)

\begin{tabular}{ccc}
\hline Step \# & $\begin{array}{c}\text { Materials } \\
\text { Added }\end{array}$ & $\begin{array}{c}\text { Mixing } \\
\text { Duration } \\
\text { (seconds) }\end{array}$ \\
\hline 1 & $\begin{array}{c}\text { Coarse \& Fine } \\
\text { Aggregate }\end{array}$ & 60 \\
\hline 2 & $\begin{array}{c}\text { Half of Mixing } \\
\text { Water }\end{array}$ & 60 \\
\hline 3 & $\begin{array}{c}\text { Cementitious } \\
\text { Material }\end{array}$ & 30 \\
\hline 4 & $\begin{array}{c}\text { Half of Mixing } \\
\text { Water }\end{array}$ \\
\hline
\end{tabular}

Additionally, by splitting the mixing water in the batching process, Ryu (2002) suggests that the reduced w/cm ratio of the slurry coating in the vicinity of the new ITZ produces a higher quality paste matrix, and thus ITZ, as shown in Figure 2.2-4. 


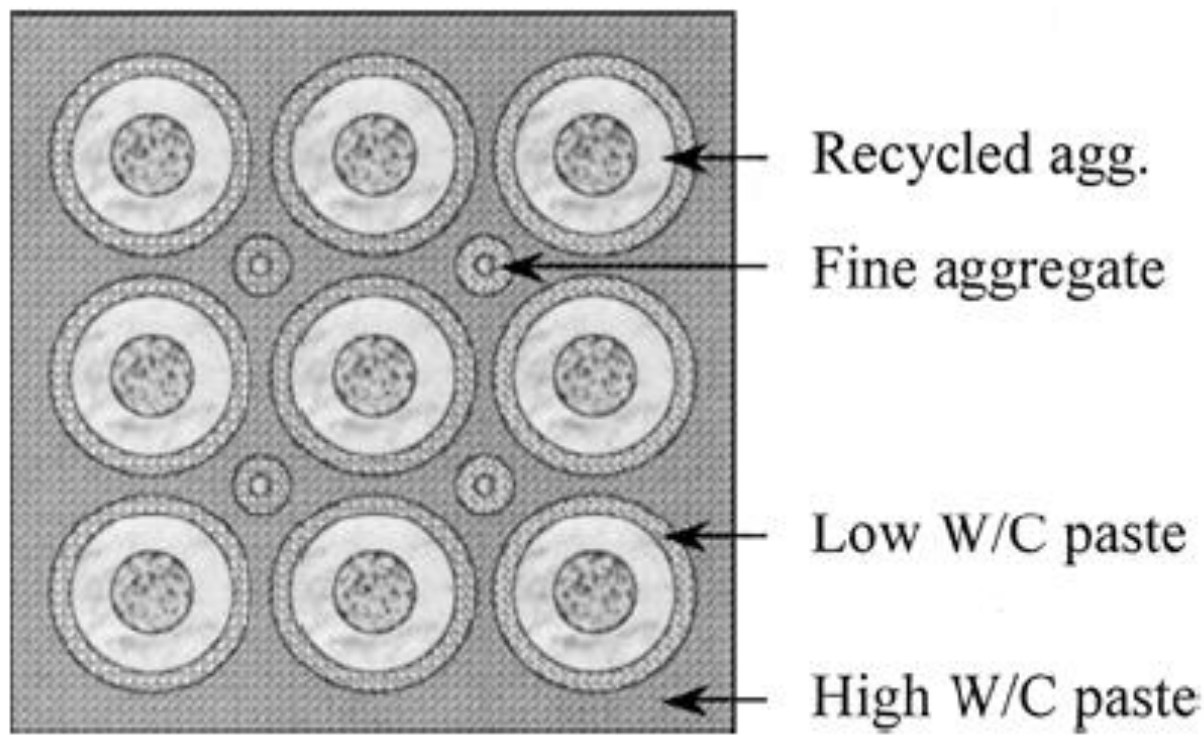

Figure 2.2-4 - RCA concrete using TSMA (Ryu, 2002)

It has been widely documented that the compressive strength of concrete with RCA depends on the strength of the original RCA. Research has proven that; if the water-tocementing materials $(\mathrm{w} / \mathrm{cm})$ ratio of the original concrete is equal to (or lower than) that of the RCA-concrete, the strength can be on par with the strength of the original concrete (Hansen, 1986). Furthermore, Zhang and Ingham (2010) reported that all grades of source RCA were suitable to produce concrete with compressive strength up to $20 \mathrm{MPa}$.

When GGBS was incorporated into the mix design with coarse RCA, Berndt (2009) observed no significant reductions in compressive strength. It is hypothesized that improved interfacial bonding between RCA and paste is exhibited with the incorporation of slag, which has been shown to densify the microstructure and increase the microhardness of the ITZ for concrete with VA (Berndt, 2009). As Class R concrete deals vastly with high w/cm ratios, the aforementioned findings act as the basis for justifying the use of RCA in such designs.

As studies have shown, RCA-concrete made with fine RCA may lower compressive strength by up to $50 \%$ and significantly impact the slump (Hansen, 1986). The 
conventional method of addressing this issue would be to increase the cementing materials content in order to improve the compressive strength. As that option is neither economically feasible, nor environmentally friendly, the study focused purely on the use of only coarse RCA. In addition to reduced strength, the use of fine RCA provides concrete of high shrinkage and high slump loss, an instability issue caused by the fineness of the powder-like nature of the fine RCA.

Limbachiya (2004) reported that RCA concrete mixes were found to posses bulk engineering and durability properties similar to their corresponding VA concretes, providing their design criteria had equivalent strength.

It has been found that drying shrinkage of concrete made with recycled aggregate is up to $100 \%$ higher than concrete with a corresponding conventional aggregate (Kosmatka, Kerkhoff, Hooton, \& McGrath, 2011). On the basis of results obtained from various research, concrete produced with coarse RCA and concrete produced with both coarse and fine RCA will commonly have increased drying shrinkage values of $50 \%$ and $70 \%$, respecively (Hansen, 1986). It thus becomes essential to investigate methods of mitigating the effects of drying shrinkage in concrete containing RCA. Furthermore, as due to RCA's influence on both shrinkage and creep strains, it has been sugested that some special considerations may need to be taken if their use in structural elements is considered (Limbachiya, Koulouris, Roberts, \& Fried, 2004).

In terms of using SCMs, such as Ground, Granulated Blast Furnace Slag (GGBS), Hooton et al. (2004) reports a negligible increase in the drying shrinkage of concrete mixtures with virgin aggregate, regardless of the replacement level of GGBS. In fact, long term restrained shrinkage cracks were found to be of smaller width.

\subsubsection{Fresh Properties of Recycled Aggregate Concrete}

The key element influencing fresh properties of RAC is the highly porous, rough-textured nature of the residual mortar comprising the RCA (American Concrete Pavement 
Association, 2010). As fine RCA is comprised mainly of ground residual mortar particles, it becomes highly unpredictable, and may significantly impact the fresh properties of concrete made with RCA. ACPA (2010) summarizes the typical effects of incorporating either only coarse, or both coarse and fine RCA, on the fresh properties of concrete made with RCA in Table 2-4. It is to be noted that these effects are typical when no particular design changes were made to the mix for the incorporation of RCA.

Table 2-4 Effect of RCA on fresh properties of concrete (American Concrete Pavement Association, 2010)

\begin{tabular}{ccc}
\hline & Range of Expected Changes from Similar Mixtures Using Virgin Aggregates \\
\hline Property & Coarse RCA Only & Coarse and Fine RCA \\
\hline Workability & Similar to slightly lower & Slightly to significantly lower \\
\hline FInishability & Similar to more difficult & More difficult \\
\hline Water Bleeding & Slightly less & Less \\
\hline Water Demand & Greater & Much Greater \\
\hline Air Content & Slightly higher & Slightly higher \\
\hline
\end{tabular}

RCA characteristically has significantly higher absorption capacities and rates than virgin aggregate due to the presence of the residual mortar. As such, a rapid loss of workability is common and must be addressed. The moisture content of the RCA thus plays a vital role in controlling the mix workability rather than exceeding design limits through the addition of water on the job site.

In terms of stability, some studies have reported negligible differences in air loss between VA and RCA concrete, suggesting no identifiable effect of RCA characteristics on the air stability (Limbachiya, Koulouris, Roberts, \& Fried, 2004).

\subsubsection{Hardened Properties of Recycled Aggregate Concrete}

The key factor in the hardened properties of the RAC still remains the volume, and composition of, the residual mortar adhering to the RCA particles. A brief summary of typical hardened properties is provided by ACPA (2010) in Table 2-5. 
Table 2-5 Effect of RCA on hardened properties of concrete (American Concrete Pavement Association, 2010)

\begin{tabular}{ccc}
\hline & Range of Expected Changes from Mixtures Using Virgin Aggregates \\
\hline Property & Coarse RCA Only & Coarse and Fine RCA \\
\hline Compressive Strength & $0 \%-24 \%$ less & $15 \%-40 \%$ Less \\
\hline Tensile Strength & $0 \%-10 \%$ less & $10 \%-20 \%$ less \\
\hline Strength Variation & Slightly more & Slightly more \\
\hline Mod. of Elasticity & $10 \%-33 \%$ less & $25 \%-40 \%$ less \\
\hline CTE & $0 \%-30 \%$ more & $0 \%-30 \%$ more \\
\hline Drying Shrinkage & $20 \%-50 \%$ more & $70 \%-100 \%$ more \\
\hline Creep & $30 \%-60 \%$ more & $30 \%-60 \%$ more \\
\hline Specific Gravity & $0 \%-10 \%$ less & $5 \%-15 \%$ less \\
\hline Permeability & $0 \%-500 \%$ more & $0 \%-500 \%$ more \\
\hline Freeze-Thaw Durability & Depends on air-void system & Depends on air-void system \\
\hline Sulfate Resistance & Depends on mix & Depends on mix
\end{tabular}

Corinaldesi V. (2011) reported a decrease in compressive strength of approximately $20 \%$ after 28 days when a substitution level of $30 \%$ coarse RCA was implemented with w/cm ration between 0.4-0.6. Even with this change, structural concrete up to C32/40 strength classes were still satisfied with a minor change in $w / \mathrm{cm}$ ratio restrictions. Further research by Limbachiya et al. (2004) found that up to $30 \%$ of coarse RCA, without any modifications in mix design, had no effect on concrete strength in mixes up to $50 \mathrm{MPa}$ with a w/cm ratio of 0.6 . In concrete mixtures having a relatively low cementing materials content $\left(250-300 \mathrm{~kg} / \mathrm{m}^{3}\right)$, Konin et. Al (2011) reports compressive strength declines below 5\% in RCA concrete relative to its VA counterparts. 
The elastic modulus and density of RAC are typically lower than its virgin aggregate counterpart. These features are attributable to the overall increase in mortar content (comprised of both residual and new mortar) found in concrete made with RCA, which characteristically has both: a lower elastic modulus, and much lower density than most virgin aggregates (American Concrete Pavement Association, 2010).

As drying shrinkage is primarily dependent on the paste content and w/cm ratio of any concrete, it thus becomes a vital parameter in any concrete with highly increased paste (such as RCA concrete). When comparing concrete mixtures of similar compressive strengths, similar shrinkage behaviours were observed by Corinaldesi V. (2011), when RCA replacement was up to $30 \%$ of coarse aggregate.

Corinaldesi \& Moriconi (2010) reported that presoaked aggregates (approximately around Saturated Surface Dry Condition), can be more effective in order to create an internal water supply, and in turn reducing the drying shrinkage, avoid water absorption during mixing, and thus aiding in maintaining concrete workability.

As the variability in sources of RCA may become a highly questionable topic, work done by Limbachiya et al. (2004), in which four variable sources of RCA were studied, suggested no significant variation in compressive strength at a given RCA content. In fact, the sources varied from low to high contamination RCA.

Unlike the durability problems occasionally associated with problematic virgin aggregates, RCA concrete can be highly durable, even when the RCA originates from concrete with durability problems, provided that the design of the new RCA concrete mix, and construction/placement, are properly performed (American Concrete Pavement Association, 2010).

\subsubsection{Durability of Concrete made with Recycled Concrete Aggregate}

As previously stated, RCA is mainly consistent of residual mortar which, due to its highly porous and absorptive nature makes it more susceptible to deterioration. The porosity of 
concrete (mainly due to the network of capillary pores) in VA concrete is typically a highly influential factor for intrusion into concrete. In the case of RCA concrete, in addition to the capillary pore network, recycled aggregate contains mechanical cracks (Konin \& Kouadio, 2011).
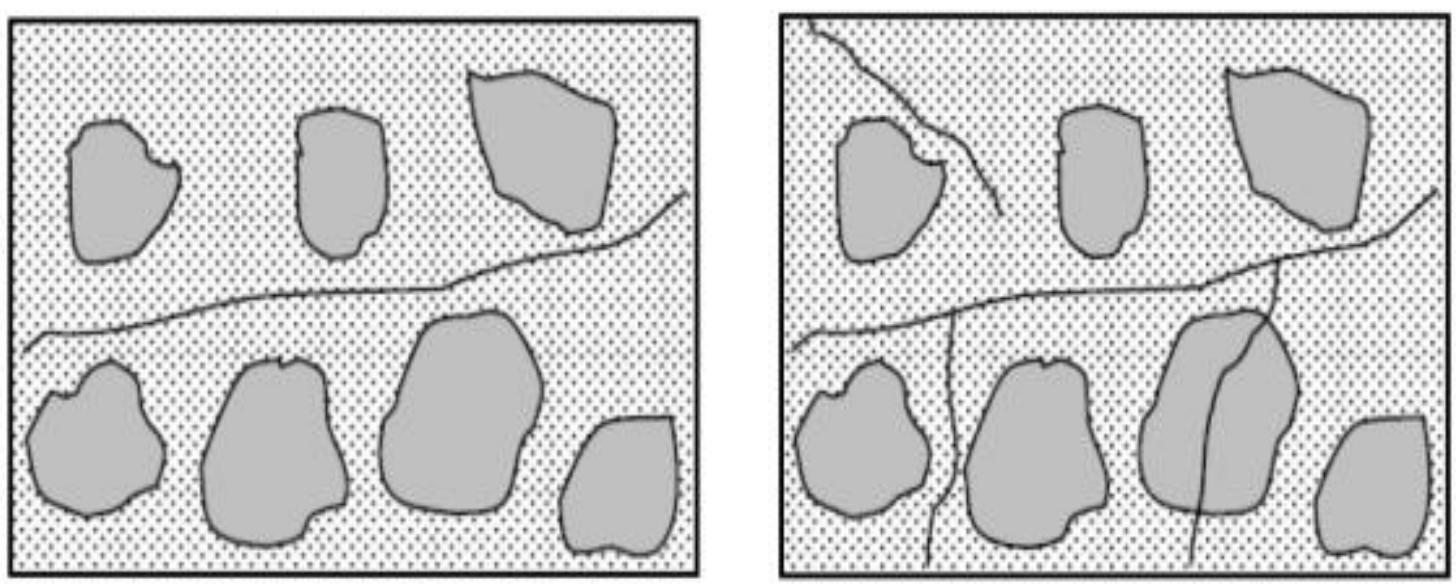

Figure 2.2-5 - Preferential path of water in VA concrete (left) and RCA concrete (right) (Konin \& Kouadio, 2011)

Figure 2.2-5 displays the preferential path of water in VA vs. RCA concrete, as suggested by Konin et al. (2011). Similar to ingression of water, these additional paths are also potential pathways for harmful intrusions such as chlorides into the concrete. Referring back to the importance of the ITZ (as emphasized in Section 2.2.2), the presence of the various new ITZs creates additional low-porosity pathways in the paste matrix.

Limbachiya et al. (2004) reported concrete made with up to $100 \%$ coarse RCA to have durability factors upwards of $95 \%$, indicating little or no deterioration under freeze/thaw attack. 


\subsection{Alkali Silica Reaction (ASR) in Concrete}

Among the various durability issues typically associated with concrete, Alkali-Silica Reaction (ASR) plays a key role in the development of concrete with uncertainties in its new aggregate, such as RCA. ASR is a reaction that occurs inside concrete between the reactive siliceous constituents of the aggregate, and the available free alkalis in the pore solution of the cementitious paste, in order to form a hydrophilic gel within the concrete matrix. With sufficient presence of moisture, the gel will absorb sufficient water and thus expand in volume, which in turn, causes the formation of internal pressures within the concrete matrix.

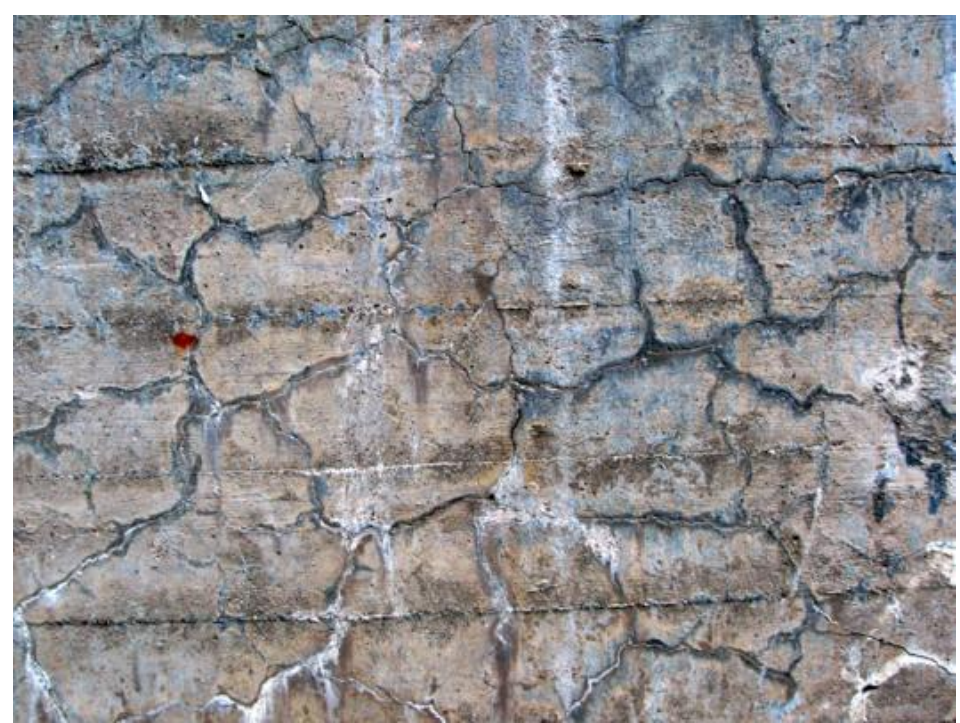

Figure 2.3-1 - Map cracking in concrete experiencing ASR (Fontana, 2013)

A build-up of these pressures requires a release in the form of cracking. In addition to the severely reduced serviceability of a structure caused by ASR, the propagation of these cracks (as seen in Figure 2.3-1) creates ideal ingression points for various detrimental agents such as chlorides (Mindess, Young, \& Darwin, 2003). 


\subsubsection{Mitigation of Alkali Silica Reaction}

In order for ASR to occur, three main factors must be satisfied (Kosmatka, Kerkhoff, Panarese, MacLeod, \& McGrath, 2002):

1. Reactive forms of silica must be present in the aggregate

2. The pore solution of the paste matrix must have a high $\mathrm{pH}$ level and thus sufficient free alkalis

3. Sufficient moisture must be present for absorption by the resulting gel formation

As such, the most effective method of mitigating ASR is to eliminate (or significantly reduce) the satisfaction of any one or more of the aforementioned criteria. Since it is highly improbable that concrete may be kept protected from any form of moisture, the focus typically shifts to controlling the aggregate sources/nature and/or regulating the available alkali content of the pore solution through careful selection of cementing material composition.

\subsubsection{Aggregate Selection}

Selection of aggregates is a common method of ASR mitigation, and a widely dominant factor in large-scale ready-mix production criteria. An aggregate must be classified as acceptable by means of local testing standards, including reactivity testing, in order to qualify as a concrete constituent.

\subsubsection{Supplementary Cementing Materials (SCMs)}

Dependent on the composition of the various SCMs, it may be an extremely effective tool in the mitigation of ASR. As certain SCMs (such as Type F Fly Ash) have been found to create a denser paste matrix, and in turn bind more alkalis in the hydration products, they prove to be viable options in the reduction of ASR when the use of reactive aggregate constituents is required. 
Type F Fly Ash, characteristically containing minimal $\mathrm{CaO}$, has been proven to be quite effective in the mitigation of ASR due to its low alkali content (Shehata \& Thomas, 2010). Lower replacement levels of Type F Fly Ash are required to effectively mitigate ASR relative to many other SCMs. In order to achieve the same effectiveness, other SCMs such as GGBS or Fly Ash with a higher $\mathrm{CaO}$ content (such as Type $\mathrm{CI}$ or $\mathrm{CH}$ ), requires much higher replacement levels (Moser, Jayapalan, Garas, \& Kurtis, 2010).

\subsubsection{Binary and Ternary Blends of Cementing Materials}

Binary and ternary blends in concrete mix design refer to concrete containing two and three different cementing materials, respectively. The combination will most commonly consist of Portland cement and either one or more SCMs. As each cementing material has its own beneficial features and drawbacks, the idea of using binary or ternary blends is to create a synergy between the cementing materials by which the drawbacks of one are addressed through the addition of the other. As an example, a common combination would be the use of Portland cement, fly ash, and silica fume. Fly ash has a tendency to improve the workability of a mix due to its spherical particle nature but suffers from causing a decreased early compressive strength. Silica fume, on the other hand, has been widely known to increase early compressive strength due to its rapid reaction of extremely fine particle. These particles however, have a tendency to significantly reduce workability of the concrete mix. The correct combination of the two would then, in turn, achieve both proper workability and early compressive strength. Additionally, the combination of the materials would also prove effective in mitigating the effects of ASR when fly ash and silica fume are combined (Moser, Jayapalan, Garas, \& Kurtis, 2010). 


\subsection{Alkali Silica Reaction and Recycled Concrete Aggregate}

As ASR is highly dependent on the available alkalis in the cementitious paste, and the reactive silica of the aggregates, RCA has the potential to contain reactive constituents of both products. The potential for ASR in concrete containing RCA is highly dependent on the original alkali levels of the RCA's residual mortar, the remaining potential reactivity of the RCA, and the alkali content of the new concrete paste (Stark, 1996). 


\section{Chapter 3}

\section{Materials and Experimental Methods}

\subsection{Materials}

\subsubsection{Aggregate}

The study focuses on producing a new concrete, which is both environmentally and economically feasible for the ready mix industry, in order to investigate the feasibility of concrete mass production with high volumes of coarse RCA. To ensure a fair representation of common commercially available RCA, the RCA used in this study was obtained from an aggregate depot from a commercial ready mix producer. All RCA is, according to the supplier, comprised of approximately 75\% Return-to-Plant RCA and $25 \%$ Reclaimed RCA from previously demolished structures of unknown origin.

Trial mixes were cast using Natural Sand (NS) as fine aggregate, in combination with either Dolostone Virgin Aggregate (VA), or RCA, as coarse aggregate. As the aggregate supplier would typically crush the hardened concrete into RCA, and to ensure proper gradation, the RCA used in this study was sieved to conform to the gradation requirements of Group 1 according to CSA A23.1-09, with $20 \mathrm{~mm}$ nominal size (Figure 3.1-1). Further aggregate properties are shown in Table 3-1.

Table 3-1 Fine and coarse aggregate properties

\begin{tabular}{cccc}
\hline & Fine Aggregate & \multicolumn{2}{c}{ Coarse Aggregate } \\
\hline & Natural Sand & VA & RCA \\
\hline Bulk Relative Density $\left(\mathrm{kg} / \mathrm{m}^{3}\right)$ & 2640 & 2600 & 2330 \\
\hline Dry-Rodded Density $\left(\mathrm{kg} / \mathrm{m}^{3}\right)$ & - & 1670 & 1420 \\
\hline Absorption $(\%)$ & 0.95 & 0.9 & 5.55 \\
\hline Micro-Deval Mass Loss $(\%)$ & - & - & 22.6 \\
\hline
\end{tabular}




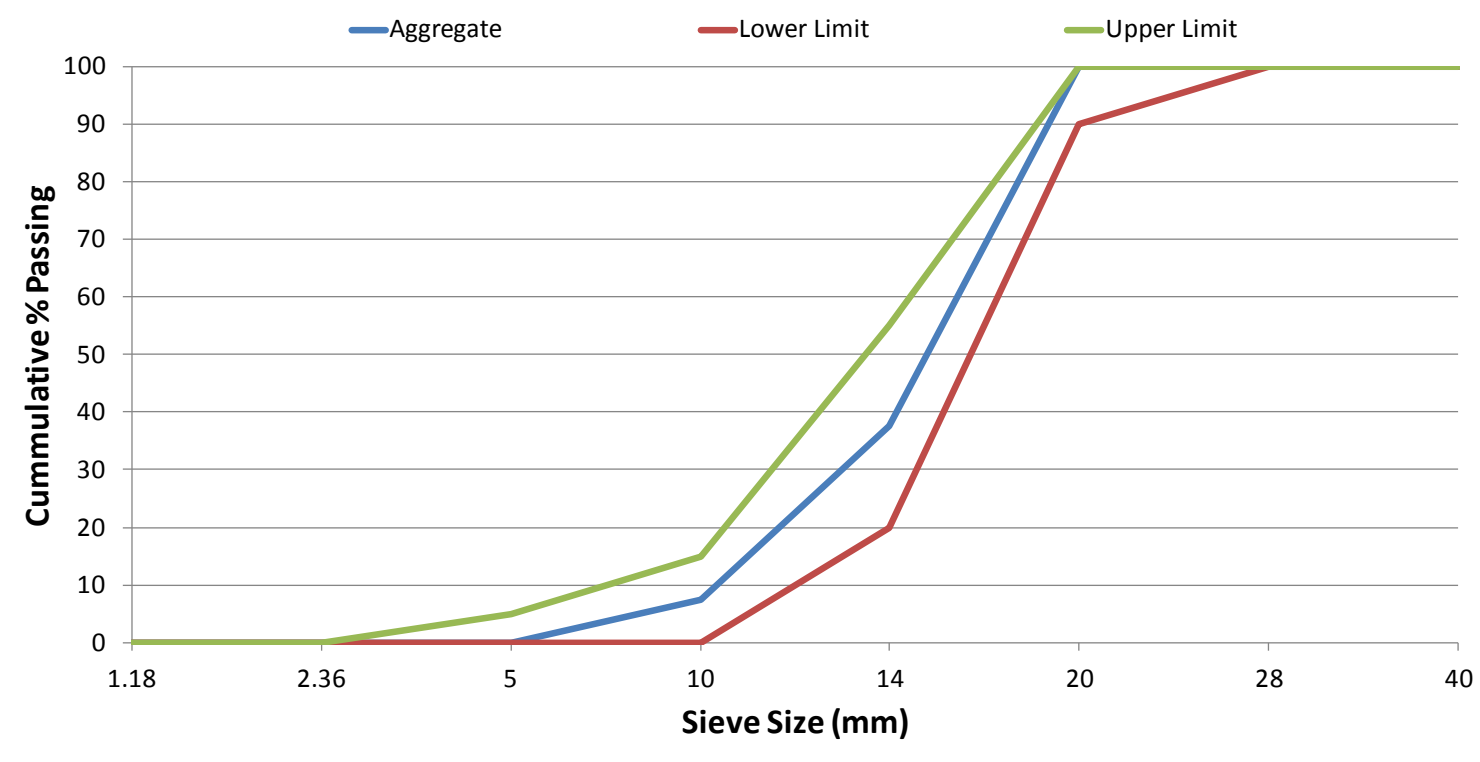

Figure 3.1-1 Coarse RCA gradation

Testing of the aggregates was performed according to ASTM C127-12 in order to obtain the aggregate densities, and an extended method to obtain the absorption rate and limit of the aggregates. This extended method is further described in section 3.2.1. ASTM D6928 was used to determine the abrasion resistance of the RCA.

Though Tam et al. (2005) orginally suggests pre-soaking of the RCA for enhanced performance prior to use in the TSMA, research performed by (Poon, Shui, Lam, Fok, \& Kou, 2004) reported that mixtures used in the Saturated Surface Dry (SSD) state may result in excessive bleeding during casting, and thus negatively impacting the compressive strength. On the other hand, mixtures using oven dry aggregate would experience significantly higher slump leading to segregation due to the addition of a large amount of initial free water. In line with these results, RCA used in the mixing process for this study was taken "as-is" at air dry conditions, along with the feasibility of presoaking complications associated with the use of RCA in a batch plant. The moisture condition of the aggregate was further addressed through a modification in batching procedure as outlined in further detail in Section 3.2.1. 
An additional source of Marginally Reactive Sand (MRS) was introduced into the study for purposes of testing alkali-silica reactivity. The MRS marginally met the expansion limit when tested according to CSA A23.2-14A. This sand was used to evaluate the RCA's potential to further trigger alkali-silica reactivity through the potential release of excess alkalis from its residual mortar content.

\subsubsection{Cementing Materials}

All mixes were produced using commercially available Type GU Portland cement conforming to the standards as used by all ready mix suppliers. To further reduce the carbon footprint of the mixes, and relate to current practices of concrete production in Ontario, the use of Ground, Granulated Blast Furnace Slag (GGBS), at a typical replacement level of $30 \%$, was also incorporated and evaluated in the mixes.

For purposes of testing ASR, the use of Type F Fly Ash was also introduced in evaluating binary blends of cementing materials, in combination with MRS and RCA, for a comparative study. The chemical compositions of all cementing materials used are summarized in Table 3-2.

Table 3-2 Chemical composition of cementing materials

\begin{tabular}{ccccccccccc}
\hline $\begin{array}{c}\text { Cementing } \\
\begin{array}{c}\text { Material } \\
(\mathrm{CM})\end{array}\end{array}$ & $\mathbf{S i O}_{2}$ & $\mathbf{A l}_{2} \mathbf{O}_{3}$ & $\mathbf{F e}_{2} \mathbf{O}_{3}$ & $\mathbf{C a O}$ & $\mathbf{M g O}$ & $\mathbf{S O}_{3}$ & $\mathbf{K}_{2} \mathbf{O}$ & $\mathbf{N a}_{2} \mathbf{O}$ & $\mathbf{T i O}_{2}$ & $\mathbf{P}_{2} \mathbf{O}_{\mathbf{5}}$ \\
\hline PC & 19.9 & 5.22 & 2.73 & 63.3 & 2.64 & 4.7 & 1.2 & 0.24 & 0.27 & 0.14 \\
\hline $\begin{array}{c}\text { Type F Fly } \\
\text { Ash }\end{array}$ & 55.7 & 27.4 & 5.59 & 4.43 & 1.56 & 0.26 & 2.29 & 0.44 & 0.67 & 0.31 \\
\hline GGBS & 37.24 & 7.83 & 0.77 & 38.49 & 10.68 & 2.28 & 0.54 & 0.37 & - & - \\
\hline
\end{tabular}




\subsubsection{Chemical Admixtures}

In order to account for the potentially harsh climate experienced in Canada, the use of Air Entraining Admixture (AEA) is essential to improve freezing and thawing resistance of concrete. All trial mixes thus incorporated the use of an organic acid salt-based AEA conforming to the requirements of ASTM C260 to meet the air requirements set forth for Class-R concrete. For purposes of evaluating the effects on drying shrinkage, the use of Water Reducing Admixture (WRA) (to reduce water and cementing materials content), and Shrinkage Reducing Admixture (SRA) to directly reduce shrinkage, were evaluated.

\subsubsection{Trial Mixes}

A total of 23 primary trial mixes were tested for evaluation of the various parameters. Trial mixture proportions, w/cm ratios, and air content of each trial mix, are displayed in Table 3-4. Houphouet-Boigny and Kouadio (2011) reported low decreases in compressive strength (relative to VA concrete) when a cementing materials content below $300 \mathrm{~kg} / \mathrm{m}^{3}$ is used. All mixes in the study contained a relatively low cementing materials content of $250 \mathrm{~kg} / \mathrm{m}^{3}$. It is to be noted that all mixes produced with VA, and $\mathrm{RCA}$, were tested at a w/cm ratio of 0.7 and 0.62 , respectively, unless otherwise specified. For clarity of coding, Table 3-3displays the coding legend for all mixes.

Table 3-3 Mixture identification legend

\begin{tabular}{cc}
\hline Variable & Definition \\
\hline $\mathrm{V}$ & $100 \%$ Virgin Aggregate \\
\hline $\mathrm{R}$ & $100 \%$ Coarse RCA \\
\hline S30 or S50 & $30 \%$ or 50\% GGBS (By Mass of CM) \\
\hline R70-V30 & 70\% Coarse RCA \& 30\% VA (By Volume) \\
\hline WR & Addition of Water Reducing Admixture \\
\hline SR & Addition of Shrinkage Reducing Admixture at $5 \mathrm{~L} / \mathrm{m}^{3}$ \\
Min \& Max & $2.5 \mathrm{~L} / \mathrm{m}^{3} \& 7.5 \mathrm{~L} / \mathrm{m}^{3}$ of SRA Addition \\
\hline FT & Specimens Tested for Freezing/Thawing \\
\hline
\end{tabular}


Table 3-4 Trial mixture proportions

\begin{tabular}{|c|c|c|c|c|c|c|c|c|}
\hline Mix Label & $\begin{array}{l}\text { Cement } \\
\left(\mathrm{kg} / \mathrm{m}^{3}\right)\end{array}$ & $\begin{array}{l}\text { GGBS } \\
\left(\mathrm{kg} / \mathrm{m}^{3}\right)\end{array}$ & $\begin{array}{c}\text { VA } \\
\left(\mathrm{kg} / \mathrm{m}^{3}\right)\end{array}$ & $\begin{array}{c}\text { RCA } \\
\left(\mathrm{kg} / \mathrm{m}^{3}\right)\end{array}$ & $\begin{array}{c}\text { Sand } \\
\left(\mathrm{kg} / \mathrm{m}^{3}\right)\end{array}$ & $\begin{array}{l}\text { Water } \\
\left(\mathrm{kg} / \mathrm{m}^{3}\right)\end{array}$ & $\begin{array}{l}\text { w/cm } \\
\text { ratio }\end{array}$ & $\begin{array}{l}\text { Air } \\
(\%)\end{array}$ \\
\hline $\mathrm{V}-1$ & 250 & - & 1035 & - & 785 & 155 & 0.62 & 6.5 \\
\hline $\mathrm{V}-2$ & 250 & - & 1035 & - & 732 & 175 & 0.7 & 5.6 \\
\hline V-FT & 250 & - & 1035 & - & 732 & 175 & 0.7 & 5.5 \\
\hline V-S30-1 & 175 & 75 & 1035 & - & 781 & 155 & 0.62 & 6.0 \\
\hline V-S30-2 & 175 & 75 & 1035 & - & 727 & 175 & 0.7 & 5.8 \\
\hline V-S30-SR & 175 & 75 & 1035 & - & 780 & 155 & 0.62 & 7.5 \\
\hline V-S30-WR & 157.5 & 67.5 & 1035 & - & 843 & 157.5 & 0.7 & 8.0 \\
\hline V-S50 & 125 & 125 & 1035 & - & 778 & 155 & 0.7 & 4.5 \\
\hline $\mathrm{R}-1$ & 250 & - & - & 880 & 839 & 155 & 0.62 & 9.5 \\
\hline $\mathrm{R}-2 *$ & 250 & - & - & 880 & 839 & 155 & 0.62 & 6.8 \\
\hline $\mathrm{R}-4^{*}$ & 250 & - & - & 880 & 839 & 155 & 0.62 & 6.6 \\
\hline $\mathrm{R}-5(\mathrm{FT})^{*}$ & 250 & - & - & 880 & 839 & 155 & 0.62 & 5.0 \\
\hline R-SR & 250 & - & - & 880 & 839 & 155 & 0.62 & 6.4 \\
\hline R-SR-3Max & 250 & - & - & 880 & 839 & 155 & 0.62 & 6.6 \\
\hline R-S30-1* & 175 & 75 & - & 880 & 834 & 155 & 0.62 & 6.5 \\
\hline R-S30-3 (FT)* & 175 & 75 & - & 880 & 834 & 155 & 0.62 & 6.6 \\
\hline R-S30-SR & 175 & 75 & - & 880 & 834 & 155 & 0.62 & 8.0 \\
\hline R-S30-SR-2Min & 175 & 75 & - & 880 & 834 & 155 & 0.62 & 7.0 \\
\hline R-S30-SR-3Max & 175 & 75 & - & 880 & 834 & 155 & 0.62 & 5.0 \\
\hline R-S30-WR & 157.5 & 67.5 & - & 880 & 897 & 139.5 & 0.62 & 7.0 \\
\hline R70-V30 & 250 & - & 311 & 616 & 818 & 155 & 0.62 & 7.2 \\
\hline R70-V30-S30* & 175 & 75 & 311 & 616 & 818 & 155 & 0.62 & 6.0 \\
\hline R70-V30-S30-2* & 175 & 75 & 311 & 616 & 818 & 155 & 0.62 & 6.6 \\
\hline
\end{tabular}

*Some mixes have been duplicated for additional testing procedures 


\subsection{Testing Procedures}

\subsubsection{Batching Sequence and Fresh Properties}

To evaluate the effects of incorporating RCA into concrete production, in terms of batching and fresh properties, careful consideration was given to monitor the procedure and behaviour of the mixes during this phase. It was essential to understand whether the behaviour of the concrete would be negatively impacted when typical practices, such as water trim and addition at the batching time, as well as during the transportation of the mix, was implemented. As such, the transportation time was simulated and controlled water addition was tested during the monitoring period.

In order to accommodate the lack of pre-saturation of RCA (as initially implemented in the use of TSMA), this study incorporated slight modifications made to the TSMA, as shown in Table 3-5.

Initially, the fine aggregate was added into the drum, and the AEA was added by "dribbling" on the sand. By ensuring that the AEA was directly deposited on the fine aggregate, as typically recommended by the manufacturer, complications in air fluctuations may be avoided. Further emphasis on this issue is addressed in Section 4.2.2. Coarse aggregate was introduced and mixed, followed by the addition of half of the mixing water. It is to be noted that all mixing water also contained $40 \%$ of the absorption water used to accommodate moisture correction. Reasoning for this is provided in Section 4.2.

All cementing materials were introduced into the drum and mixed to allow for the formation of slurry to coat the aggregates. The remaining mixing water was then introduced to complete the mixing procedure. The mix was allowed to rest for a minute, at which point any additional chemical admixtures were added and followed by a final mixing period. 
Table 3-5 Modified TSMA procedure

\begin{tabular}{ccc}
\hline Step \# & Materials Added & $\begin{array}{c}\text { Mixing Duration } \\
\text { (seconds) }\end{array}$ \\
\hline 1 & $\begin{array}{c}\text { Coarse \& Fine Aggregate with } \\
\text { Air Entraining Admixture }\end{array}$ & 60 \\
\hline 2 & Half of Mixing Water & 60 \\
\hline 3 & Cementing Materials & 30 \\
\hline 4 & Half of Mixing Water & 120 \\
\hline 5 & Rest - Addition of WRA or & 60 \\
\hline 6 & SRA & 120 \\
\hline
\end{tabular}

To ensure the mix remains within acceptable slump limits in field conditions, truck transport was simulated for 45 minutes, after batching, by spinning the drum for one minute every five minutes. A slump test was carried out every 15 minutes. For mixes containing RCA, any remaining absorption water was divided into three equal parts and mixed into the drum prior to taking each slump test. This was done in order to simulate water addition that may occur on site when the mix experiences inadequate slump upon arrival, and thus maintain an appropriate slump for placement. It is to be noted that this additional water was originally trimmed back during the batching, as is typical practice at the plant level, and thus ensuring that the maximum w/cm ratio is still maintained upon final addition. At the plant level, this practice allows for additional water to be used for rinsing the truck's loading hopper.

\subsubsection{RCA Absorption Rate}

Absorption rate of RCA was tested by oven drying a representative sample of coarse RCA, allowing it to cool down to room temperature, and then soaking the aggregate and performing an absorption test according to ASTM C127 after 1, 4, 7, 15, 30 and 45 
minutes of soaking. A portion of the aggregate was left to saturate for over 24 hours to determine maximum absorption of the aggregate.

\subsubsection{Compressive Strength Testing}

Each mix was tested for compressive strength using cylinders (100 mm diameter, 200 mm length) at 7 and 28 days, after curing, in accordance with ASTM C39. Results were recorded based on an average of three test specimens for each trial, or a minimum of two specimen results, depending on the variation in specimen results. The within-test variation was monitored for all samples with no values exceeding the $10.6 \%$ variation specified by ASTM C39. As the compressive strength was a primary requirement in the

production of Class-R concrete, it was important to monitor the strength development of these mixes within 7 and 28 days upon placement.

\subsubsection{Drying Shrinkage Testing}

Due to the presence of the excessive residual mortar on the recycled aggregate, the overall paste volume (incorporating residual and new mortar) is significantly higher in concrete containing high volumes of RCA. Additionally, concrete with much higher water content (high w/cm ratio) will tend to have higher drying shrinkage due to the excessive amount of water expected to leave the hydrated paste matrix. Class R concrete containing RCA is thus exposed to both of these worst-case scenarios where drying shrinkage is concerned. As such, it must be understood that this creates the potential for significantly higher drying shrinkage complications, and must thus be addressed in the investigation.

Trial mixes were used to investigate the effect of different parameters on drying shrinkage including the use of GGBS, replacement level of RCA, and the use of WRA, and SRA. A two-phase approach was taken to determine the drying shrinkage of conventional concrete and the parametric influences. 
The initial phase consisted of casting shrinkage specimens at a w/cm ratio of 0.52 and cementing materials content of $350 \mathrm{~kg} / \mathrm{m}^{3}$. This was used to establish a baseline for conventional concrete shrinkage prior to implementing the drying shrinkage extremities: inclusion of RCA and higher water content. The second phase consisted of casting various Class R criteria mixes incorporating the various aforementioned parameters.

Drying shrinkage testing was performed in accordance with ASTM C157 using concrete prism samples having approximate dimensions of $75 \times 75 \times 285 \mathrm{~mm}$. Samples were cured in lime-saturated water prior to being placed into drying conditions at an age of 7 days in phase II and only 24 hours in phase I. It is to be noted that all drying shrinkage results are reported in reference to the 7-day initial length reading.

All samples were monitored incrementally for drying shrinkage behaviour past the age of 180 days, in controlled conditions, to ensure that the ultimate drying shrinkage is determined and a relative behaviour may be correlated.

\subsubsection{Alkali Silica Reaction (ASR) Testing}

Additional to the shrinkage potential of the residual mortar, it may contain excess free alkalis that have the potential to promote further alkali-silica reactivity in the presence of a reactive aggregate. As such, it was important to test this potential as to avoid unacceptable expansion behaviour. Since ASR is a widely common long-term durability issues with many concrete developments, it was important to determine its potential for reactivity due to the already relatively unpredictable nature of the RCA. 


\subsubsection{Concrete Prism Testing}

The effects of calcium and alkali contribution from the coarse RCA used in this study were evaluated using the concrete prism test, in accordance with CSA A23.2-14A, for a period of 90 weeks. Utilizing Marginally Reactive Sand (MRS), in combination with coarse RCA, testing was done in order to determine whether the combinations would trigger further ASR expansion due to the release of alkalis from the RCA into the mix (Shehata \& Thomas, 2010). Table 3-6 summarizes the mixes tested for ASR and their respective compositions.

Table 3-6 - Summary of concrete prism test specimens

\begin{tabular}{cccc}
\hline $\begin{array}{c}\text { Mix } \\
\text { ID }\end{array}$ & Coarse Aggregate & Fine Aggregate & $\begin{array}{c}\text { Cementing Materials } \\
(\% \text { Composition })\end{array}$ \\
\hline 1 & $\begin{array}{c}\text { Non- Reactive Coarse } \\
\text { (NRC) }\end{array}$ & $\begin{array}{c}\text { Marginally Reactive } \\
\text { Sand (MRS) }\end{array}$ & PC (100\%) \\
\hline 2 & Recycled Aggregate (RCA) & MRS & PC (100\%) \\
\hline 3 & RCA & MRS & $\begin{array}{c}\text { PC \& GGBS } \\
(70 \& 30 \%)\end{array}$ \\
\hline 4 & RCA & MRS & $\begin{array}{c}\text { PC \& Type F FA } \\
(80 \text { \& 20\%) }\end{array}$ \\
\hline
\end{tabular}

\subsubsection{Alkali Leaching Test}

The alkali-leaching test (Shehata \& Thomas, 2006) is meant to determine the amount of available alkalis in the pore solution of the paste. It is meant to verify the results of the concrete prism test and explain the resulting mitigation effects of ASR by evaluating the SCM blend's ability to chemically bind alkalis. All specimens were prepared using the same cementing materials as described in Section 3.2.6.1. 


\subsubsection{Preparation of Paste Specimens}

All paste specimens were prepared using an industrial high-shear blender at a w/cm ratio of 0.5. The blends and proportions tested are outlined in Table 3.2.

Table 3.2 Paste composition for alkali leaching test

\begin{tabular}{ccc}
\hline Label & Portland Cement & SCM (\%) \\
\hline CTR & 100 & - \\
\hline S 30 & 70 & GGBS (30\%) \\
\hline F FA 20 & 80 & Type F Fly Ash (20\%) \\
\hline
\end{tabular}

\subsubsection{Moulding and Curing of Paste Specimens}

Upon completion of mixing, all specimens were cast and cured as per the following procedure:

1. Paste specimens were poured into plastic cylindrical moulds having a diameter of $50 \mathrm{~mm}$ and depth of $100 \mathrm{~mm}$. A total of two (2) cylinders were cast for each blend

2. The cylinder was placed into a curing room maintained at $23 \pm 2^{\circ} \mathrm{C}$ and $100 \%$ relative humidity. Specimens were left to cure in these conditions for a period of 28 days

3. When the curing cycle was completed, specimens were de-moulded and immediately placed into an oven to dry at $105^{\circ} \mathrm{C}$ to ensure all moisture was removed and no further reactions occurred

4. Once dry, all cylinders were placed into a vacuum sealed desiccator to prevent contact with both moisture and air until needed

\subsubsection{Crushing and Grading of Paste Specimens}

Cylinders were crushed into large particles by impact of a $2.5 \mathrm{~kg}$ hammer and then further ground down using a ceramic mortar and pestle to meet the gradation requirements set by Shehata \& Thomas (2006), having a particle size between $1.18 \mathrm{~mm}$ 
and $150 \mu \mathrm{m}$. Once sufficient material was obtained, it was stored back in the vacuumsealed desiccator until needed.

\subsubsection{Preparation of Alkali Leaching Solution and Specimens}

Leaching testing was performed into two varying solutions. The first was simply distilled water; to test the total amount of alkalis which could potentially leach from the paste. The second was a solution prepared to $0.25 \mathrm{~N} \mathrm{NaO}_{\mathrm{e}}$ using $99.5 \% \mathrm{NaOH}$ pellets and $88 \% \mathrm{KOH}$ pellets. The $\mathrm{Na} / \mathrm{K}$ ratio for each specimen was calculated based on the chemical composition of the paste's individual cementing materials, and adjusted based on the weighted average of the paste's content. Solutions were prepared to match the $\mathrm{Na} / \mathrm{K}$ ratio as close as possible to simulate the paste's pore solution.

A $25 \mathrm{ml}$ vial was filled with paste particles and solution at a ratio of 1:10 by mass, respectively. A total of three (3) vials marked A, B, and C, were made to ensure consistency in results. All samples were sealed with adhesive plastic wrap to ensure an airtight seal. Samples made from cylinders cured at $23 \pm 2{ }^{\circ} \mathrm{C}$ were left to leach at STP.

\subsubsection{Correction of Paste Specimens due to Evaporable and Non-Evaporable Water Content}

As specimens had been oven-dried for a minimum of 24 hours following the de-moulding sequence and maintained inside a vacuum-sealed desiccator, it was assumed that evaporable water content would be minimal and only due to the short duration of sample preparation. As such, a sample of the ground particles (taken from the same source as those used for sample preparation) was taken and placed into an oven to dry to determine the minimal evaporable water content. Once removed from the oven, the sample was weighed and placed into a crucible and placed into an ignition furnace at a temperature of $1050 \pm 50^{\circ} \mathrm{C}$ for a minimum of 30 minutes to eliminate all chemically bound water known as the Non-Evaporable Water Content. Upon cooling in a desiccator, the sample 
was weighed once again. Corrections to paste mass are then calculated based on the results as shown in Appendix A - Alkali Leaching Test Calculation.

\subsubsection{Flame Photometry Testing}

As the concentrations of alkalis contained in the sample solutions far exceed the apparatus' capacity, dilution was required. Both distilled water, and solution samples, were diluted to a 50:1 ratio as per the following procedure:

1. $2.0 \mathrm{ml} \pm 0.001 \mathrm{ml}$ of solution was obtained from the sample using an ultra-fine tip disposal pipette

2. The solution was added to a $100 \mathrm{ml} \pm 0.03 \mathrm{ml}$ volumetric flask

3. Sufficient distilled water was added to bring the total solution to $100 \mathrm{ml}$ and thus ensuring a 50:1 dilution ratio

4. Solutions were thoroughly mixed prior to being poured into a testing vial

The use of flame photometry testing was implemented in order to determine the alkali concentrations of Sodium $\left(\mathrm{Na}^{+}\right)$and Potassium $\left(\mathrm{K}^{+}\right)$ions in the leached solution. As sample solutions were prepared to match the cementing material's $\mathrm{Na} / \mathrm{K}$ ratios, a common calibration solution was used containing $10 \mathrm{ppm}$ and $80 \mathrm{ppm}$ of $\mathrm{Na}^{+}$and $\mathrm{K}^{+}$, respectively. Recalibration was performed either after 5 sets, or if a drastic change in readings was observed from one test specimen to the other of the same set, whichever came first.

Following calibration, the diluted solution specimens were tested as follows:

1. In-between readings, sampling needle is kept in distilled water to ensure the system is flushed prior to measuring the next specimen. When ready, the needle is removed from the distilled water, wiped with a lint-free wipe, and placed into the testing solution

2. Needle is left for a minimum of 10 seconds to allow sufficient solution to pass through the system and ensure consistency in readings 
3. Five (5) readings are taken prior to removing the needle from the solution, wiping off excess moisture and placing it back in the distilled water.

4. The volumetric flask containing the original solution is thoroughly mixed and another sample is taken and tested

5. This procedure is repeated until at least three (3) samples from the volumetric flask have been tested to acquire a total of 15 readings from a single specimen

6. If peculiar readings are observed, the apparatus is cleaned and an additional set of five readings is taken

Upon completion, resulting readings are analyzed for outliers and averaged. The final concentrations are determined using the corrections procedure found in Appendix A Alkali Leaching Test Calculation.

\subsubsection{Paste Testing - Shrinkage Reducing Admixture (SRA)}

In order to further investigate the effects of the shrinkage reducing admixture on the characteristics of the cement paste, various paste samples were cast incorporating different dosages of SRA into a cement paste containing 100\% PC, or a 70/30 PC/GGBS blend having a constant $w / \mathrm{cm}$ ratio of 0.62 , equivalent to that of the RCA concrete tested.

\subsubsection{Preparation of Paste Specimens}

All paste specimens were prepared using an industrial high-shear blender at a w/cm ratio of 0.62. The blends and proportions tested are outlined in Table 3-7, below.

Table 3-7 Paste composition for SRA trials

\begin{tabular}{ccccccc}
\hline Name & $\begin{array}{c}\text { Portland } \\
\text { Cement } \\
\left(\mathrm{kg} / \mathrm{m}^{3}\right)\end{array}$ & $\begin{array}{c}\text { GGBS } \\
\left(\mathrm{kg} / \mathrm{m}^{3}\right)\end{array}$ & $\begin{array}{c}\text { SRA } \\
\left(\mathrm{L} / \mathrm{m}^{3}\right)\end{array}$ & $\begin{array}{c}\text { SRA } \\
(\mathrm{mL} / \mathrm{kg} \\
\mathrm{CM})\end{array}$ & $\begin{array}{c}\text { Water } \\
\left(\mathrm{L} / \mathrm{m}^{3}\right)\end{array}$ & $\begin{array}{c}\text { W/CM } \\
\text { Ratio }\end{array}$ \\
\cline { 1 - 5 } CTR & 250 & 0 & 0 & 0 & 155 & 0.62 \\
\cline { 1 - 5 } PC 2.5 & 250 & 0 & 2.5 & 10 & 153 & \\
\hline
\end{tabular}




\begin{tabular}{cccccc}
\hline PC 5 & 250 & 0 & 5 & 20 & 150 \\
\hline PC 7.5 & 250 & 0 & 7.5 & 30 & 148 \\
\hline PC S30 7.5 & 175 & 75 & 7.5 & 30 & 148 \\
\hline
\end{tabular}

\subsubsection{Moulding and Curing of Paste Specimens}

Upon completion of mixing, all specimens were cast and cured as per the following procedure:

1. Paste specimens were poured into plastic cylindrical moulds having a diameter of $50 \mathrm{~mm}$ and depth of $100 \mathrm{~mm}$.

2. The cylinder was placed into a curing room maintained at $23 \pm 2^{\circ} \mathrm{C}$ and $100 \%$ relative humidity. The specimens were left to cure in these conditions for a period of 7 days.

3. When the curing cycle was completed, specimens were de-moulded and immediately placed into a $99 \%$ isopropanol solution for 14 days to ensure no further reaction of the paste occurs.

4. Upon completion of the alcohol saturation, the samples were placed in an oven to dry at $105^{\circ} \mathrm{C}$ to ensure all moisture was removed

5. Once dry, all cylinders were placed into a vacuum sealed desiccator to prevent contact with both moisture and air until testing

\subsubsection{Determination of Evaporable and Non-Evaporable Water Content}

Upon removal from the dessicator, specimens were exposed to room conditions and crushed into finer particles. Two trials of testing were performed to verify the hydration results. In the first trial, three chunks were taken from each cylinder for testing, followed by a second trial in which the specimen particles were ground to a sand-like size prior to testing. In either trial, the evaporable water content was determined by placing the specimens into an oven at a temperature of $105 \pm 5^{\circ} \mathrm{C}$ for a minimum of 24 hours. Once removed from the oven, the sample was weighed, and placed into an ignition furnace at a 
temperature of $1050 \pm 50^{\circ} \mathrm{C}$ for a minimum of 30 minutes to eliminate all chemically bound water. Upon cooling in a desiccator, the sample was weighed once again. The hydration rate of the specimens was then calculated based on the non-evaporable water content readings taken from these samples.

\subsubsection{Rapid Chloride Permeability Testing (RCPT)}

In order to determine the potential of RCA concrete to resist chloride intrusion, test cylinders were cast, prepared, and tested according to ASTM 1202, as outlined below. All samples had undergone moist curing well beyond the 90-day cycle for full hydration of all the cementing materials. It is to be noted that, although CSA standards do not require Class $\mathrm{R}$ concrete to meet chloride intrusion requirements, the test was performed to evaluate the behaviour of the concrete in its worst-case condition.

Samples were cut from the centre-point of a cylinder having a diameter of $100 \mathrm{~mm}$ to a thickness of $50 \mathrm{~mm} \pm 5 \mathrm{~mm}$, as seen in Figure 3.2-1.

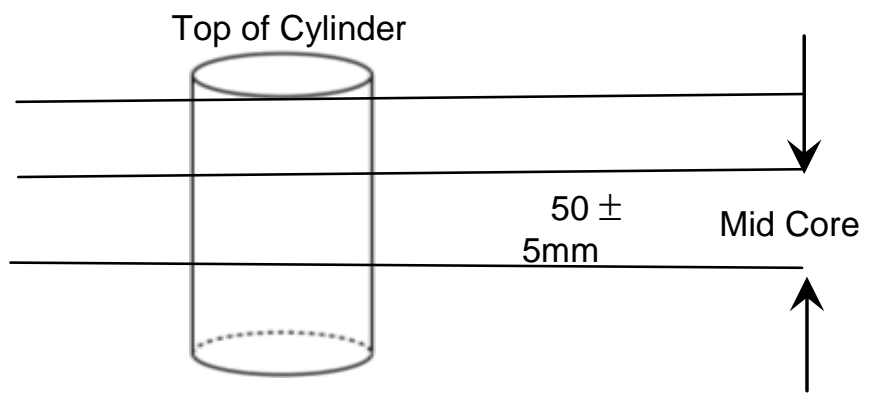

Bottom of Cylinder

Figure 3.2-1 RCPT specimen preparation

1. Each sample was coated with a thin layer of epoxy to seal the outer membrane of the concrete specimen, preventing any contact with outside conditions during the testing process and ensuring the sample's outer face does not dry-up during the testing procedure 
2. Samples were placed in a vacuum desiccator for a minimum duration of 3 hours, follow by a submerging period where de-aerated water was introduced to saturate the specimens in a vacuum condition for an additional hour

3. The samples were left submerged in the de-aerated water for a duration of 18 hours \pm 2 hours to ensure full saturation of the specimens occurs prior to testing.

4. Upon removal from the submerged state, samples were brought to saturatedsurface dry condition and placed into the RCPT cells

5. Silicone was applied to the outer perimeter of the specimens within the cells to ensure no leakage were to occur during the testing procedure

6. Solutions of $\mathrm{NaOH}$ and $\mathrm{NaCl}$ were prepared at concentrations of $0.3 \mathrm{~N}$ and $3 \%$ (by mass), respectively. These solutions were placed into opposing ends of the testing cells to ensure proper conductivity

7. Testing of all specimens occurred for duration of 6 hours by passing a current through the testing cells.

8. Coulomb charges passing each specimen were recorded

\subsubsection{Freezing and Thawing Resistance Testing}

To determine the adequacy of the proposed RCA concrete mixes in terms of resisting the effects of freezing and thawing, prism specimens $(75 \mathrm{~mm} \times 75 \mathrm{~mm} \times 285 \mathrm{~mm})$ in accordance with ASCM C666. The detailed procedure is outlined below.

1. Concrete prism samples were cast and moisture cured for a period of 14 days prior to testing

2. Upon removal from curing conditions, specimens were brought to room temperature where length, weight, and the initial reading was taken in accordance with ASTM C597 using the pulse-velocity method

3. Specimens were individually submerged in water and tested according to Procedure A of ASTM C666 where the specimen is submerged during both freezing and thawing cycles 
4. During the testing phase, all specimens were contained in a chamber capable of fluctuating temperatures between $-18^{\circ} \mathrm{C}$ for freezing and $4^{\circ} \mathrm{C}$ for thawing

5. Freezing and thawing cycles were started inside the chamber and were aborted after each set of 30 cycles in order to take readings

6. Once a set of 30 cycles was completed, specimens were removed from their respective chambers, weighed, dimensions were recorded, pulse-velocity readings were taken, and defects were noted

7. Specimens were returned to the chamber and another round of cycles was started

8. The process was repeated until 300 cycles were completed

9. Each time readings were taken, the dynamic modulus of elasticity was calculated based on the following equation:

$$
\begin{gathered}
V=\sqrt{\frac{E(1-\mu)}{\rho(1+\mu)(1-2 \mu)}} \\
\mathrm{E}=\text { dynamic modulus of elasticity } \\
\mu=\text { dynamic Poisson`s ratio } \\
\rho=\text { density of the concrete } \\
\mathrm{V}=\text { velocity }
\end{gathered}
$$

10. The durability factor was calculated as a $\%$ change of the initial dynamic modulus of elasticity (E) 


\section{Chapter 4}

\section{Results and Discussion}

\subsection{RCA Absorption Rate}

In order to confirm the need for some sort of pre-soaking procedure to the RCA, it was critical to understand the absorption behaviour of the aggregate by testing, not only its ultimate absorption capacity, but also the rate at which the water is absorbed. This would allow for the proper determination of a batching sequence, in terms of water addition and retention, and understanding the slump retention/loss behaviour of the concrete.

As the RCA was prepared to conform to the gradation requirements of Group 1 according to CSA A23.1-09, the source RCA was first sieved into three fraction of coarse RCA (19 $-12.7 \mathrm{~mm}, 12.7-9.5 \mathrm{~mm}$, and $9.5-4.76 \mathrm{~mm}$ ). These three sizes were blended to meet the gradation criteria. The gradation ranges were individually tested for absorption rate and ultimate absorption capacity. The results of these tests are plotted in Figure 4.1-1. The graph in Figure 4.1-1 (d) displays the weighted average of aggregate absorption, calculated based on the coarse RCA gradation.

Due to the RCA's high absorption, the absorbed water is equivalent to approximately up to $20 \%$ of the free water in mixes containing up to $100 \%$ replacement of coarse aggregate. Figure 4.1-1 (d) displays the graded RCA's tendency to absorb $60 \%$ of its maximum absorption in just one minute after soaking, and about $75 \%$ within the first 10 minutes. This translates into a $12 \%$ and $15 \%$ reduction in free water, respectively. Similarly, results by a variety of studies have found that concrete with RCA requires approximately $5 \%$ - $15 \%$ more free water, in order to achieve the same slump as a mixture with only VA (Hansen, 1986). 


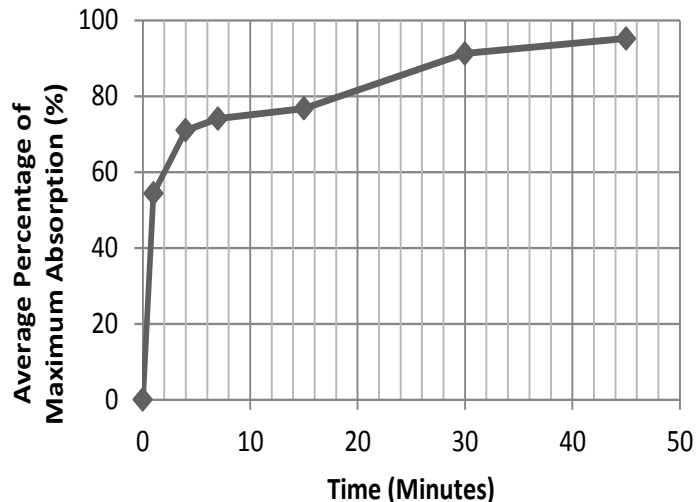

(a) $12.7-19 \mathrm{~mm} \mathrm{RCA}$

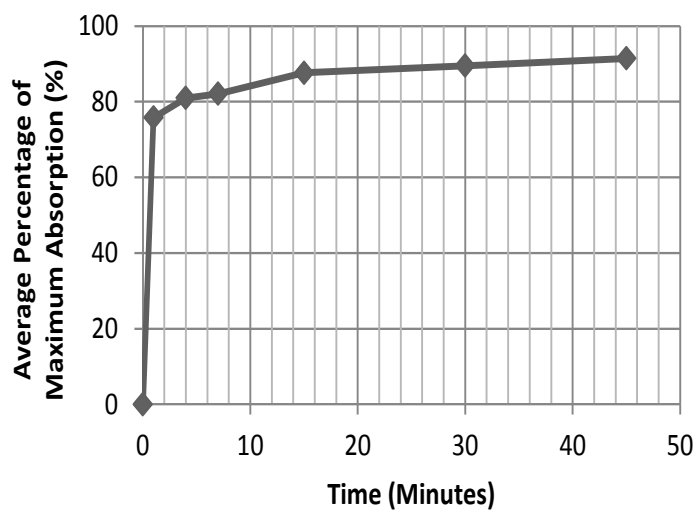

(c) $4.76-9.51 \mathrm{~mm} \mathrm{RCA}$

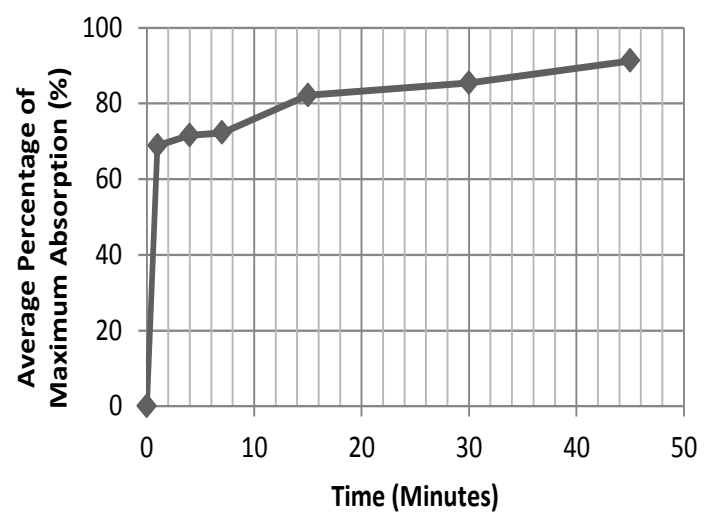

(b) $9.51-12.7 \mathrm{~mm} \mathrm{RCA}$

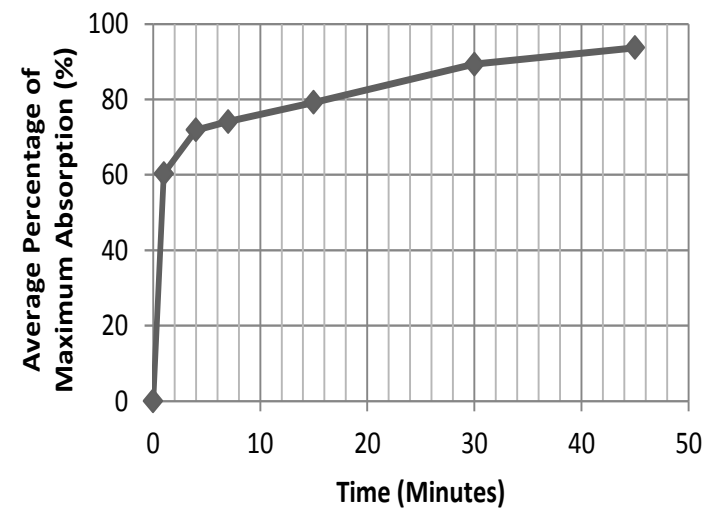

(d) Blended coarse RCA

Figure 4.1-1 Absorption rate of coarse RCA

Based on Figure 4.1-1, it can be seen that coarse RCA will, regardless of size, reach approximately $80 \%$ of its maximum absorption within just the first 15 minutes of saturation. This would imply that, if the absorption correction is not considered properly, or moistures of the aggregate are not accurately taken, only about $80 \%$ of the design water is actually available for proper mixing during the mixing process, and could thus reduce the desired slump.

The initial addition of at least $40 \%$ of the absorption water thus replenishes the mixing water, to allow for proper mixing, as per the design. On the other hand, if all absorption 
water was added immediately, an extremely fluid mixture (200 $\pm 20 \mathrm{~mm}$ slump) results, and can potentially tend to segregate severely. The remaining water, in order to obtain the desired slump, should thus be added slowly during transport to maintain proper mixing and avoid segregation.

It is believed, based on the absorption rate of the coarse RCA, that; in allowing half of the mixing water to mix with the aggregate for at least one minute, prior to the addition of cementing materials (as suggested in the TSMA), sufficient water is absorbed to "presoak" the aggregate. This would thus minimize the effect of rapid absorption of mixing water by the RCA and, in turn, reduce slump problems during batching, and minimize slump retention problems associated with water demand. As the mixing process also has a tendency to abrade cementitious particles from the residual mortar of the RCA, an excess amount of fines is thus introduced into the mixtures and may also contribute to the accelerated slump loss typically experienced by RAC. By performing the initial "presoak" cycle, this abrasion would take place mainly at the batching facility and could thus be addressed immediately with additional water, if required, to further reduce potential slump loss issues on-route to the site.

Poon et al. (2004) reported that air-dry RCA exhibited the highest strength when compared to oven dry and SSD RCA. Perhaps this may be attributed to the balance of absorption rate achieved. If the aggregate is allowed to freely absorb water for a minute, then it will act more like VA, in the sense that its additional absorption rate is now closer to that of VA and thus not significantly affecting the mixing process.

On a contrary belief, as previously mentioned in Section 2.2.2, Ryu (2002) believed that a superior layer of slurry is formed at the ITZ of the RCA and new paste, and the slurry permeation mechanism described by Tam et. al (2005) is able to take full effect due to the thirsty nature of the RCA's residual mortar. By creating the pull of moisture into the residual mortar, a deeper penetration of slurry may be achieved, thus resulting in the formation of a stronger bond and exhibiting superior strength performance. 


\subsection{Batching Procedure and Fresh Properties}

Prior to commencement of variable testing with RCA, a proper batching procedure needed to be determined and maintained throughout the study. The fresh properties, focusing mainly on slump and slump retention, as well as air content of the mixtures and air retention, were evaluated throughout the batching procedure for every mix. Tampering of the mix, to simulate actual jobsite conditions, through the addition of water at various times throughout the mixing and transport cycle, were evaluated to ensure realistic case scenarios are followed for the specified concrete.

\subsubsection{Slump and Slump Retention}

Upon gaining an initial understanding of the behaviour of RCA, in terms of water demand, the potential issues had thus been addressed by following the recommended batching approach when testing all mixtures, including both VA and RCA.

As concrete mixes with virgin aggregate were made to simulate extreme "worst-case" scenarios of the Class $\mathrm{R}$ exposure, with a w/cm ratio of 0.7 (maximum), without altering the overall cementing material content (fixed at $250 \mathrm{~kg} / \mathrm{m}^{3}$ ), a relatively high initial slump was always achieved during batching. Slump was monitored for a period of 45 minutes following the initial mixing procedure, to assess slump retention. No need for additional water was observed to maintain the mix in workable conditions. Figure 4.2-1 displays the relatively minimal slump loss over time for all virgin aggregate mixes. Mixes marked with `*'were batched at a reduced $w / \mathrm{cm}$ ratio of 0.62 .

For mixes with RCA, the maximum w/cm ratio was restricted to 0.62 and batched as such. Due to the large amount of additional water required (relative to VA), to accommodate the high absorption of the RCA, water had been retained as not to segregate the mix initially and added into the mix as needed. Due to the high absorption value of RCA, the water was divided into two parts: free water and absorption water. It was found, that in order to maintain an initial slump of at least $50 \mathrm{~mm}$ for proper mixing; 
approximately $40 \%$ of the absorption water must be added to the initial free water. As the TSMA involves an initial dry mixing period, any old mortar being abraded off the RCA would introduce additional fines and thus further increasing the initial water demand. As previously mentioned in Section 3.2.1, this issues is addressed by following this dry mixing period with a pre-soaking cycle.
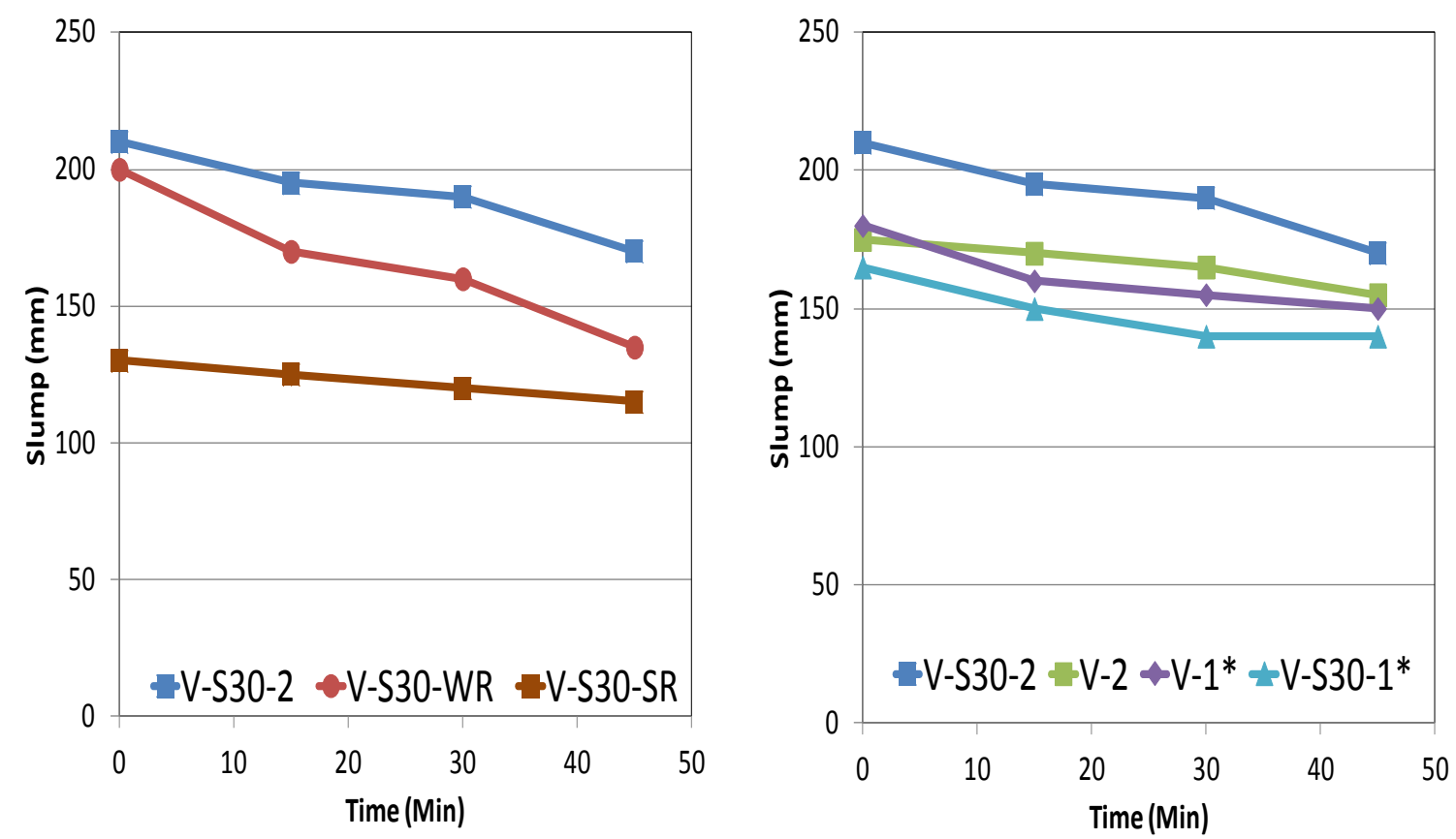

Figure 4.2-1 Virgin aggregate mixure slump retention

As the mixing process continues, and transport of the concrete commences, potentially further breaking off residual mortar from the RCA in the drum, resulting in more cementing fines being released, and must be addressed to accommodate the increased water demand. As such, upon commencement of transport, the remaining $60 \%$ of the absorption water is split into three equivalent parts and added in 15-minute intervals to account for the additional absorption of the aggregate during transportation. By following this routine, a final slump of $130 \pm 20 \mathrm{~mm}$ was always achieved in concrete with RCA and thus provided easy placement and finish-ability without segregation. 
Over time, unless modified with chemical admixtures to temporarily delay the phenomenon, a conventional concrete mix will have the tendency to experience slump loss over time as the batching procedure commences and the hydration process continues, and thus consuming up the free water.

By the time the concrete truck reaches the job site, especially for prolonged travel times, it is thus likely that the mix is no longer in the desired workable condition. To address this issue, the applicators will tend to add water into the mix to bring the slump up to desired conditions, a practice which has been widely shown to potentially negatively impact the mix's strength and durability.

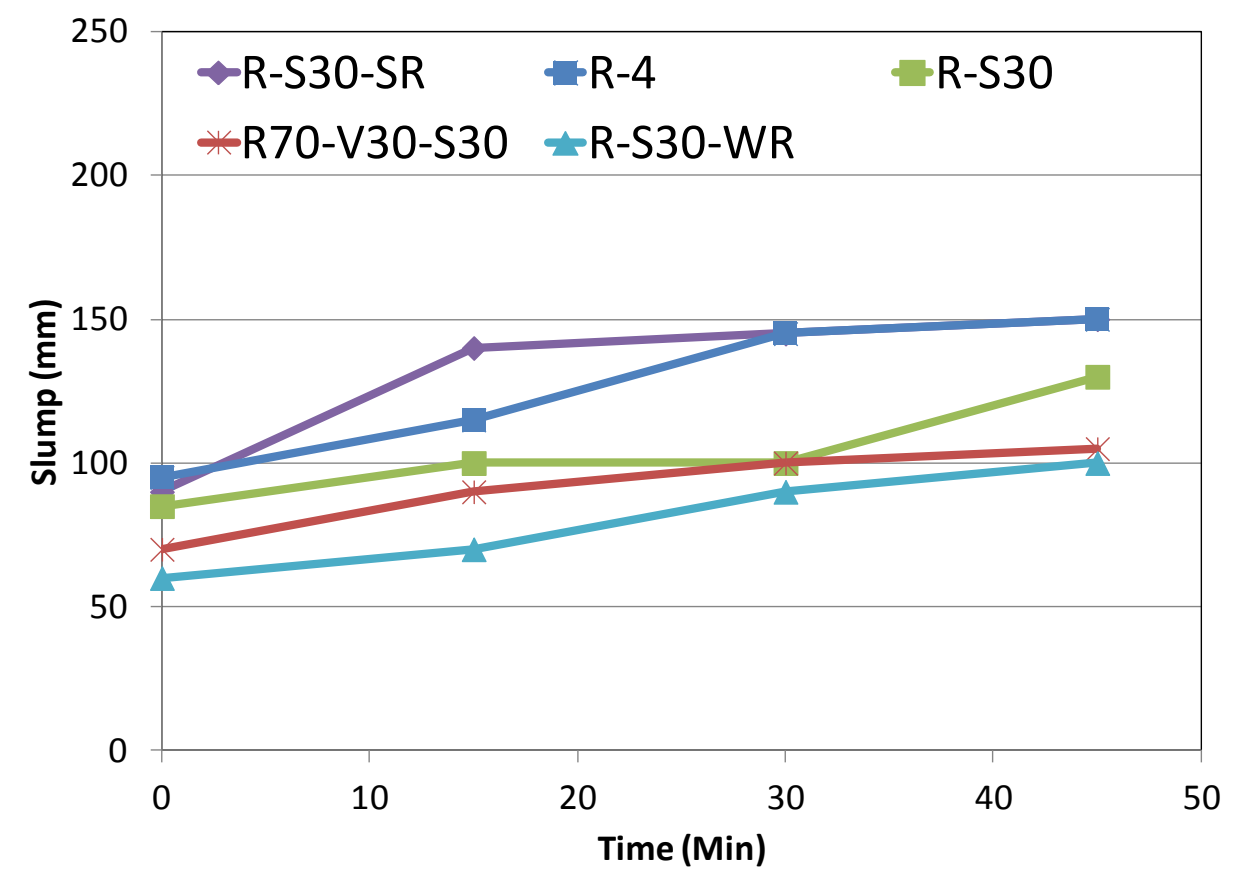

Figure 4.2-2 RCA mix slump monitoring with additional water tampering throughout retention cycle

Figure 4.2-2 displays the slump change over time during the batching and transport process for mixes containing RCA. It is to be noted that the maximum $\mathrm{w} / \mathrm{cm}$ ratio (fixed at 0.62 for mixes containing RCA) was never exceeded following the addition of the remaining water. Rather, the initially withheld water was meant to simulate the trim 
typically applied at the batch plant which is meant to accommodate the additional water added for washing of the truck hopper and fins following the batching procedure, as well as extra water required to bring the slump up to achieve desired workability conditions on the site. Regardless of the timing of water addition, the mixes were shown to perform adequately and thus suggesting that such practice does not negatively impact the performance of the RCA concrete.

\subsubsection{Air Content}

In order to ensure that Class $\mathrm{R}$ air specifications (4-7\%) were still met in each of the test batches, air content was tested at the end of the retention cycle, as the addition of extra water to any mix is known to impact air content.

Two alternative methods of AEA addition sequence were investigated. Mixes R-1 and R2 were batched by diluting the AEA in the final absorption water (added at the 45-minute mark), and thus experienced a drastic jump in final slump. Trial R-1, in which the AEA was diluted in the initial mixing water, had a tendency to entrain excessive amounts of air into the mix $(9.5 \%)$, and thus causing significantly reduced compressive strength.

Alternatively, AEA was added by sprinkling onto the sand during step 1 of the TSMA, and thus allowed for more consistent air control of the mix. By having the AEA sprinkled on the sand, the sand it said to create a net-like effect during the mixing process to properly allow the admixture to react with the paste, rather than excessively entraining air when diluted in the mixing water and being added in at several intervals.

All mixes in Figure 4.2-1 and Figure 4.2-2 were batched using this method and displayed adequate air retention as shown in Table 3-4. An air test was performed at the end of the retention cycle prior to casting of testing specimens. The sprinkling method was adapted for all subsequent mixes, as testing displayed that desired air content was achievable every time at the end of the retention cycles, even when tampering with the mix, by the addition of water, several times throughout. It was thus concluded that air retention was 
not affected when the slump was brought up during the retention cycle and thus ensuring that the durability of the final product would not be negatively impacted by the addition of water on site, as long as the maximum recommended w/cm ratio of 0.62 was respected.

\subsection{Compressive Strength}

Aside from air content, CSA A23.1-09 specifies a minimum 28-day compressive strength of $15 \mathrm{MPa}$ for air-entrained, residential wall concrete, with a maximum allowable w/cm ratio of 0.7 . To ensure all trial mixtures were able to satisfy the compressive strength criteria of Class $\mathrm{R}$ concrete, compression tests were performed on cylinders after 7 and 28 days of curing according to ASTM C39.

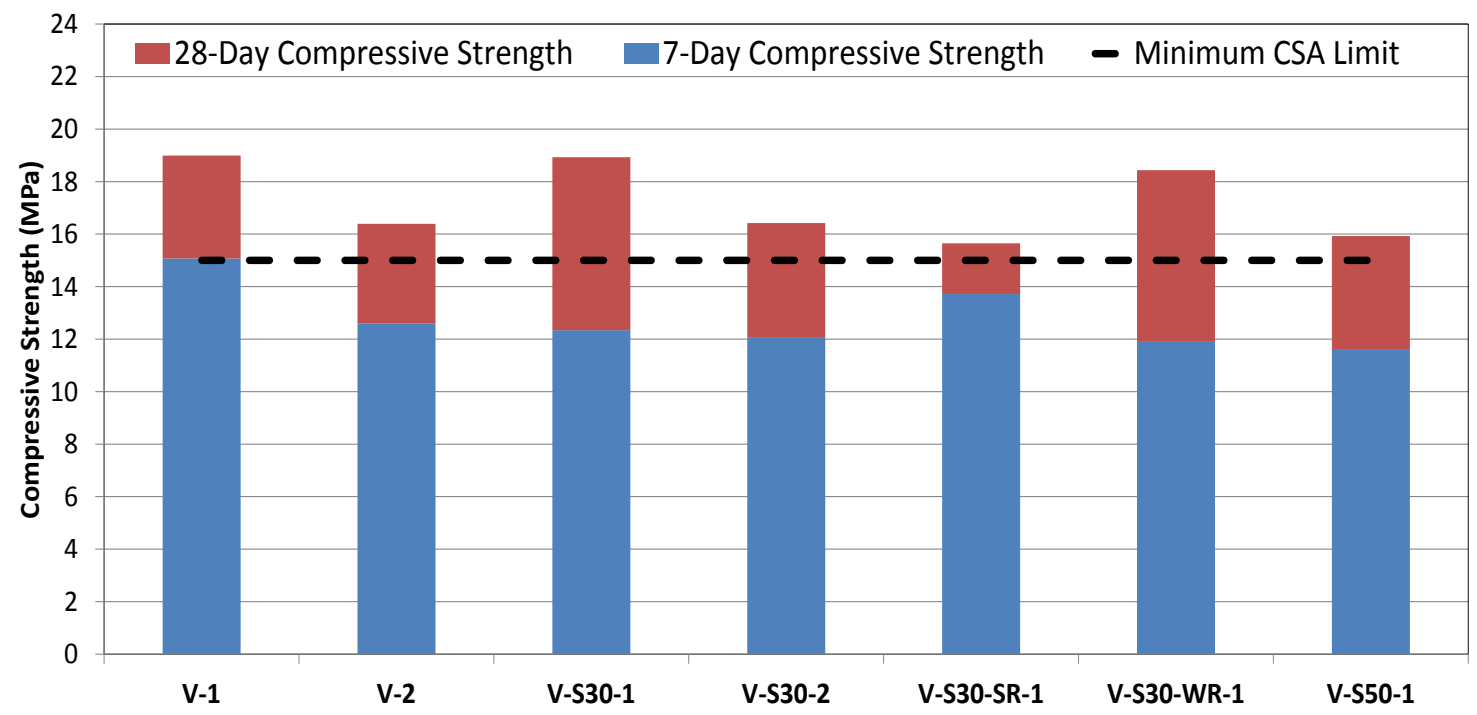

Figure 4.3-1 Compressive strength (100\% VA)

All VA control mixes, when produced at the maximum allowable $\mathrm{w} / \mathrm{cm}$ ratio, marginally passed this requirement (Figure 4.3-1). Mixes V-1 and V-S30-1 displayed a slightly higher compressive strength, due to a reduced $w / \mathrm{cm}$ ratio of 0.62 . These were cast to establish a comparative baseline between the RCA mixes cast at the same w/cm ratio. 
By maintaining a maximum w/cm ratio of 0.62 , all RCA mixes were also able to surpass this minimum requirement, as seen in Figure 4.3-2. Full results are shown in Table 4-1.

It is to be noted that mix R-1 was unable to meet this minimum requirement, as the mix resulted in excessive entrained air content (9.5\%). This was due to the early addition of the AEA into the mixing water. This finding further emphasized the importance of sequencing during the batching process, as previously emphasized in Section 4.2.2.

During the 45-minute retention period, water was added to maintain the high slump requirements for this class of concrete, and as such, replicating the likely scenario of water addition post-batching to the mix once the truck leaves the plant. It has been widely documented that such practice may significantly reduce the performance of concrete, and thus required addressing.

It is to be noted that all subsequently added water into the RCA, was originally withheld from the original mix design. This was to ensure that a final $w / \mathrm{cm}$ of 0.62 is ultimately maintained once the water had been re-introduced, and still satisfy the maximum w/cm criteria for Class R concrete. Even with such tampering, all mixes were able to meet the minimum compressive strength requirement of Class $\mathrm{R}$ residential wall mixes.

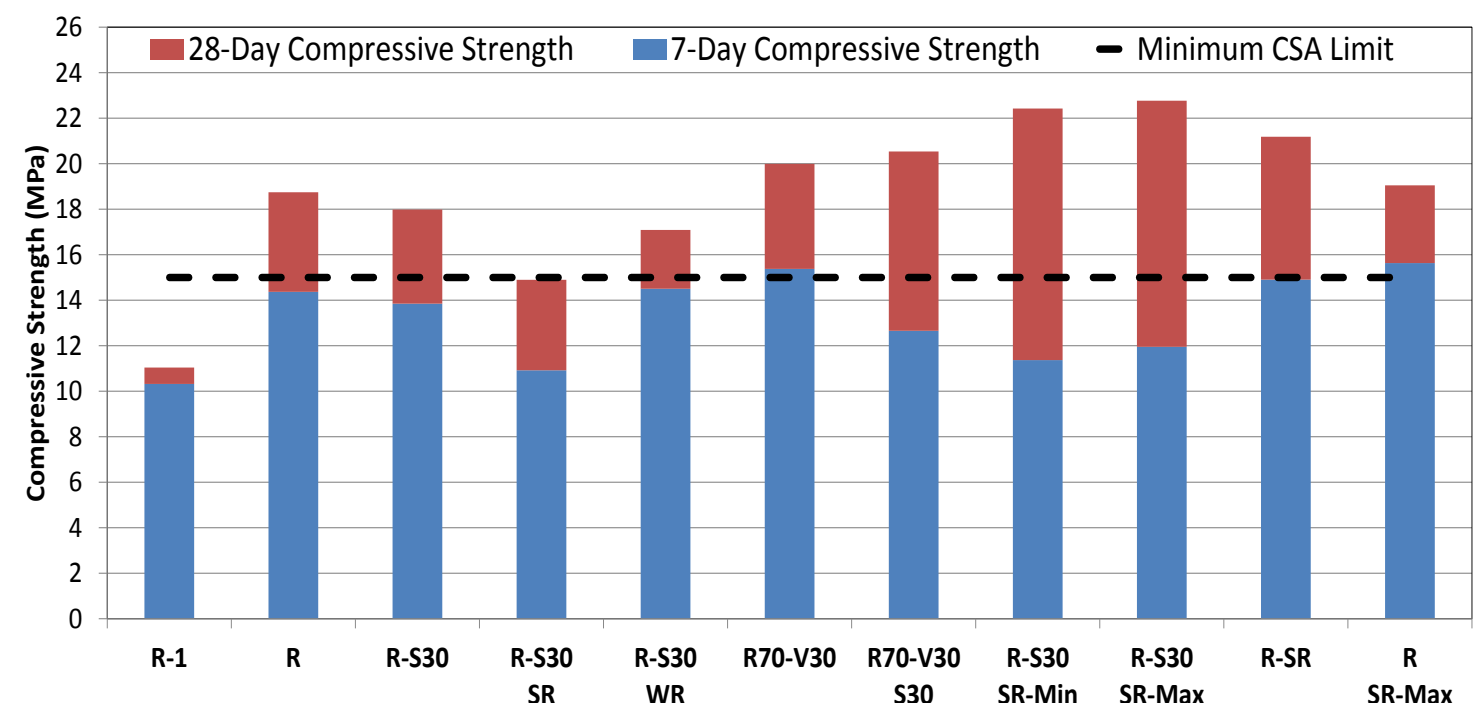

Figure 4.3-2 Compressive strength (100\% RCA) 
Table 4-1 - Compressive strength and standard deviation of trial mixtures

\begin{tabular}{ccccc}
\hline & \multicolumn{4}{c}{ Average Compressive Strength (MPa) } \\
\hline Mix Label & 7 -Days & Std Dev. & 28-Days & Std. Dev. \\
\hline V-1 & 15.07 & 1.05 & 18.99 & 0.73 \\
\hline V-2 & 12.59 & 0.53 & 16.53 & 1.26 \\
\hline V-FT & 16.71 & 0.53 & 21.75 & 1.41 \\
\hline V-S30-1 & 14.45 & 0.64 & 20.91 & 1.37 \\
\hline V-S30-2 & 12.08 & 1.22 & 16.42 & 0.56 \\
\hline V-S30-SR & 13.72 & 1.51 & 15.65 & 1.55 \\
\hline V-S30-WR & 11.90 & 0.25 & 18.43 & 1.58 \\
\hline V-S50 & 10.59 & 0.17 & 14.93 & 1.81 \\
\hline R-1 & 10.32 & 1.46 & 11.04 & 0.78 \\
\hline R-2 & 16.77 & 0.38 & 22.21 & 1.42 \\
\hline R-4 & 12.52 & 0.31 & 15.23 & 0.26 \\
\hline R-5 (FT) & 13.82 & 1.55 & 18.80 & 0.32 \\
\hline R-SR & 14.91 & 1.43 & 21.19 & 1.08 \\
\hline R-SR-3Max & 15.64 & 0.74 & 19.05 & 1.10 \\
\hline R-S30-1 & 13.87 & 0.74 & 17.17 & 1.50 \\
\hline R-S30-3 (FT) & 13.71 & 1.67 & 19.65 & 1.52 \\
\hline R-S30-SR & 10.92 & 0.67 & 14.90 & 0.33 \\
\hline R-S30-SR-2Min & 11.37 & 0.27 & 22.43 & 1.26 \\
\hline R-S30-SR-3Max & 15.64 & 0.74 & 19.05 & 1.10 \\
\hline R-S30-WR & 14.50 & 0.53 & 17.09 & 1.06 \\
\hline R70-V30 & 15.38 & 1.12 & 19.99 & 1.21 \\
\hline R70-V30-S30 & 13.15 & 0.31 & 19.63 & 0.50 \\
\hline R70-V30-S30-2 & 12.17 & 1.35 & 21.44 & 0.77 \\
\hline & & & & \\
\hline & 1.53 & \\
\hline
\end{tabular}


Most mixes even surpassed the minimum $20 \mathrm{MPa}$ requirement for residential floor applications, which do not require air-entrainment. It stands to reason that if these mixes were to be batched without air entrainment; their compressive strength would potentially be even higher. This may allow for an increased w/cm ratio to be used in the production of non-air entrained floor mixes with RCA and thus reducing the overall cost without impacting the performance.

\subsection{Drying Shrinkage Evaluation of RCA Concrete}

Though CSA A23.1-09 does not specify a requirement on drying shrinkage of Class R concrete, it is a crucial factor to be tested at high-volume RCA replacement levels. This is due to the overall increased mortar content of the concrete produced. As drying shrinkage is highly affected by the high $\mathrm{w} / \mathrm{cm}$ ratio, and high paste/mortar content, both the residual mortar from the RCA, as well as the high w/cm ratio paste (forming the new mortar), contribute highly toward what makes RCA concrete notorious for drying shrinkage problems. Sections 4.4.2 through 4.4.7 display the long-term drying shrinkage curves obtained for various Class R trial mixes containing VA and RCA up to the age of 180 days.

\subsubsection{Drying Shrinkage of Conventional VA vs. RCA Concrete}

In order to establish a baseline for comparison of conventional VA and RCA concrete, drying shrinkage specimens were cast at the same initial cement content and $\mathrm{w} / \mathrm{cm}$ ratio for mixes containing either $100 \%$ VA or $100 \%$ RCA as coarse aggregate. The values were $350 \mathrm{~kg} / \mathrm{m}^{3}$ and 0.52 , respectively.

Comparing the shrinkage of both groups in Figure 4.4-1, it is evident that the shrinkage of RCA-concrete was much higher than those of VA concrete when the w/cm ratio and volume of paste (excluding residual mortar on RCA) is kept constant. In fact RCAconcrete suffered from nearly a $100 \%$ increase in drying shrinkage compared to its VA counterpart. It is to be noted however, that these mixtures only underwent a 24-hour 
curing period prior to being placed in shrinkage conditions. Addition of GGBS did not show any noticeable improvement relative to the control mixes in terms of drying shrinkage.

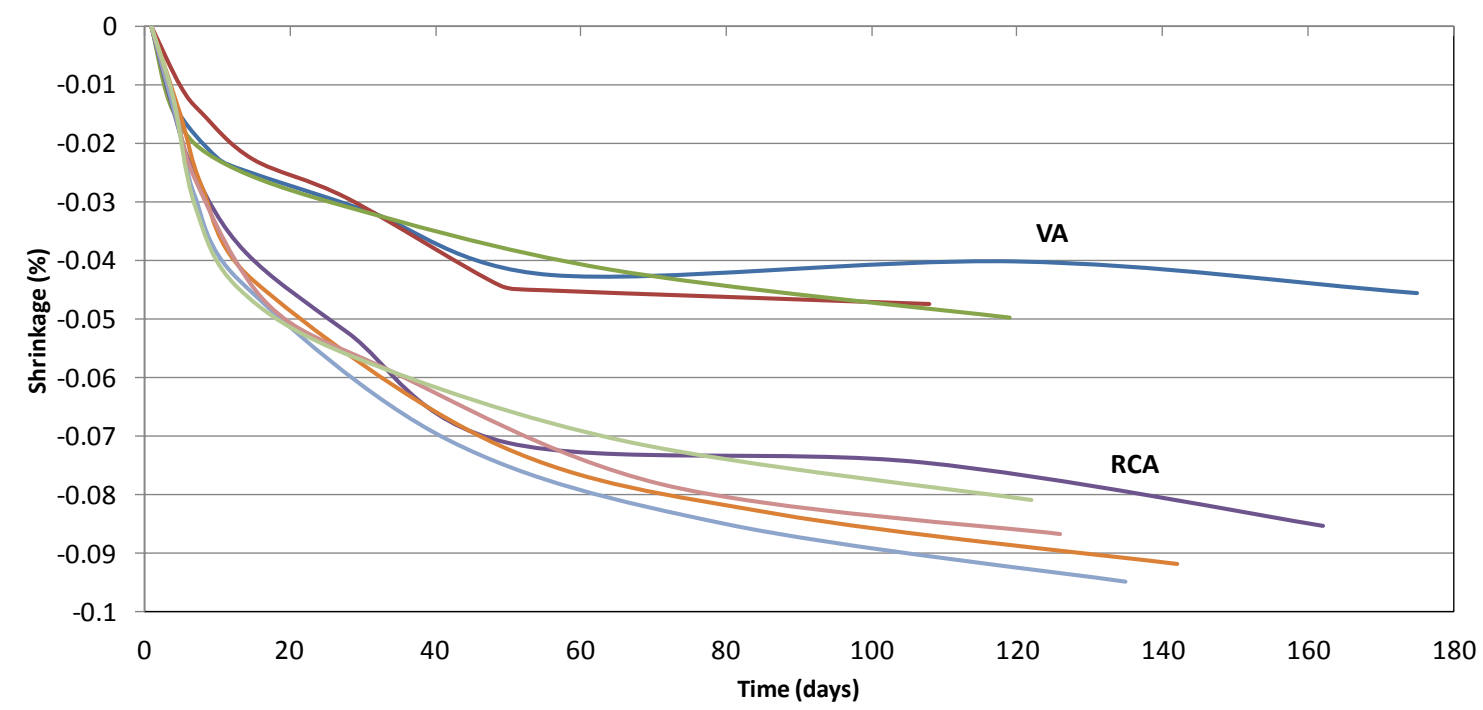

Figure 4.4-1 Drying shrinkage of conventional VA concrete and experimental

RCA-concrete

Drying shrinkage testing was performed according to ASTM C157 and all subsequent samples were cured in lime-saturated water prior to being placed into drying conditions at an age of 7 days. It is to be noted that all shrinkage results are in reference to the 7-day initial reading.

\subsubsection{Effect of GGBS Addition to VA Concrete}

As shown in Figure 4.4-2 and Figure 4.4-4, various control mixes were cast at a w/cm ratio of 0.7 and 0.62 , using only $\mathrm{VA}$, to establish a baseline for shrinkage of conventional Class $\mathrm{R}$ concrete. An average 180-day shrinkage, ranging between $0.05-0.06 \%$, was observed to be common in VA mixes conforming to Class R requirements. 
Seen in Figure 4.4-2, the replacement of 30\% PC with GGBS exhibited negligible differences in drying shrinkage, as was also reported by Hooton et al. (2004). The mix containing 50\% GGBS displayed slightly reduced initial drying shrinkage but also ultimately achieved a final drying shrinkage equivalent to the control mix, as shown in Figure 4.4-3.

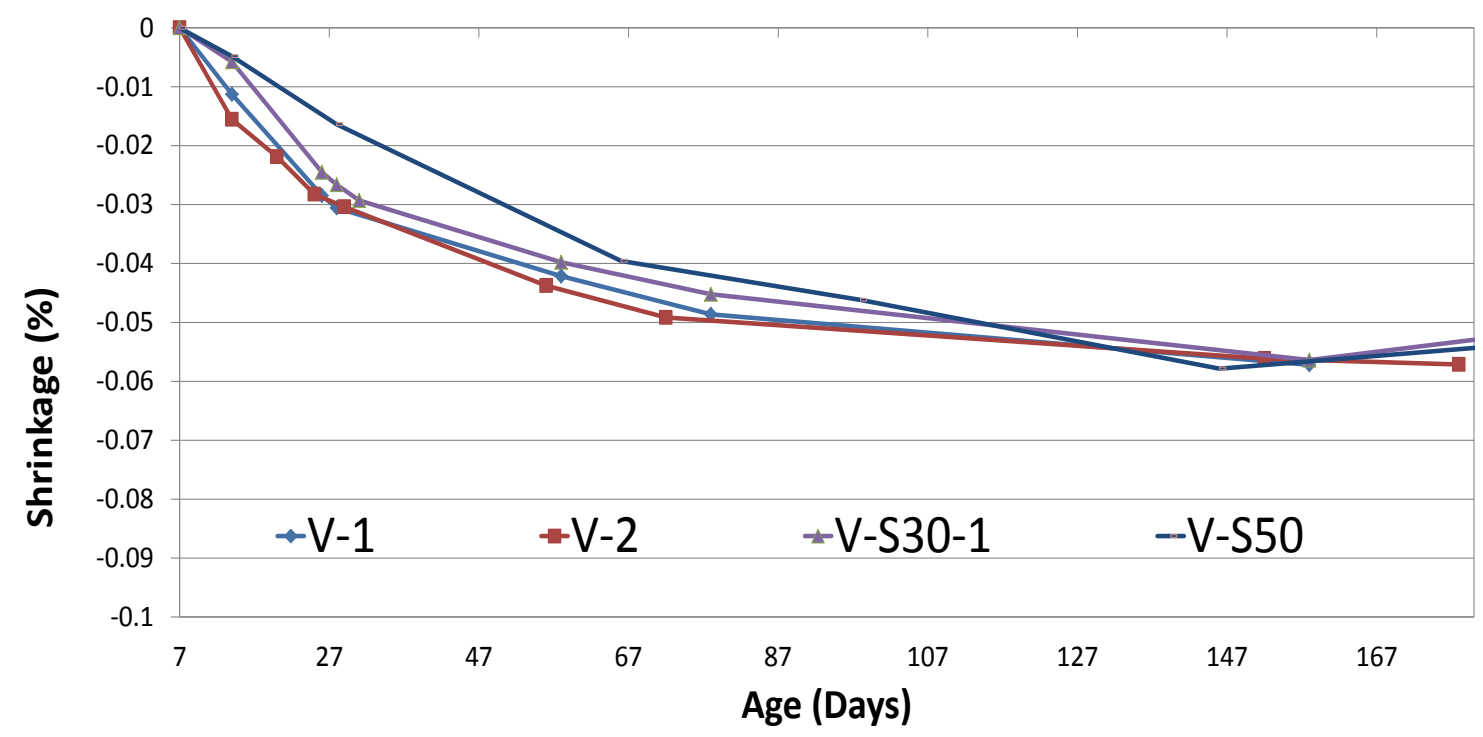

Figure 4.4-2 Drying shrinkage of mixes with virgin aggregates and GGBS replacement

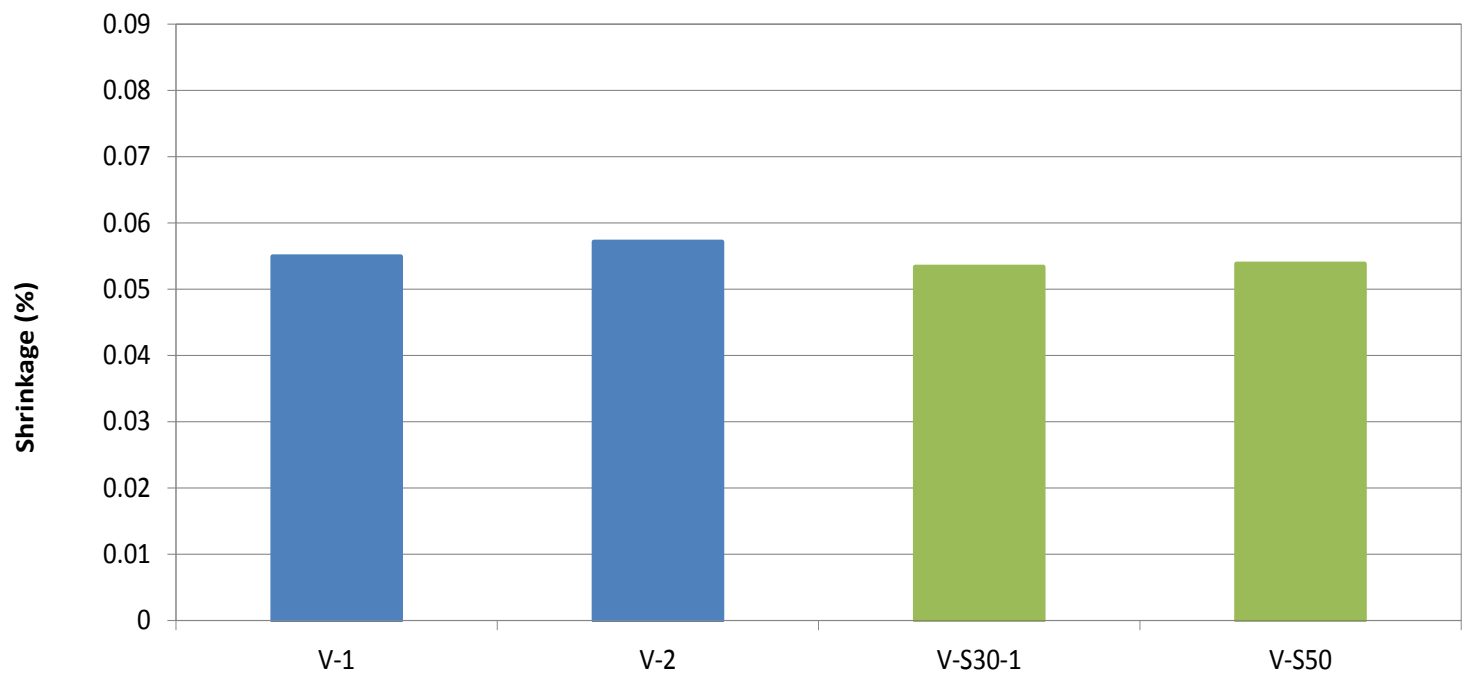

Figure 4.4-3 Ultimate 180-day drying shrinkage of class $\mathrm{R}$ virgin aggregate mixtures 
These mixes provided a clear indication of the behaviour and consistency of VA mixes conforming to CSA Class R. The mixtures cast at w/cm ratios of $0.62(\mathrm{~V}-1)$ and $0.7(\mathrm{~V}-2)$ displayed increasing drying shrinkage relative to the benchmark mixtures (Figure 4.4-1). This is mainly attributable to the difference in $w / \mathrm{cm}$ ratios between the various mixes.

\subsubsection{Effect of Chemical Admixtures on VA Concrete Shrinkage}

Through the use of chemical admixtures, the goal was to test various factors upon the effect of drying shrinkage on the VA concrete specimens to establish a behaviour pattern as a control point for comparison to the RCA companion samples.

Mixtures V-S30-1 and V-S30-2 were cast at w/cm ratios of 0.62 and 0.7 , respectively. Mixture V-S30-WR was cast at $0.70 \mathrm{w} / \mathrm{cm}$ ratio but also containing WRA in order to maintain the same w/cm ratio but lower both the water and cementing material content. Finally, Mixture V-S30-SR was cast at $0.7 \mathrm{w} / \mathrm{cm}$ ratio but containing the mid-range recommended dosage (as per the manufacturer's suggestion: $5 \mathrm{~L} / \mathrm{m}^{3}$ ) of SRA in order to evaluate the direct effect on the VA mix.

Figure 4.4-4 shows the effects of adding chemical admixtures to concrete conforming to Class $\mathrm{R}$ requirements using VA. With respect to drying shrinkage, the use of waterreducing admixture (to reduce the overall cementing materials content by $10 \%$ ), did not display significant improvement.

Figure 4.4-5 displays only a slight reduction in drying shrinkage observed due to the reduction of overall paste content. In a similar study, Sagoe-Crentsil et al. (2001) investigated the effects of varying cementing content by $5 \%$ and discovered similar results. As also reported by Tavakoli and Soroushian (1996), it is clear from the results in Figure 4.4-5, that the w/cm ratio is the main factor affecting shrinkage. 


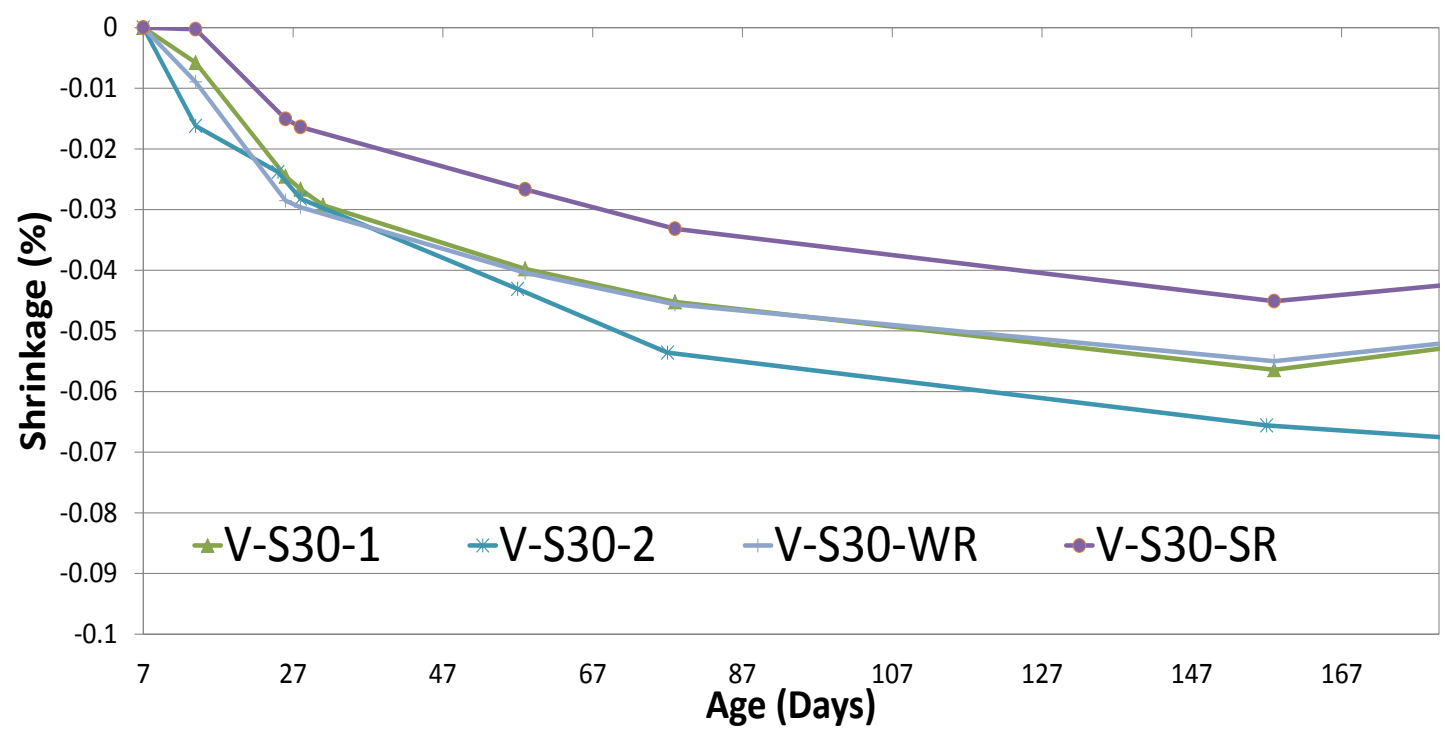

Figure 4.4-4 Drying shrinkage of mixes with virgin aggregates \& chemical admixtures

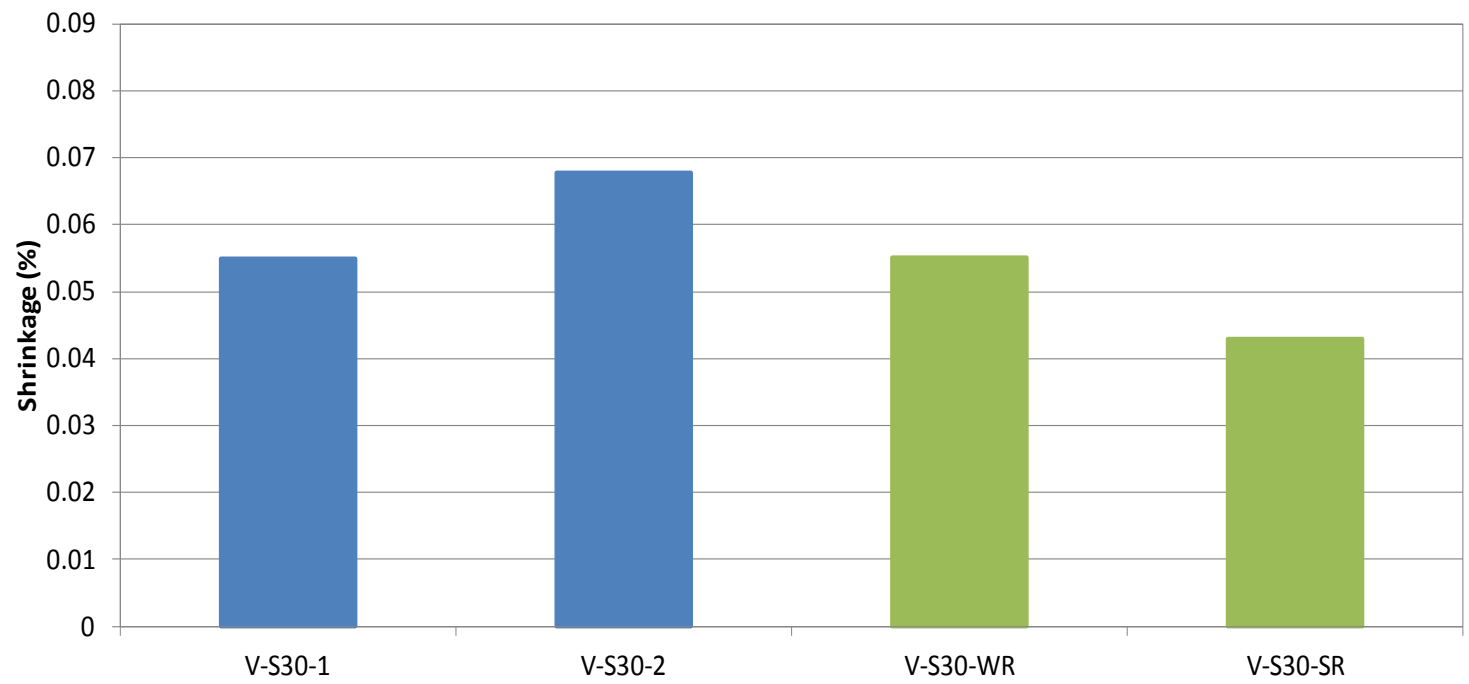

Figure 4.4-5 Ultimate drying shrinkage of VA mixtures containing chemical admixtures

The role of total cementing materials is minimal for the mixtures investigated here. Indeed, the mixes V-S30-1 and V-S30-2 are of the same composition except for the w/cm ratio. The shrinkage of the mixture with $\mathrm{w} / \mathrm{cm}$ of 0.70 exhibited higher values than that of w/cm of 0.62 due to the additional water content. However, the use of SRA in these mixes was able to reduce the overall shrinkage by approximately up to $20 \%$ overall. 
Considering these findings as the benchmark drying shrinkage behaviour of Class $\mathrm{R}$ concrete, further comparative testing was then possible by incorporating high replacement levels of coarse RCA into the subsequent mixes.

\subsubsection{Effect of $100 \%$ RCA replacement of Coarse Aggregate}

In order to evaluate the drying shrinkage of RCA concrete, specimens were cast at a w/cm ratio of 0.62 , and a relative comparison was made. Both PC and GGBS mixes were evaluated to establish a relation for the drying shrinkage behaviour of mixes incorporating a full $100 \%$ RCA as coarse aggregate.

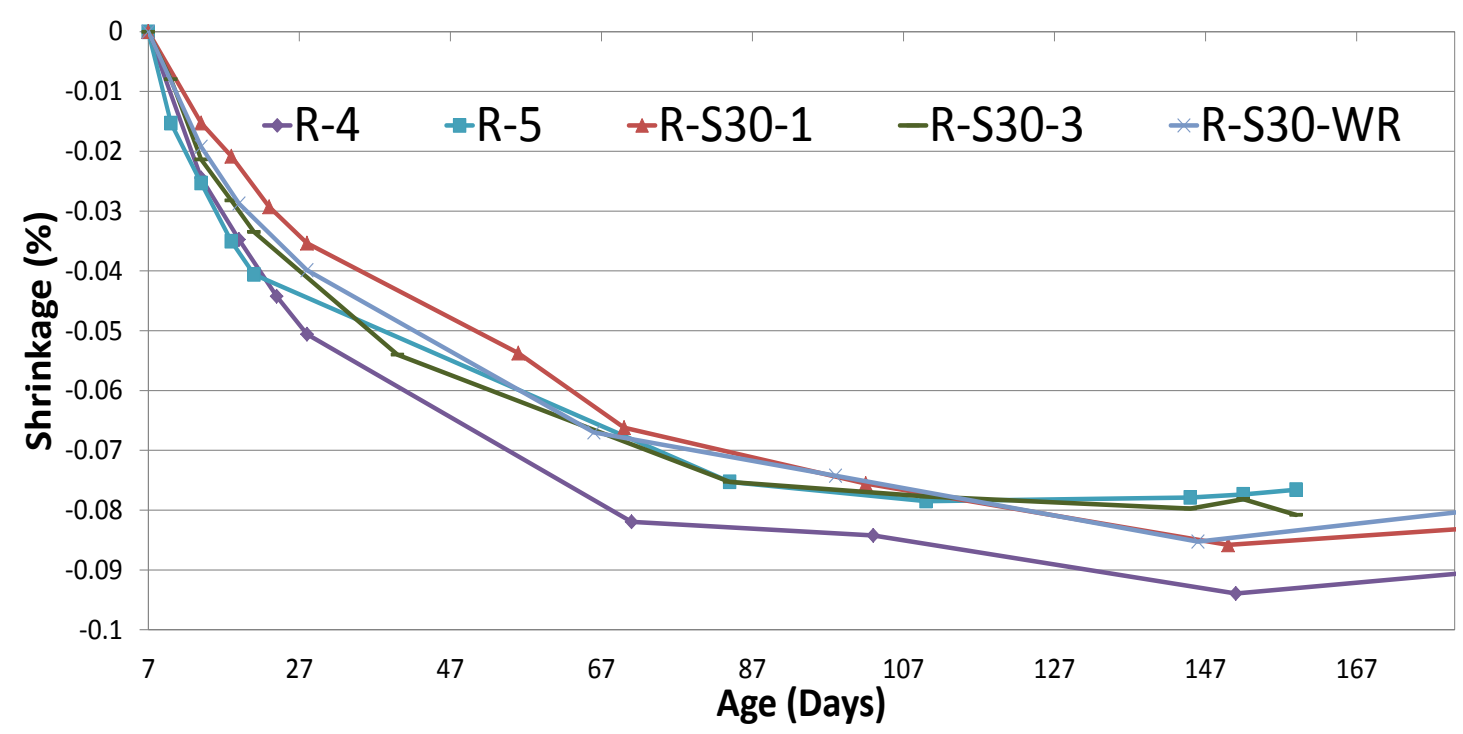

Figure 4.4-6 Drying shrinkage of mixes with 100\% RCA replacement and 30\% GGBS

Figure 4.4-6 displays the various mixes cast at a w/cm ratio of 0.62 with a complete replacement of coarse aggregate by RCA. A common overall shrinkage of approximately $0.08 \%$ (at 180 days) was observed for mixes containing only RCA as coarse aggregate. This translates into an approximate 50\% increase in drying shrinkage compared to mixtures containing only VA ( $0.055 \%$ at 180 days). 
As was the case with VA, the addition of GGBS (at $30 \%$ replacement by mass of CM) did not play a significant role in reducing the effects of overall drying shrinkage. Slightly reduced earlier drying shrinkage was observed up to 28 days and tended to ultimately balance off with the $100 \%$ PC mixes. Perhaps this may suggest ensuring shrinkage testing is performed past the 28-day cycle in the case of RCA mixes containing SCMs in order to ensure proper evaluation. Such behaviour is to be expected due to the variable reaction rate of SCMs relative to $\mathrm{PC}$.

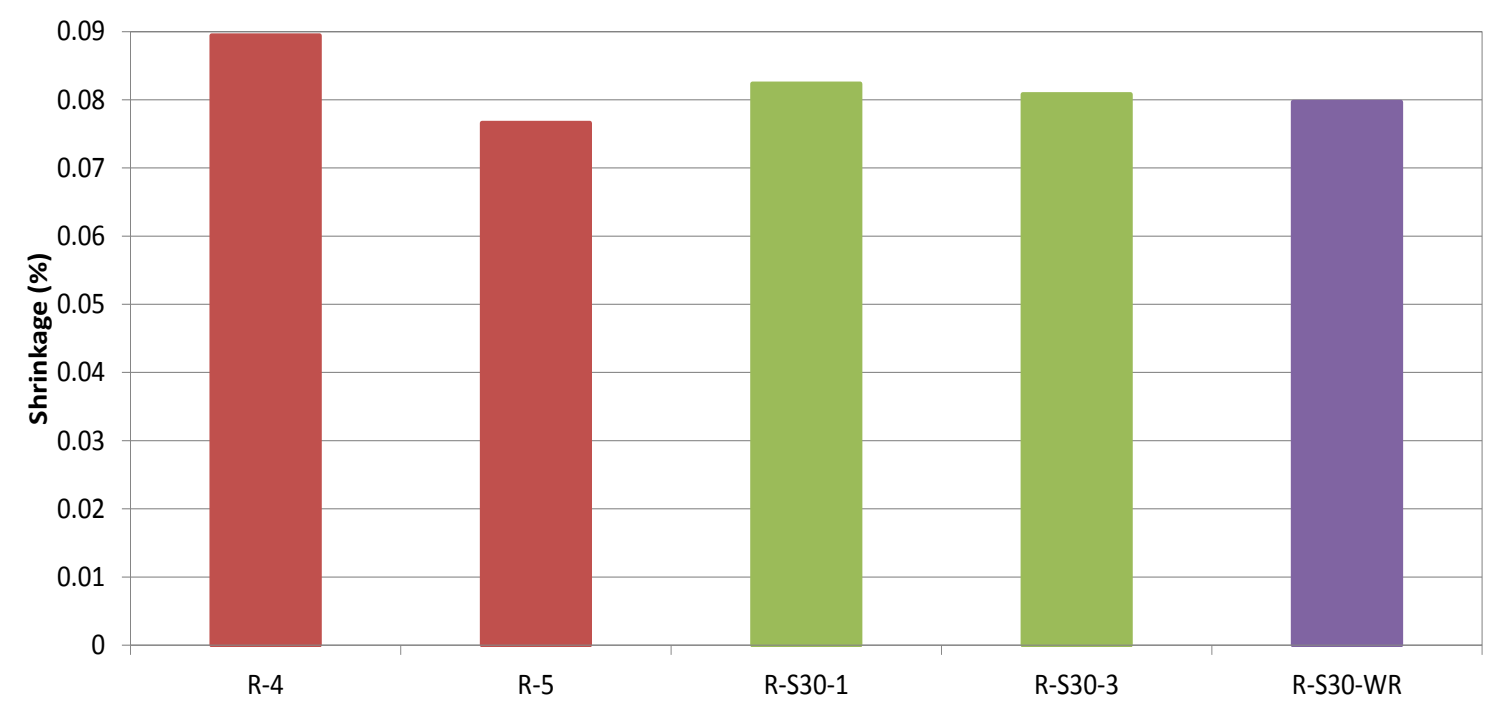

Figure 4.4-7 Ultimate drying shrinkage of mixtures containing 100\% RCA

Figure 4.4-7 displays the ultimate drying shrinkage of these Class R mixtures made with $100 \%$ RCA as coarse aggregate. Once again, a slight reduction in powder (and paste) content, through the addition of WRA, did not affect shrinkage results, thus remaining a viable option for use in the production of such mixes where a lower powder content is desired. Regardless of this, the shrinkage of $100 \%$ RCA specimens remains high relative to their VA counterparts and thus must be addressed in order to mitigate these effects. 


\subsubsection{Effect of RCA Replacement Level (70\%)}

An effective middle ground must also be established for the case that a full replacement of RCA is not desirable and the adverse shrinkage effects needed to be mitigated. As such, mixes were tested incorporating a 70\% replacement level of coarse VA with RCA to establish a relationship.

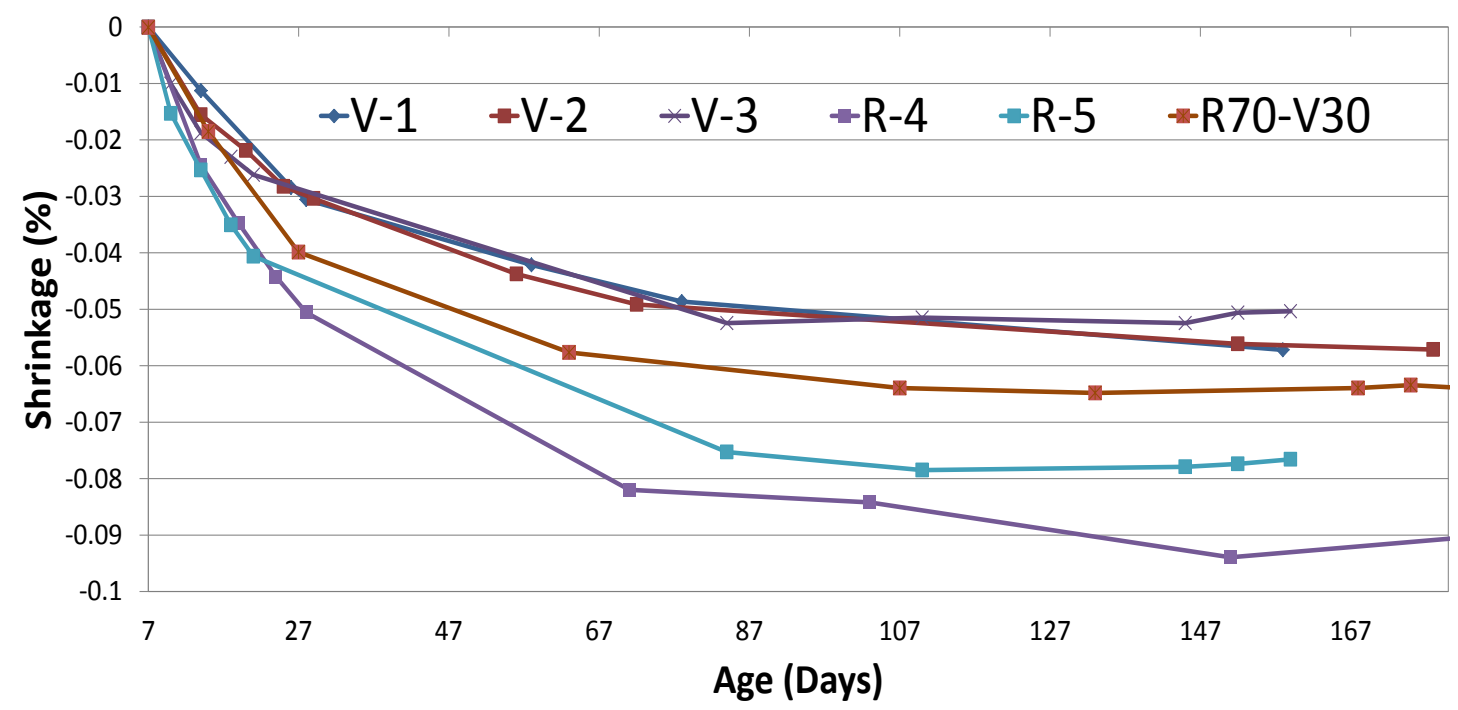

Figure 4.4-8 Drying shrinkage of mixtures containing varying RCA replacement levels

Figure 4.4-8 displays mixes cast at a w/cm ratio of 0.62 , but with a blend of RCA and VA at a ratio of 70:30\% of the total coarse aggregate content evaluated against its VA and RCA counterparts. As shown in Figure 4.4-9, the 70/30 mix exhibited an ultimate drying shrinkage of $0.065 \%$; only an approximate $18 \%$ increase relative to that of $100 \%$ VA, compared to the near 50\% increase observed with $100 \%$ replacement. Relative to the high replacement level of RCA, this increase in drying shrinkage may be easily mitigated in most applications. 


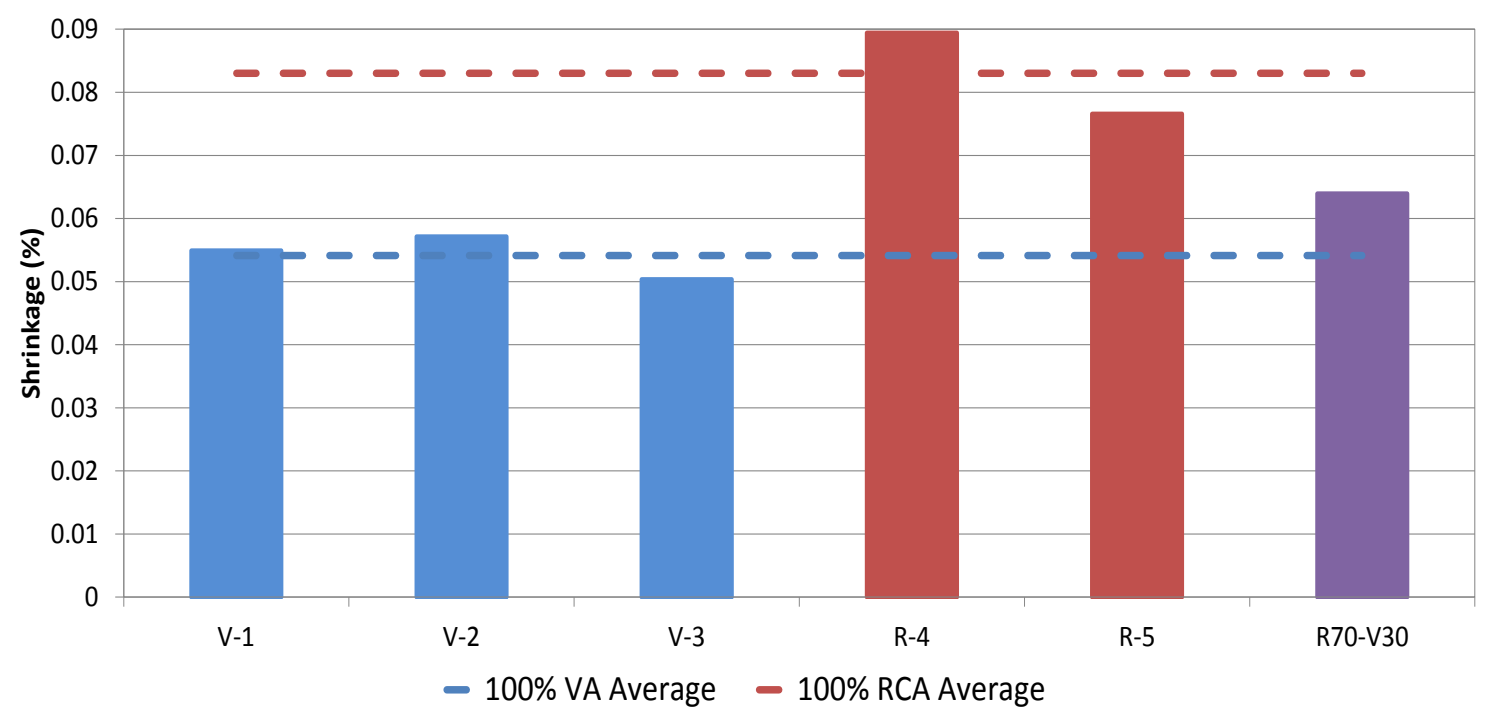

Figure 4.4-9 Ultimate drying shrinkage of mixes containing both VA and RCA

The 70/30 blend mix exhibits various different characteristics as a comparison to its VA and RCA extremities. The overall total amount of water (incorporating mix water and absorption water) is significantly reduced (relative to $100 \%$ RCA mixes), due to the difference in absorbed water between RCA and VA, as well as the reduction in overall paste content (incorporating both residual mortar paste and fresh paste) in the mixes. Drying shrinkage is typically decreased by both of these factors and may thus explain the relatively large difference observed in the drying shrinkage behaviour of this blend. Further evidence to suggest similar behaviour was observed with mixes in Section 4.4.6 .

\subsubsection{Effect of 70\% RCA Replacement and GGBS Addition}

To verify the substantial variation in drying shrinkage, 70/30 blend mixes were also cast incorporating GGBS. Varying only the RCA replacement level, mixes were made containing identical paste and sand volumes. 


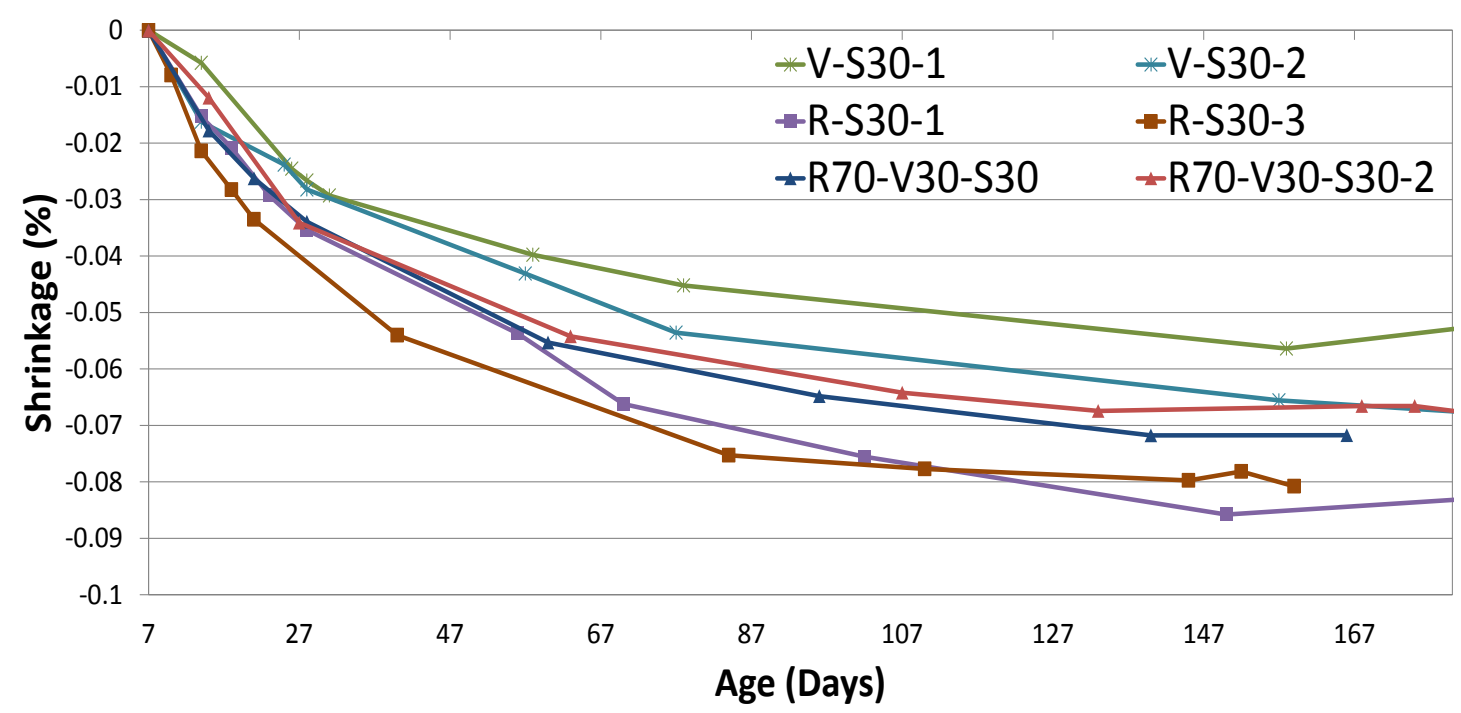

Figure 4.4-10 Drying shrinkage of mixes containing both 70\% RCA \& 30\% GGBS

Figure 4.4-10 displays the drying shrinkage over time of mixes cast using both $30 \%$ GGBS replacement and a $70 \%$ replacement of $\mathrm{RCA}$ at $0.62 \mathrm{w} / \mathrm{cm}$ ratio. Based on the average ultimate drying shrinkage displayed in Figure 4.4-11, it can be observed that drying shrinkage in these mixtures reduces (relative to VA mixes) from an increase of $35 \%$ to only $15 \%$ when the RCA replacement level is reduced from $100 \%$ to $70 \%$, respectively. Once again, this significant reduction is believed to be attributable to the reduction in both (overall) water and paste contents of the mixes. This indicates that a $70 \%$ substitution of coarse RCA for VA is a reasonable alternative in terms of mitigating the effects of drying shrinkage where a high volume of coarse RCA is to be incorporated.

It remains to be seen through trials between $50 \%$ and $70 \%$ replacement, which optimum replacement level may cause negligible differences. The effects of such high replacements should also be studied when a much less drastic w/cm ratio is used in the development of the new concrete. 


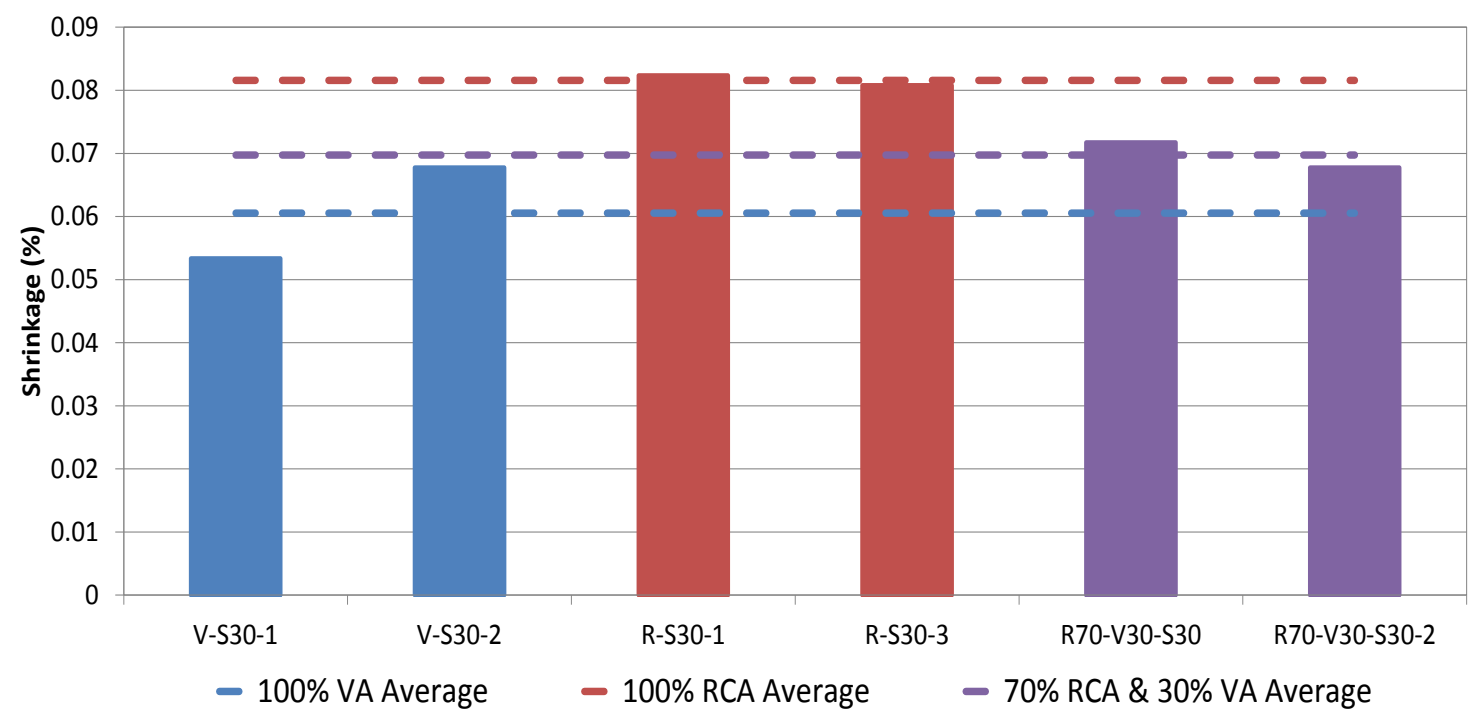

Figure 4.4-11 Ultimate drying shrinkage of mixes with VA, RCA, and 30\% GGBS

\subsubsection{Effect of Shrinkage Reducing Admixture (SRA) Dosage}

The use of SRA has proven to be quite effective in mitigating the effects of drying shrinkage in various applications using VA. It remained to be seen whether the effectiveness of such an admixture would be affected by the use of RCA in the concrete. Figure 4.4-12 displays mixes cast using various dosages of SRA to control drying shrinkage. Mixes were cast by varying from the manufacturer's minimum (R-S30-2Min) to maximum (R-S30-3Max) recommended dosage of SRA. Though the trend over time remains similar to that of mixes without SRA, the overall shrinkage remains significantly lower.

Displayed in Figure 4.4-13, of particular significance is the fact that, at the maximum recommended dosage, the SRA was able to completely cancel out the increased drying shrinkage effects of RCA, and reduce it down to that of VA, even at $100 \%$ replacement. 


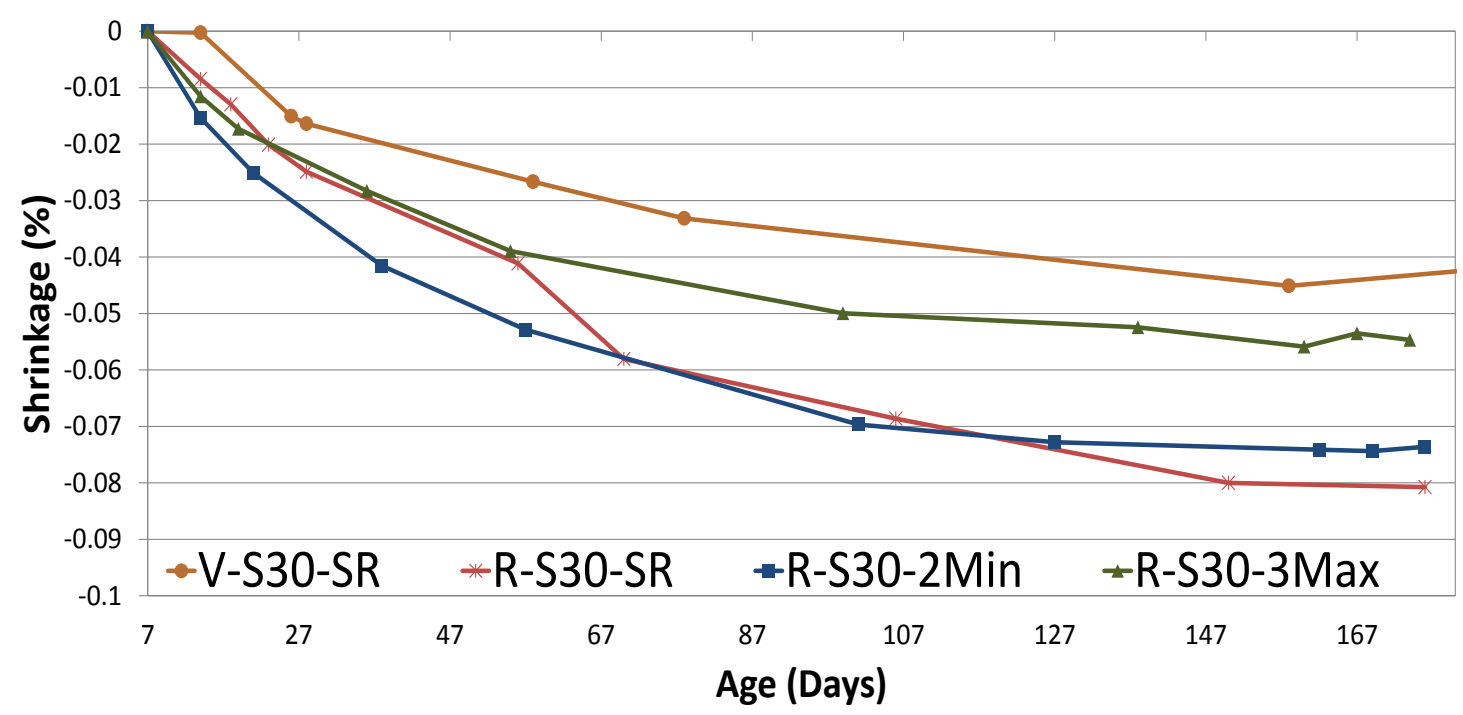

Figure 4.4-12 Drying shrinkage of mixtures with varying SRA dosages

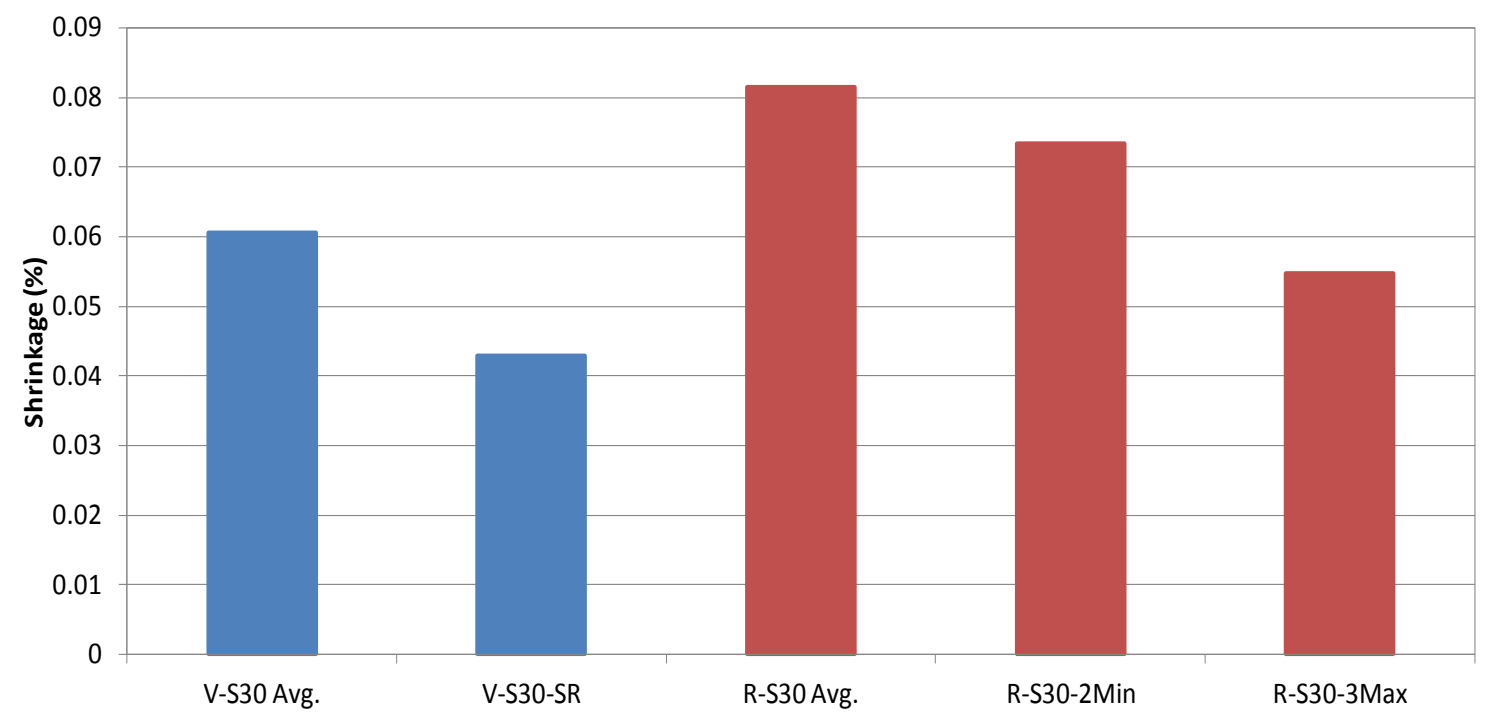

Figure 4.4-13 Ultimate drying shrinkage of VA and RCA mixtures containing SRA

Through introduction of sufficient SRA, applications where drying shrinkage must be regulated thus become another potential source for the use of RCA in concrete production to display its feasibility. 


\subsection{Alkali-Silica Reactivity (ASR)}

This part of the study focused on investigating the effects of alkali and calcium contribution from RCA on the expansion of sand that marginally meets the expansion limit in accordance with CSA A23.2-14A. The sand incorporated here (Marginally Reactive Sand, MRS), marginally met the expansion limit when tested according to CSA A23.2-14A. In order to establish a proper account of the coarse RCA's effects in terms of ASR, marginally reactive sand was used to judge the influence of RCA towards the reaction. By providing reactive sand in the mix, the influence of RCA on regulating the amount of available alkalis in the pore solution of the paste for ASR to occur could thus be judged.

These effects were studied in several phases. A control point was initially established (as described in Section 4.5.1) by testing the reactivity of the MRS in mixes containing NonReactive Coarse (NRC) aggregate, and comparing this to similar mixtures containing coarse RCA. Further reactivity and mitigation of ASR effects were studied by incorporating SCMs such as GGBS and Type F Fly Ash into the mix as outlined in Section 4.5.2. To quantify the available alkalis in the pore solution, and further relate the observed expansion of the specimens, Section 4.5.3 presents results of alkali-leaching testing performed on paste samples.

\subsubsection{Effect of RCA}

Concrete prisms were cast in order to effectively evaluate the reactivity of MRS and the effects of RCA on influencing the alkali-silica reactions. The specimens were monitored over a 90-week period to determine the long-term effects.

Figure 4.5-1 displays the expansion of MRS with both Non-Reactive Coarse (NRC) aggregate and RCA. Utilising such sand allowed for direct testing of the effects of the alkalis released from the residual mortar of the RCA on triggering excessive expansion in the marginally reactive sand. 


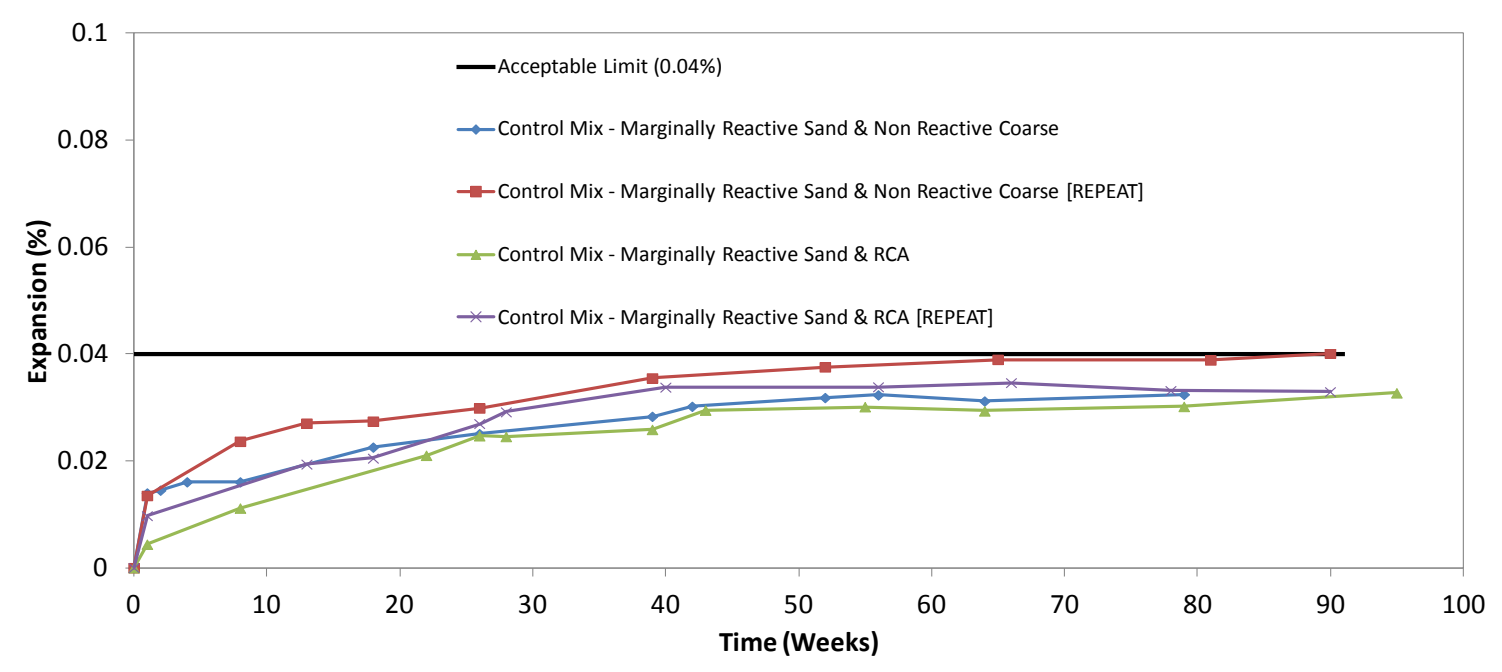

Figure 4.5-1 Reactivity of marginally reactive sand with $100 \%$ coarse RCA

By replacing the NRC with RCA, no further expansion was observed and thus demonstrating that RCA does not have a tendency to trigger further expansion in concrete with MRS. This suggested that the reaction was perhaps limited to the amount of level of reactivity in the sand, and not to the amount of alkalis in the system. This is assuming that RCA releases alkalis to the mix (Shehata \& Thomas, 2010).

\subsubsection{Effect of SCMs}

The incorporation of SCMs into mixes to create binary and ternary blends has been a widely documented practice to effectively mitigate the effects of ASR. As a pure PC mix was proven not to trigger additional reaction when RCA is introduced into the mix, it remained important to determine whether the RCA itself is sufficient enough to depress the effects of ASR, or whether even further mitigation was possible through the use of common blends of SCMs incorporation in the presence of a reactive aggregate.

Figure 4.5-2 displays the effects of incorporating SCMs into the mix to mitigate ASR. It was observed that a $30 \%$ replacement of PC with GGBS, or a $20 \%$ replacement of Type F Fly Ash, in combination with RCA, was able to reduce the effects of ASR far below the acceptance when the marginally reactive sand was used in the mix. 
In fact, further reduction in expansion was observed in the mixes containing SCMs relative to those containing only $\mathrm{PC}$, thus indicating that the available level of alkalis in the pore solution of the paste may be reduced even further by binding them in the hydration products, and not consuming all available reactive silica from the MRS. This claim is further investigated in Section 4.5.3.

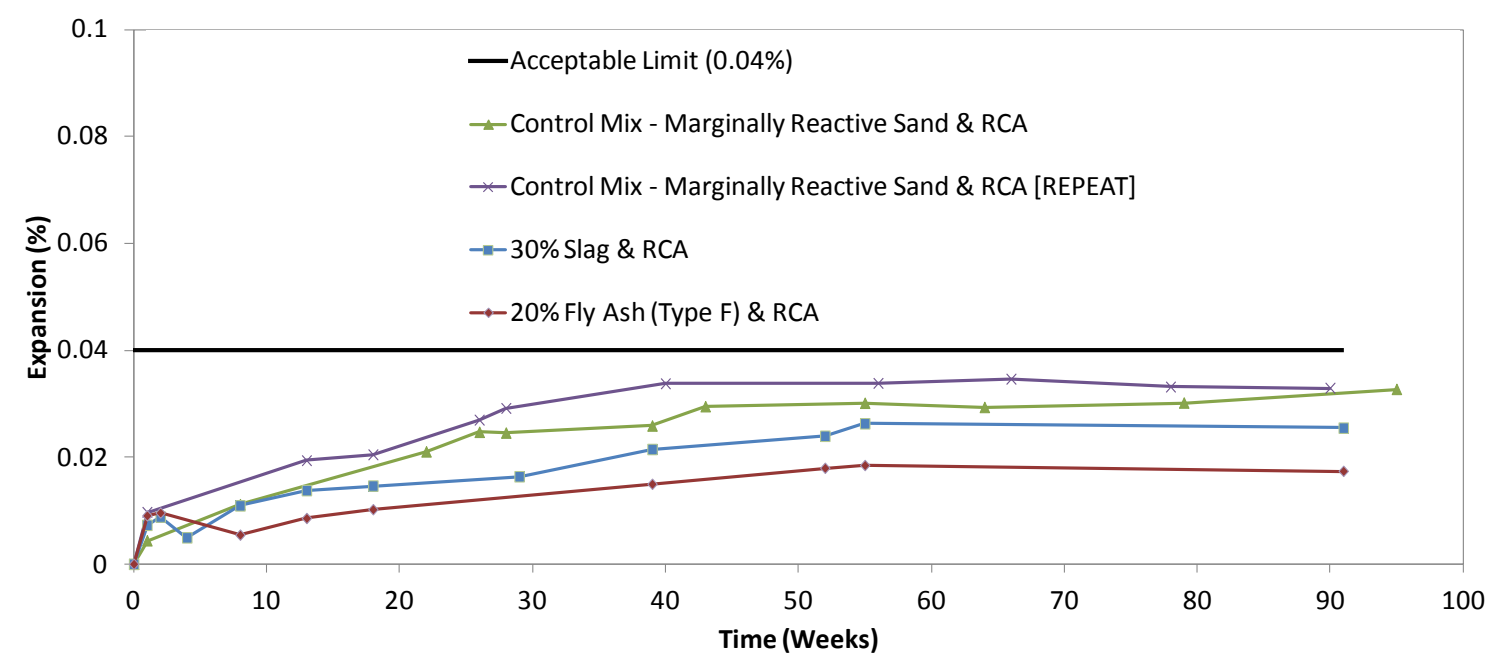

Figure 4.5-2 Reactivity of marginally reactive sand and $100 \%$ coarse RCA with SCMs

\subsubsection{Alkali-Leaching Test}

The alkali-leaching test, as originally proposed by Shehata and Thomas (2006), was performed in order to determine the alkali binding characteristics of the various cementing material compositions investigated for ASR.

Testing of the prepared samples was performed with the aid of a flame photometer in order to provide an accurate analysis of the dissolved alkali ions in the solution. By using extremely sensitive photo-sensors, the apparatus is able to distinguish the individual wavelength from the atomization of various ions when burned in a flame. The accuracy of the device, when calibrated properly, is able to identify concentration of ions in a solution to $0.2 \mathrm{ppm}$. 
Precise readings and measurements were taken to account for all possible correction factors in the readings. A detailed step-by-step analysis, in order to calculate out the $\mathrm{Na}_{2} \mathrm{O}_{\mathrm{e}}$ change as a factor of the cementing materials is discussed in Appendix A.

A simultaneous analysis of $\mathrm{Na}^{+}$and $\mathrm{K}^{+}$ions in the solutions was performed for each set of samples. Specimens were tested in two solutions: Distilled Water (DW) and a solution prepared to be equivalent to $0.25 \mathrm{~N} \mathrm{NaOH}$. Each set of specimens was kept in solution for over 2 years, past the duration mention by Shehata and Thomas (2006) to be sufficient for no further alkali exchanges to occur between the paste and solution. The $0.25 \mathrm{~N}$ solutions were prepared using $\mathrm{NaOH}$ and $\mathrm{KOH}$ pellets to simulate similar $\mathrm{Na} / \mathrm{K}$ ratios as those in the paste matrix, according to the chemical composition of the PC and SCMs.

Three test specimens were made for each paste sample in both Distilled Water (DW) and $0.25 \mathrm{~N}$ solution. The alkalis released from the DW specimens are displayed in

Figure 4.5-3. Type F FA, containing the highest amount of alkalis (by composition) was leached into the DW solution of the paste samples and proved to bind the alkalis more efficiently then PC and GGBS, as seen by its low contribution in solution.

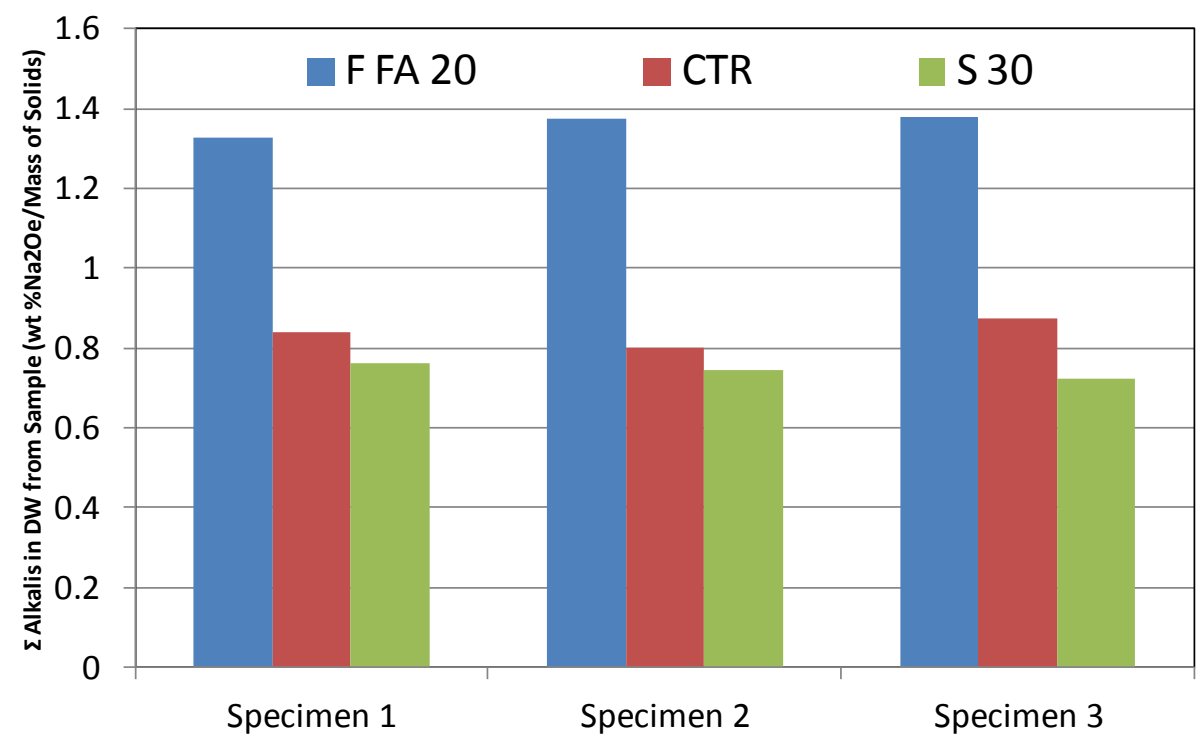

Figure 4.5-3 Released alkalis from paste specimen results in DW 


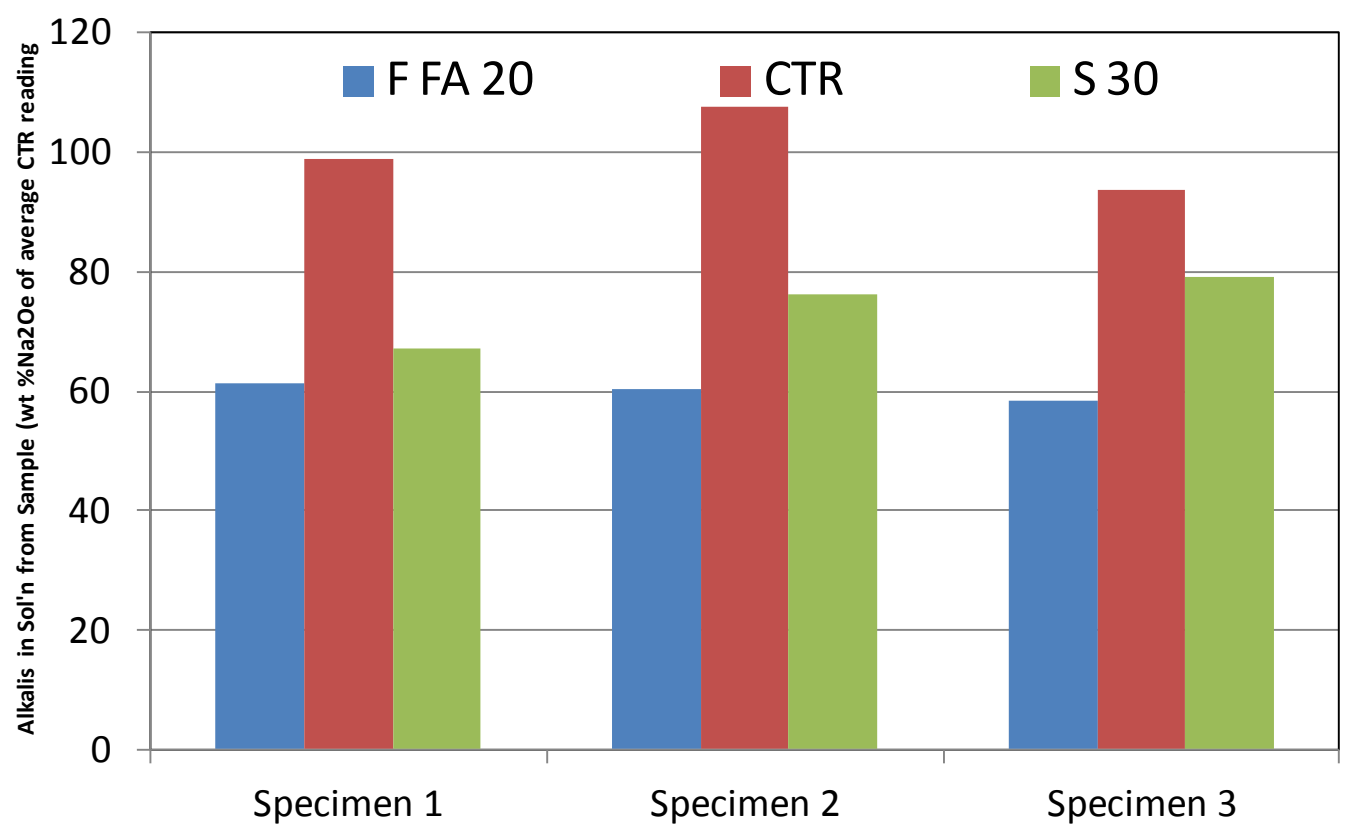

Figure 4.5-4 Released alkalis from paste specimens results in solution (\% of CTR mix)

From the solutions tested, it can be seen in Figure 4.5-4 that the most alkalis are leached by the control sample containing $100 \%$ PC (CTR) in $0.25 \mathrm{~N}$ solution. The figures displays the percentage of alkalis released relative to the average of the control specimens. A significant decrease is observed in both SCM mixes containing either 20\% Type F Fly Ash (F FA 20) or 30\% GGBS (S 30). This indicates that the hydration products of the SCMs have a much higher capacity to bind alkalis in the pore solution, and thus effectively reducing their ability to react with reactive silica to form the gel product and cause expansion. 
A direct correlation between the 90-week ASR expansion results and the available alkalis leached into the pore solutions may thus be established. Figure 4.5-5 displays the relationship between the 90-week expansion of the RCA specimens cast with MRS and the amount of alkalis leached into the pore solution by a paste containing the same cementing material composition.

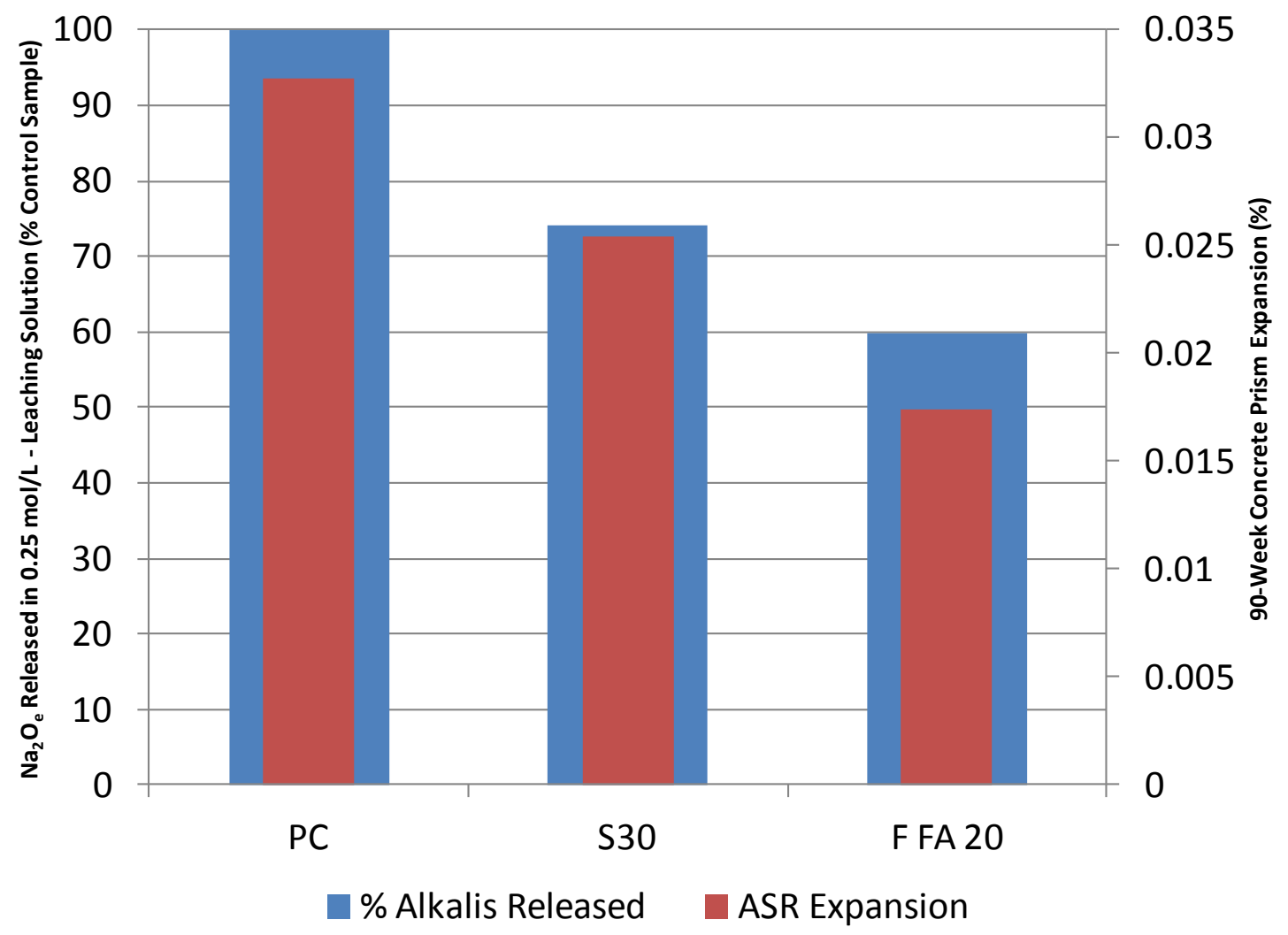

Figure 4.5-5 90-week expansion versus available alkalis for tested paste samples

The trend is in agreement with work published previously by Shehata and Thomas (2006). However, there seem to be a consistent order of magnitude error in the results of the samples leached in the nominal solution of 0.25 moles/litre. Hence, the results are presented here as a percentage of the alkalis leached from the control sample. As the graph shows, the alkalis contributed from the fly ash sample is $60 \%$ of that from the control sample. This is directly responsible for the reduced expansion observed. 


\subsection{Freezing and Thawing Resistance}

Freezing and thawing resistance testing was performed in accordance with ASTM C666 using $75 \mathrm{~mm} \times 75 \mathrm{~mm} \times 285 \mathrm{~mm}$ prism specimens. Readings were taken in accordance with ASTM C597 using the pulse-velocity method for determination of dynamic modulus. Three mixes were tested; a control mix (V-CTR-FT) using VA, cast at a maximum w/cm ratio of 0.7 as per CSA A23.1-09, a mix incorporating 100\% RCA replacement (R-FT), and a mix incorporating both 100\% RCA replacement and 30\% GGBFS (R-S30-FT), both cast at a $/ \mathrm{cm}$ ratio of 0.62 . To set a benchmark for expectations in the deterioration mechanism, Figure 4.6-1 depicts the difference in possible deterioration in the testing.

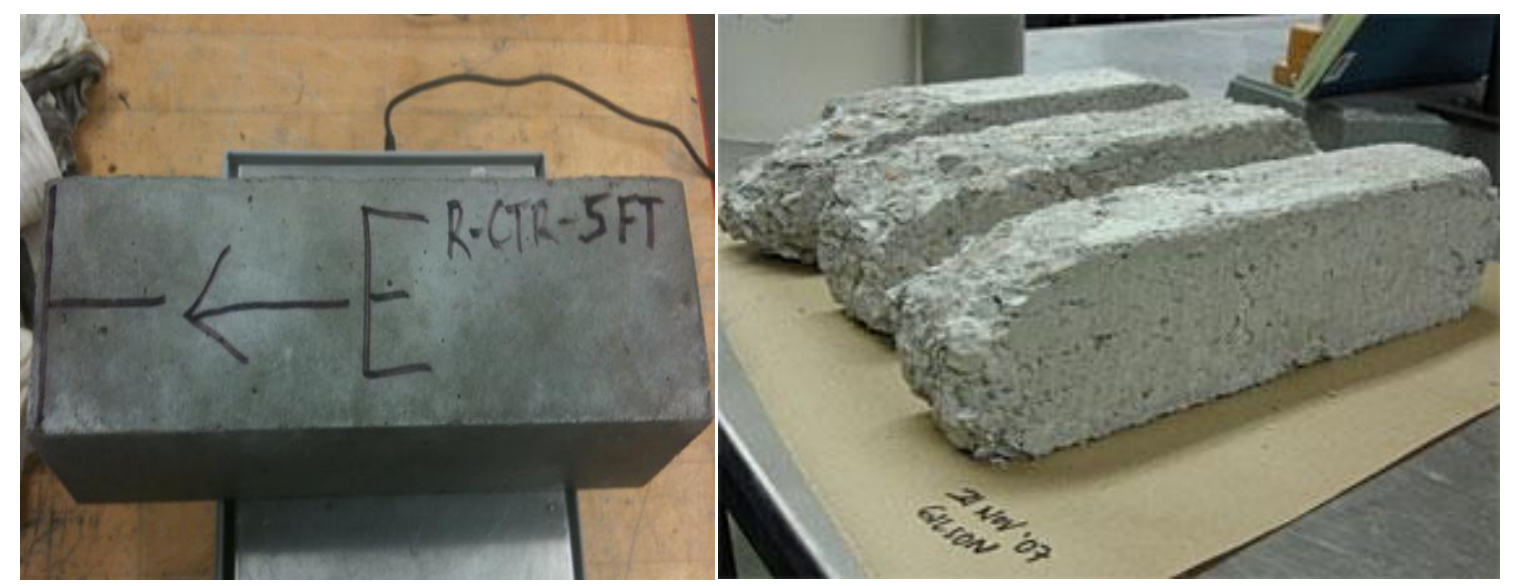

Figure 4.6-1 Adequate (left) and poor (right) performance freezing and thawing test specimens (Wang \& Steffes, 2009)

\subsubsection{Virgin Aggregate Control Mix (V-CTR-FT)}

By ensuring that both air content and compressive strength requirements were met, when casting the VA control mix in accordance with CSA standards, this mix acted as a control point to evaluate the freezing and thawing resistance of Class $\mathrm{R}$ wall mixes. The durability of the control mix would determine the adequacy of other mix designs as a relative comparative study. 


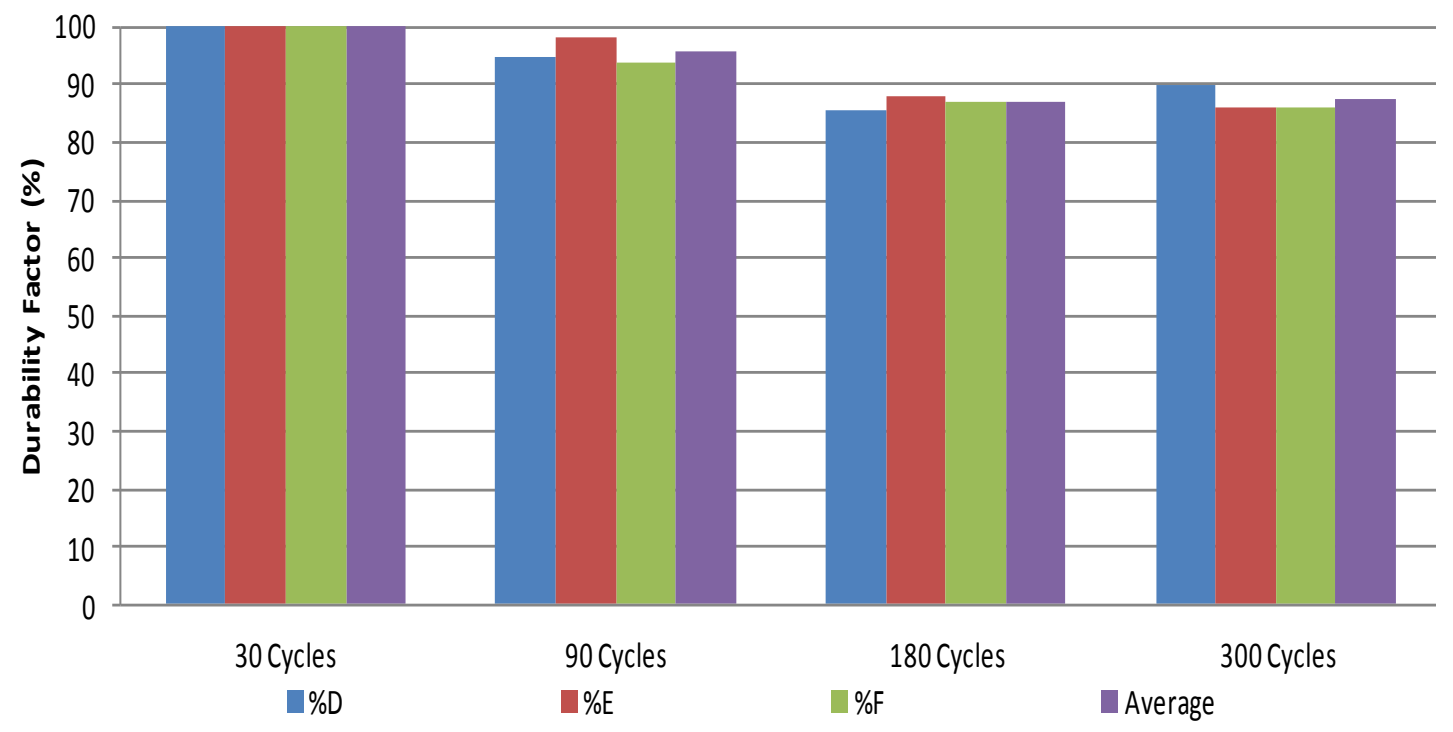

Figure 4.6-2 Durability factor of VA class R mixes cast at $0.7 \mathrm{w} / \mathrm{cm}$

As shown in Figure 4.6.1-1, the control mix exhibited only minor fluctuations in durability throughout the 300 cycle testing period. An overall durability factor of $88 \%$ was observed for the control mixes.

Figure 4.6-3 displays the overall deterioration of the control specimens using VA after 300 cycles. Overall, the specimens did not exhibit major structural deterioration on any of the three samples due to the sufficient air content in the mix. However, it is to be noted that all samples had signs of pop-out occurrences. This phenomenon is quite typical in concrete exposed to freezing and thawing in a super saturated condition. The pressures built up inside the saturated aggregate caused the final pop-outs observed below. 


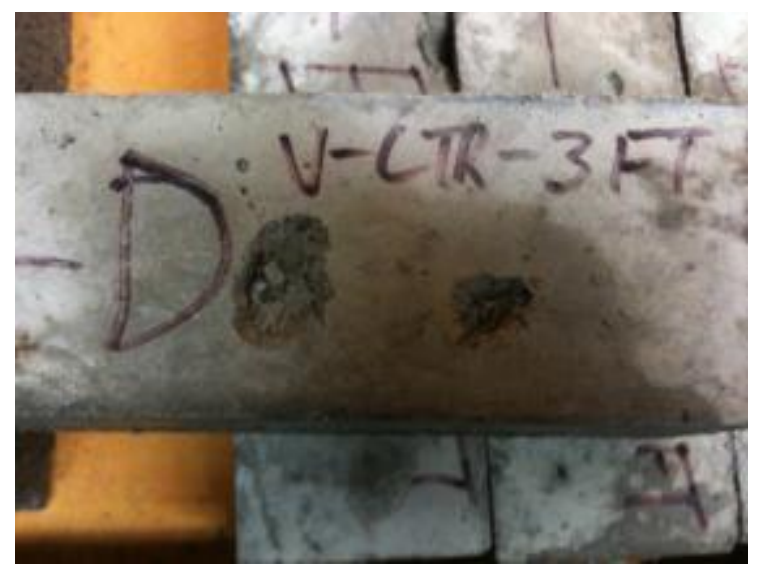

a) Pop-outs on specimen surface

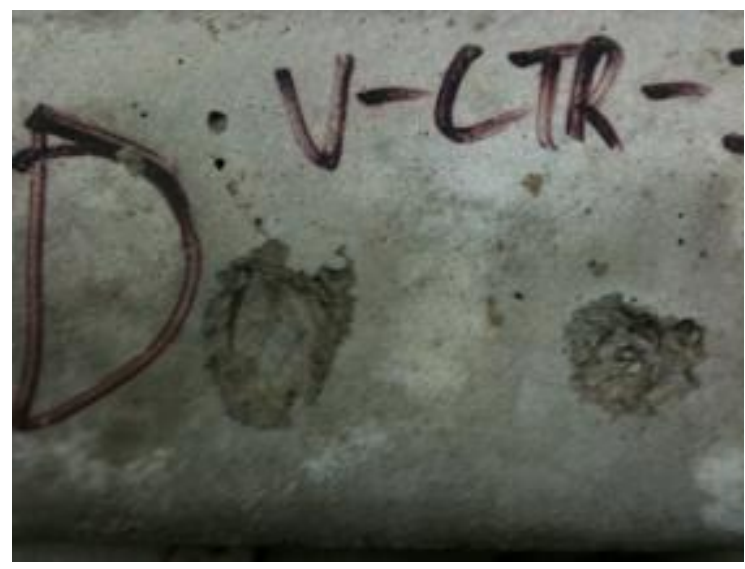

c) Close-up of pop-outs

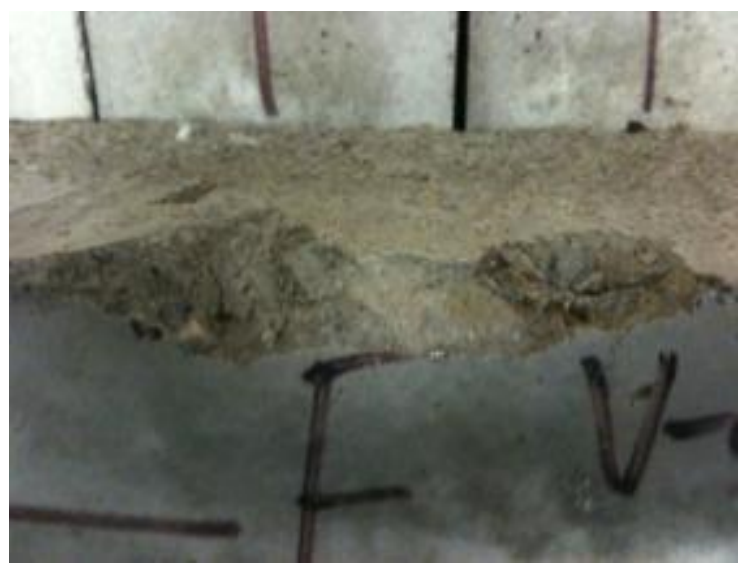

b) Deterioration of weaker edges

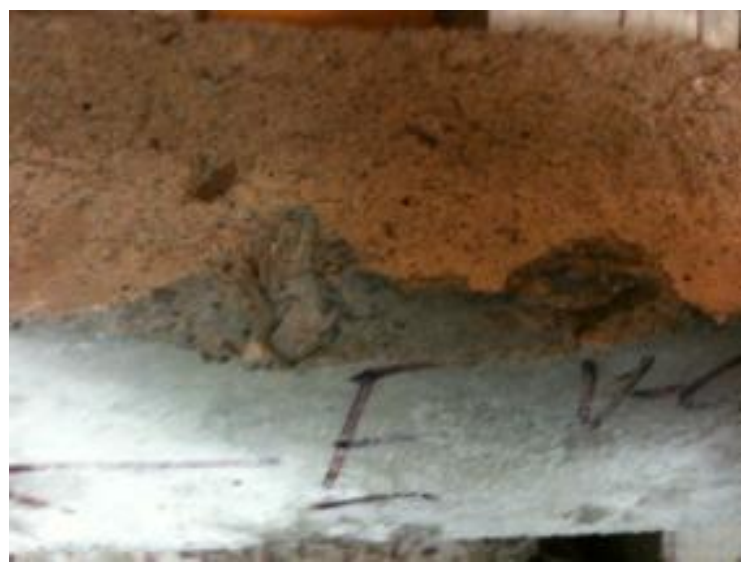

d) Close-up of weak edge deteriaration

Figure 4.6-3 Freezing/thawing specimens - VA control mix at $0.7 \mathrm{w} / \mathrm{cm}$ ratio

\subsubsection{0\% Recycled Concrete Aggregate Mix (R-CTR-FT)}

In order to evaluate the freezing and thawing performance of RCA, a mix was cast to conform to the same air standards as the control mix, but with the reduced recommended w/cm ratio of 0.62 . As seen in Figure 4.6-4, the overall durability factor of this mix (approximately 87\%) is very similar to the control mix. No major changes in fluctuation of the specimens' dynamic modulus were observed throughout the testing period. 
Further evidence of adequate performance is displayed by the physical appearance of the specimens, as seen in Figure 4.6-5. Once again, only some pop-outs were observed on these specimens due to the aggregate failure.

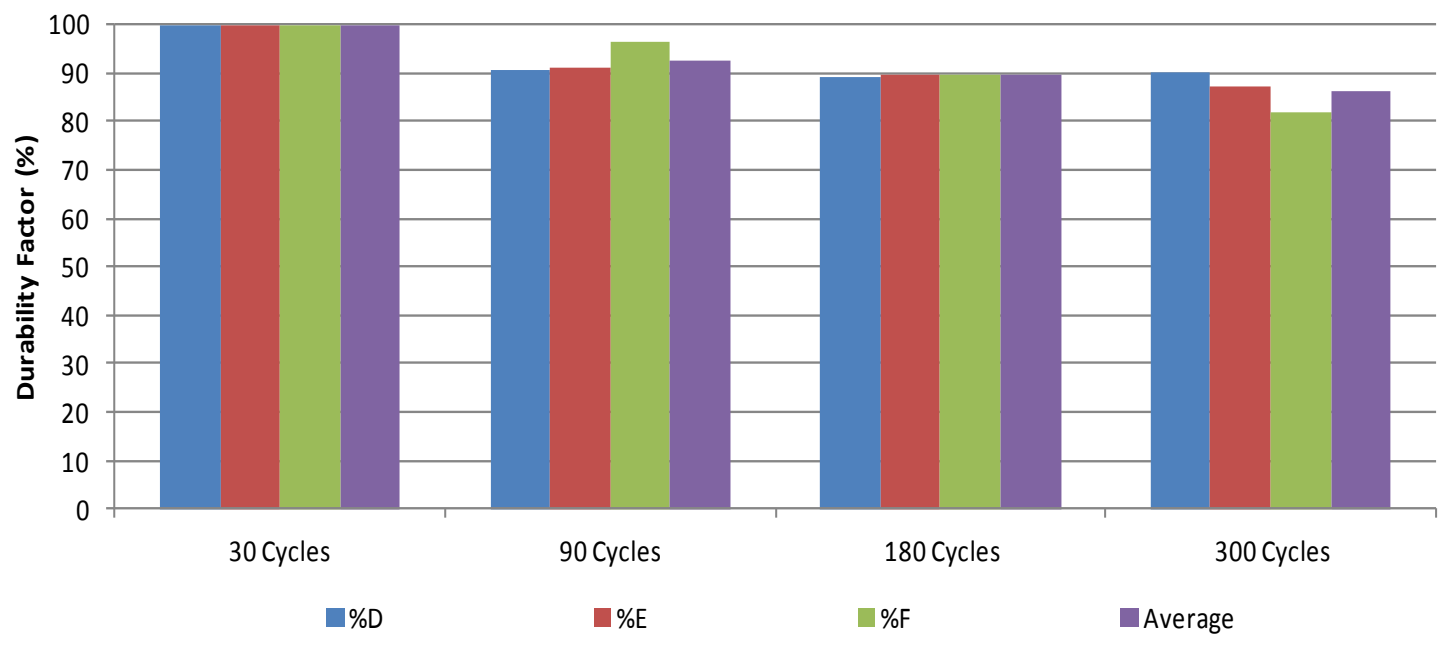

Figure 4.6-4 Durability factor of $100 \%$ coarse RCA mixes cast at $0.62 \mathrm{w} / \mathrm{cm}$ ratio

Typically, no major issues with freeze/thaw durability are to be expected for RCA concrete due to the air entrained nature of the RCA aggregate's residual mortar providing sufficient expansion room for frozen water. Only in a super-saturated state may this become an issue to cause failure of the aggregate to propagate the cracks into the surrounding mortar and thus leading to pop-outs. That is to say, as most concrete in Canada requires air entrainment, to withstand the winter climates, the RCA is likely comprised mainly of air-entrained mortar and is thus able to withstand the exposure.

As the pop-outs may be an issue with any hydrophilic aggregate, no issues were observed in these specimens, and thus allowing for the assumption that a full replacement of coarse RCA in the production of the mix does not negatively impact the overall integrity.

Figure 4.6-5 displays a pop-out occurring in the RCA specimen, which appeared to be a piece of hardened dirt that had contaminated the RCA bin. The piece had absorbed moisture, and due to lack of air, swelled up in the freezing stage to finally cause the popout. 


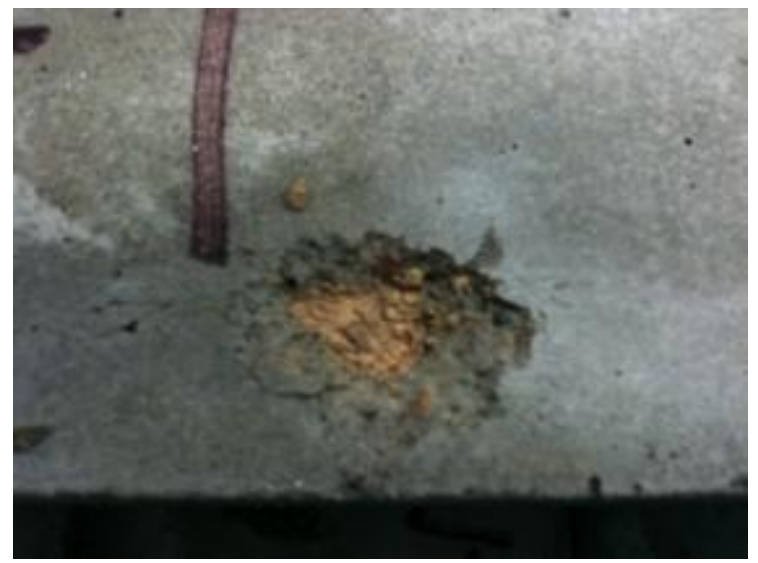

a) Close-up of pop-out (Specimen F)

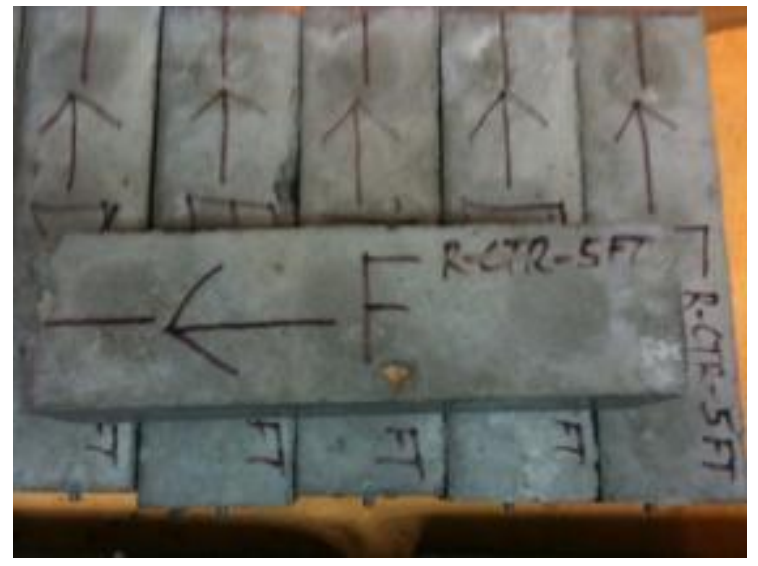

c) Specimen $\mathrm{F}$

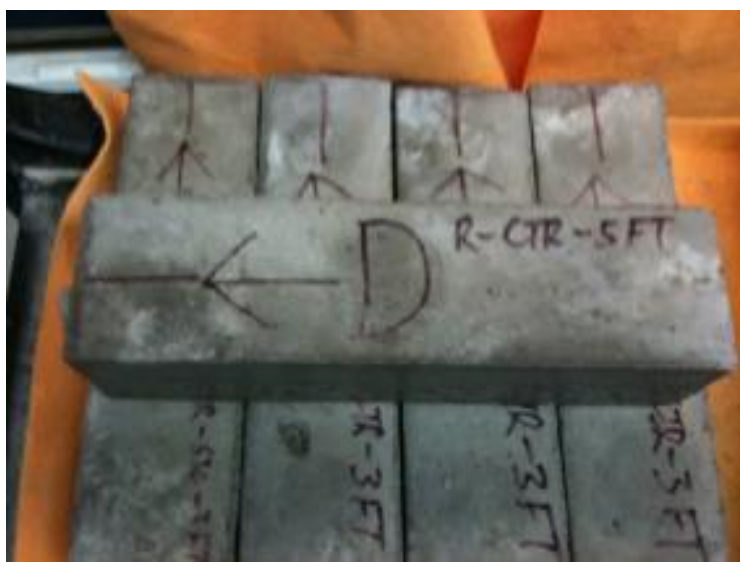

b) Specimen $\mathrm{D}$

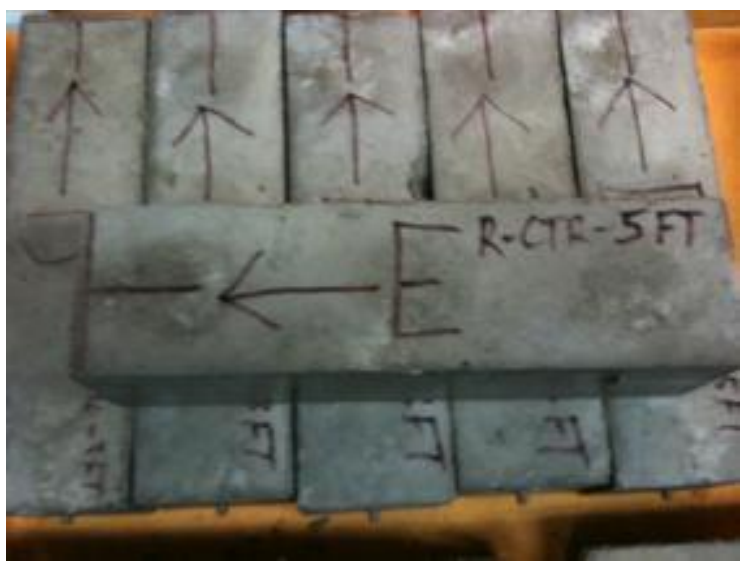

d) Specimen $E$

Figure 4.6-5 Freezing/thawing specimens $-100 \%$ Coarse RCA at $0.62 \mathrm{w} / \mathrm{cm}$ ratio

\subsubsection{0\% Recycled Concrete Aggregate Mix with 30\% Slag Replacement}

To compare a typical industry mix using a 30\% GGBS replacement, specimens were cast and evaluated with the use of $100 \%$ coarse RCA. These specimens were also cast at the recommended $0.62 \mathrm{w} / \mathrm{cm}$ ratio for a direct comparison. As displayed in Figure 4.6-6, little change was observed in the overall durability factor as the specimen averages a durability factor around $85 \%$ after 300 cycles. 


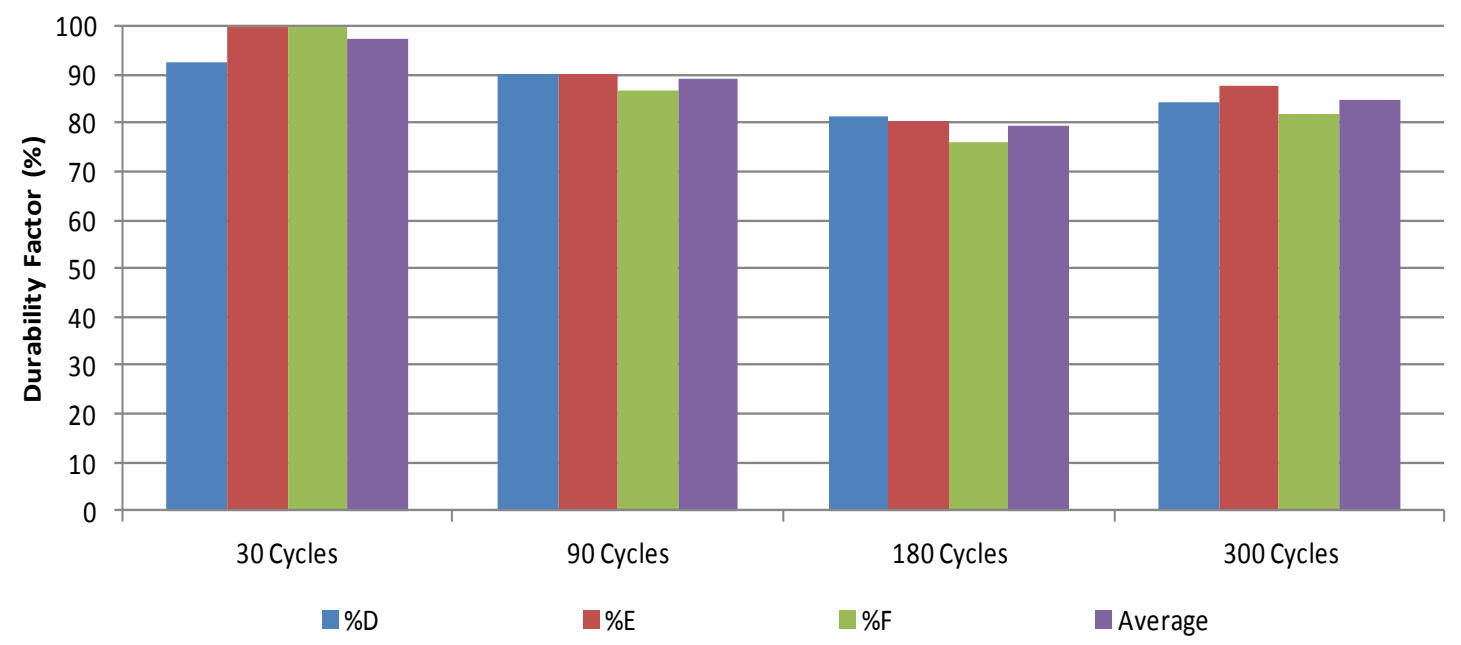

Figure 4.6-6 Durability factor of $100 \%$ RCA mixes \& $30 \%$ GGBS at $0.62 \mathrm{w} / \mathrm{cm}$ ratio

Though two of the three tested specimens displayed little signs of visual defects, some major deterioration was observed on one of the specimens. As displayed in Figure 4.6-7, some initial cracking occurred on the corner of one specimen after 210 cycles and continued to propagate further. Eventually, this caused a full deterioration on the corner surrounding the affected area of the specimen. A deeper look into the sample revealed the presence of a large aggregate at the epicentre of the crack formation.

Due to the full saturation of the aggregate, both the original virgin aggregate (located inside the RCA particle), as well as its residual mortar underwent freezing, and thus expansion of the water, causing the eventual cracking pattern formed. Once the cycles continued, the already exposed mortar continued to deteriorate in larger flakes around the area. By the time 300 cycles had been completed, the original aggregate had been found to be fully deteriorated and spreading the effects to the surrounding area.

Based on these observations, it may be argued that the GGBS replacement was not a contributing factor towards the deterioration, but that the deterioration may be rather attributed to the aggregate selection. As two specimens displayed no significant deterioration, $30 \%$ GGBS remains a viable option in the production of this concrete. 


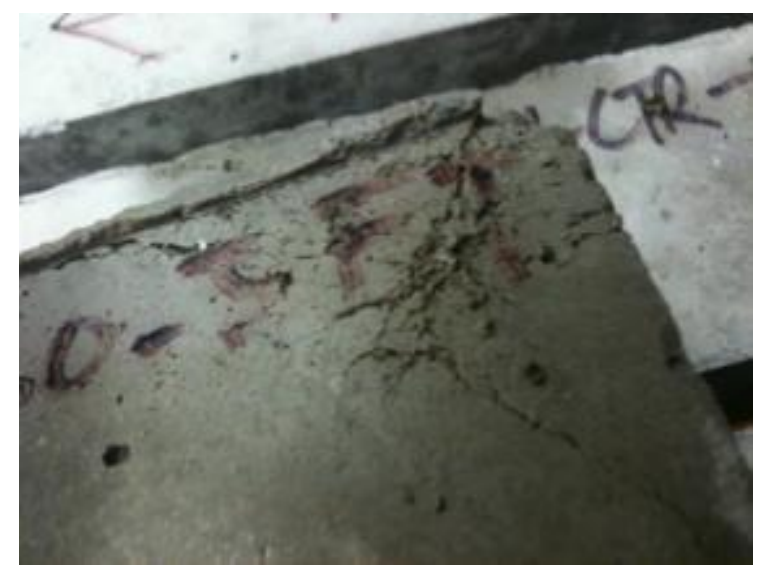

a) Initial cracking

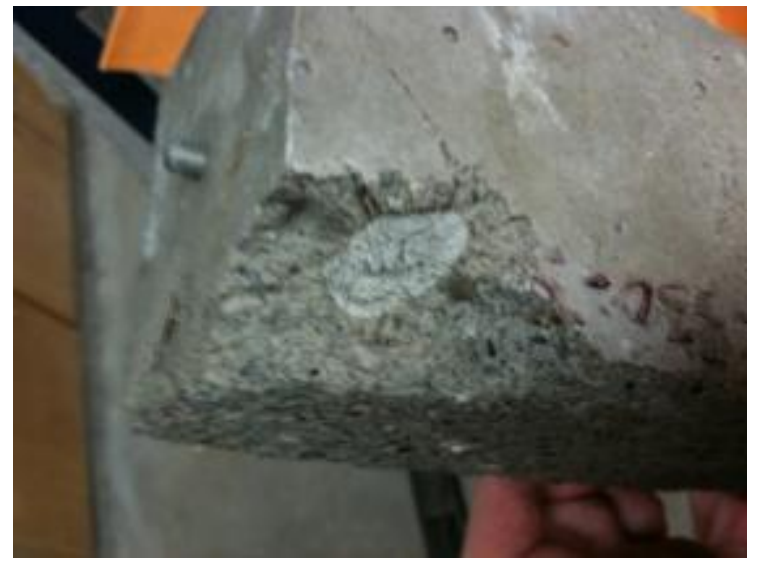

c) Deleterious particle

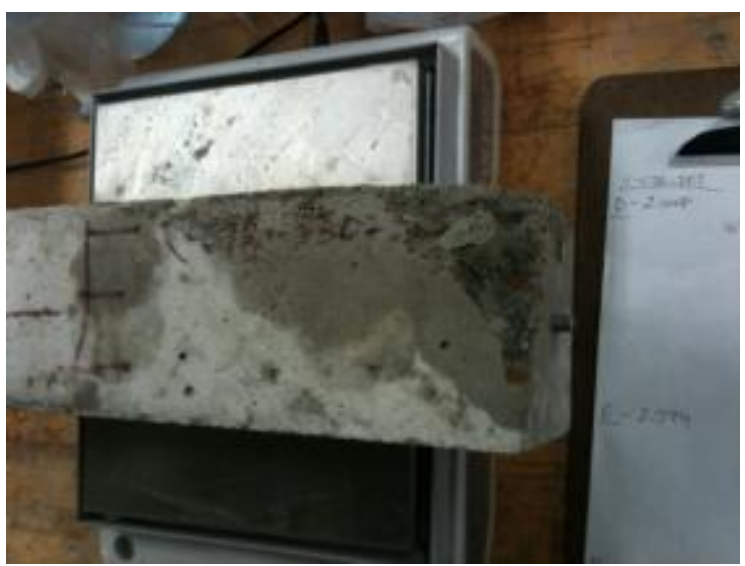

b) Deterioration of corner

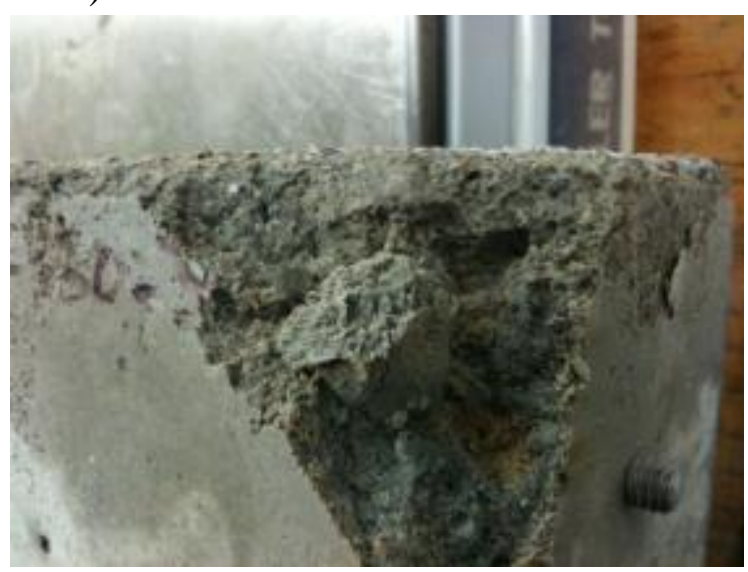

d) Close-up of deleterious particle

Figure 4.6-7 - Freezing/thawing specimens of 100\% RCA \& 30\% GGBS at $0.62 \mathrm{w} / \mathrm{cm}$

This finding further emphasizes the importance of aggregate selection and control of aggregate consistency. Freeze-thaw testing of aggregates remains a critical factor to be considered when the proposed concrete is to be exposed to these conditions. Specifically in the case of RCA, where variability in aggregate properties may tend to be higher, a screening process is recommended to separate types of RCA. As the source aggregate is comprised of a combination of both Return-to-Plant and clean RCA, some unwanted aggregate particles might intrude and cause these deteriorations. Separation of the waste concrete in piles at the concrete and aggregate yards may help reduce these occurrences. 


\subsubsection{Relative Behaviour of Freeze/Thaw Specimens}

Some deterioration was observed on both control and RCA samples. The total decline in dynamic modulus of elasticity (E) was approximately 12\%, 13\%, and 15\% for V-CTRFT, R-FT, and R-S30-FT, respectively.

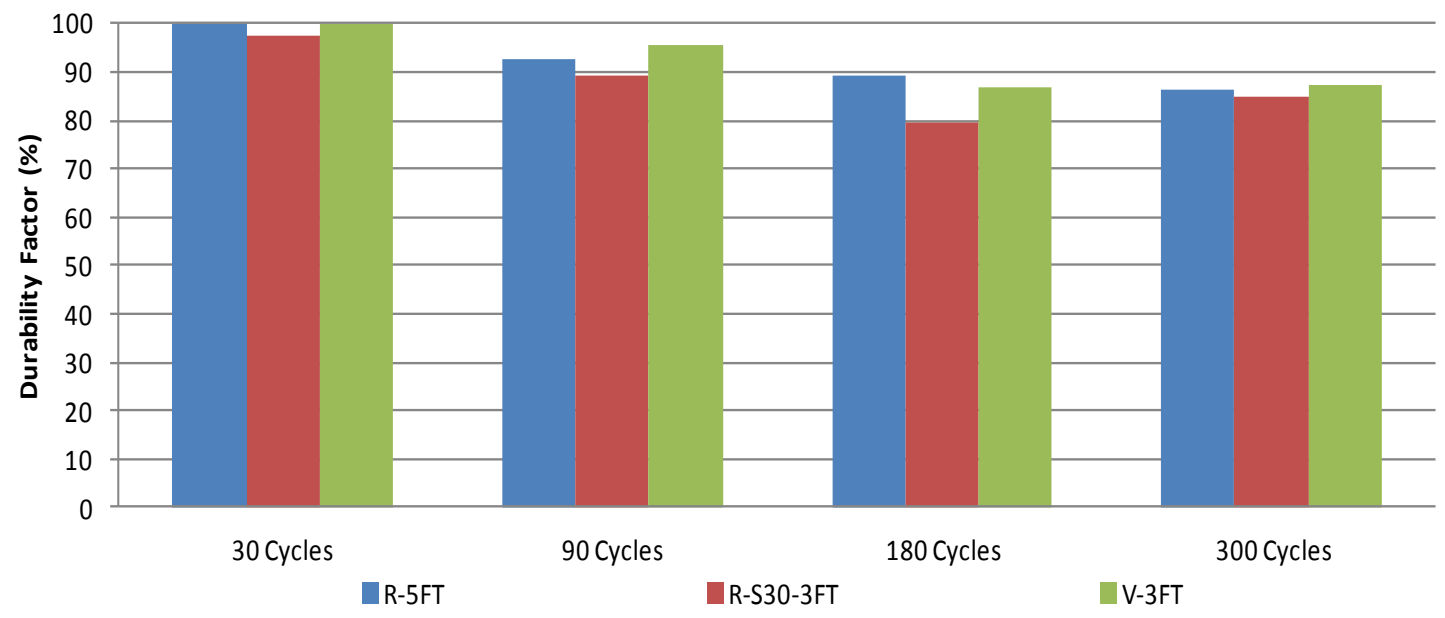

Figure 4.6-8 Average durability factors for all freezing/thawing specimens

Figure 4.6-8 displays that all mixes exhibited similar behaviour throughout the freezing/thawing process and thus indicating adequate performance in all cases.
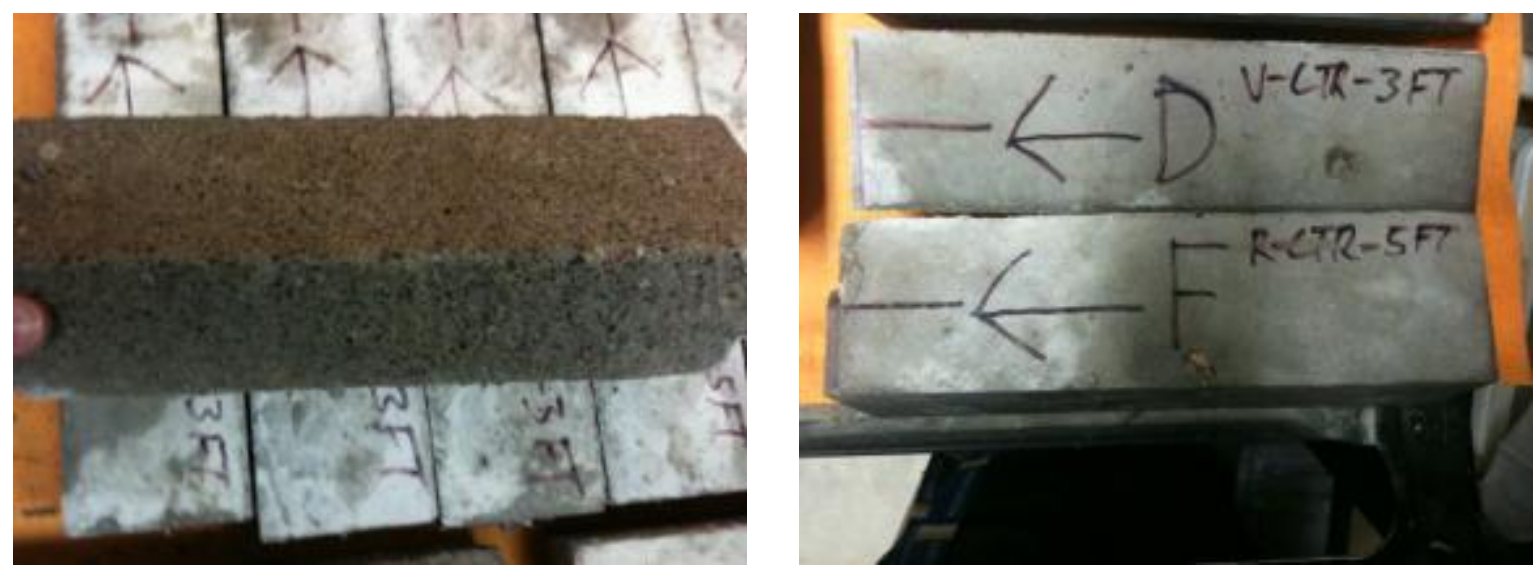

Figure 4.6-9 Freezing/thawing specimens - general observations 
As shown in Figure 4.6-9, a common observation amongst all specimens was the appearance of scaling around the exterior surface of the specimens. This is most likely due to the fact that this concrete is relatively weak, due to the high $\mathrm{w} / \mathrm{cm}$ ratio used in the production process, and thus forming a less dense paste matrix, which would allow for easier deterioration to occur. The occurrence of pop-outs was also common amongst the mixes where an aggregate particle was present near the outer surface of the specimen and expanded in the super-saturated state.

\subsubsection{Testing Method}

It must be noted that inaccuracies in the testing method may play an important role in the determination of the dynamic modulus of the concrete specimens when evaluating such a concrete. As the pulse-velocity method relies on two contact points during the time of testing, and a fixed travel path, it may be assumed that only an accurate representative reading of the path in question may be taken. This however does not represent the state of the entire specimen accurately.

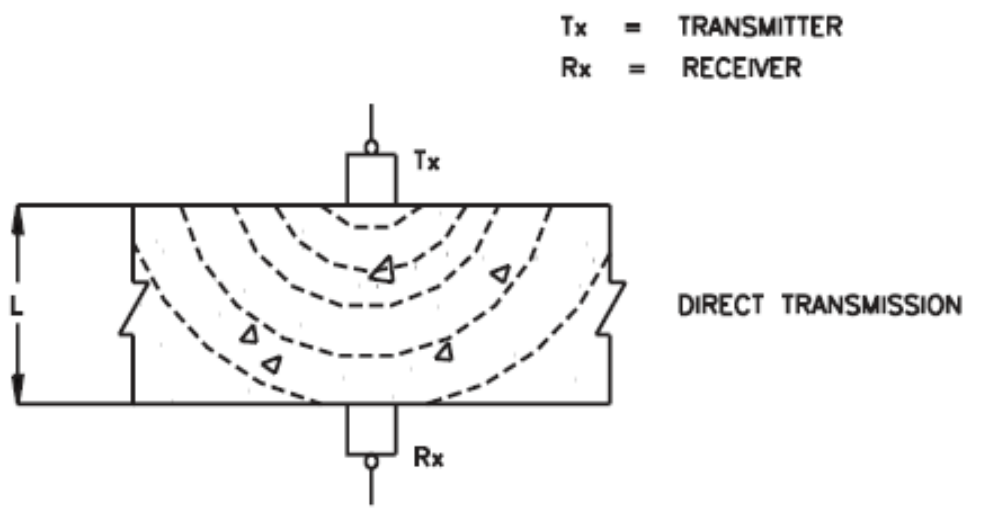

Figure 4.6-10 Pulse-velocity testing method - direct (The Constructor, 2012)

Figure 4.6-10 displays the testing method used for determination of the dynamic modulus. Three reading were taken along the length using the shortest distance on each specimen and then averaged. As some deterioration, such as pop-outs, may occur in a localized area, inaccurate readings may results and thus skewing the final results. 
Similar work performed by (Sriravindrajah, Loo, \& Tam, 1988) suggested that the use of ultrasonic pulse-velocity would significantly underestimate the compressive strength of the concrete created with RCA. It is not known whether this is relevant to dynamic modulus, but it is worth mentioning.

In cases such as the high $w / \mathrm{cm}$ ratio concrete tested here, it is advised to perhaps utilize the impact-echo method for determination of the dynamic modulus as it can provide a more accurate representation of the entire sample.

\subsection{Rapid-Chloride Permeability Testing (RCPT)}

Resistance to chloride ion penetration was tested in accordance with ASTM C1202. All specimens were cured past the minimum of 90 days to ensure full reaction of all cementing materials. Various factors were investigated to determine chloride ion penetrability of Class R concrete including RCA replacement level, use of GGBS, and introduction of SRA.

Though Class R concrete does not specify a limit for chloride penetrability, the test provides a good relative indication of performance when a high volume of recycled coarse aggregate is used in the production of new concrete. The resultant chloride ion penetrability readings are displayed in Table 4-2.

The benchmark virgin aggregate mix "V-FT", cast according to specifications at a w/cm ratio of 0.7 exhibited 'Moderate' chloride ion penetrability, most likely due to the high w/cm ratio of the mix, which leads to a lower density of concrete and thus more favourable conditions for chloride intrusion. 
Table 4-2 Chloride ion penetrability

\begin{tabular}{ccc}
\hline Specimen & $\begin{array}{c}\text { Charge Passed } \\
(\text { Coloumbs })\end{array}$ & $\begin{array}{c}\text { Chloride Ion } \\
\text { Penetrability }\end{array}$ \\
\hline R70-V30 & 4344 & High \\
\hline R-4 & 6267 & High \\
\hline R-S30-3FT & 2650 & Moderate \\
\hline V-S30-SR-2Min & 1939 & Low \\
\hline V-FT & 2098 & Low \\
\hline V-S30 & 2568 & Moderate \\
\hline
\end{tabular}

When a $30 \%$ addition of GGBS is introduced into the benchmark mix: "V-S30", a denser matrix of hydration products is formed, and thus lowers the chloride ion penetrability significantly by over $50 \%$, as seen in Figure 4.7-1. A similar trend was observed for $30 \%$ Slag mixes containing $100 \%$ RCA, as R-S30-3FT exhibited nearly a $60 \%$ decrease in penetrability, relative to mix R-4. The resultant value is comparable to that of the control virgin aggregate mix V-FT and may thus be considered as acceptable.

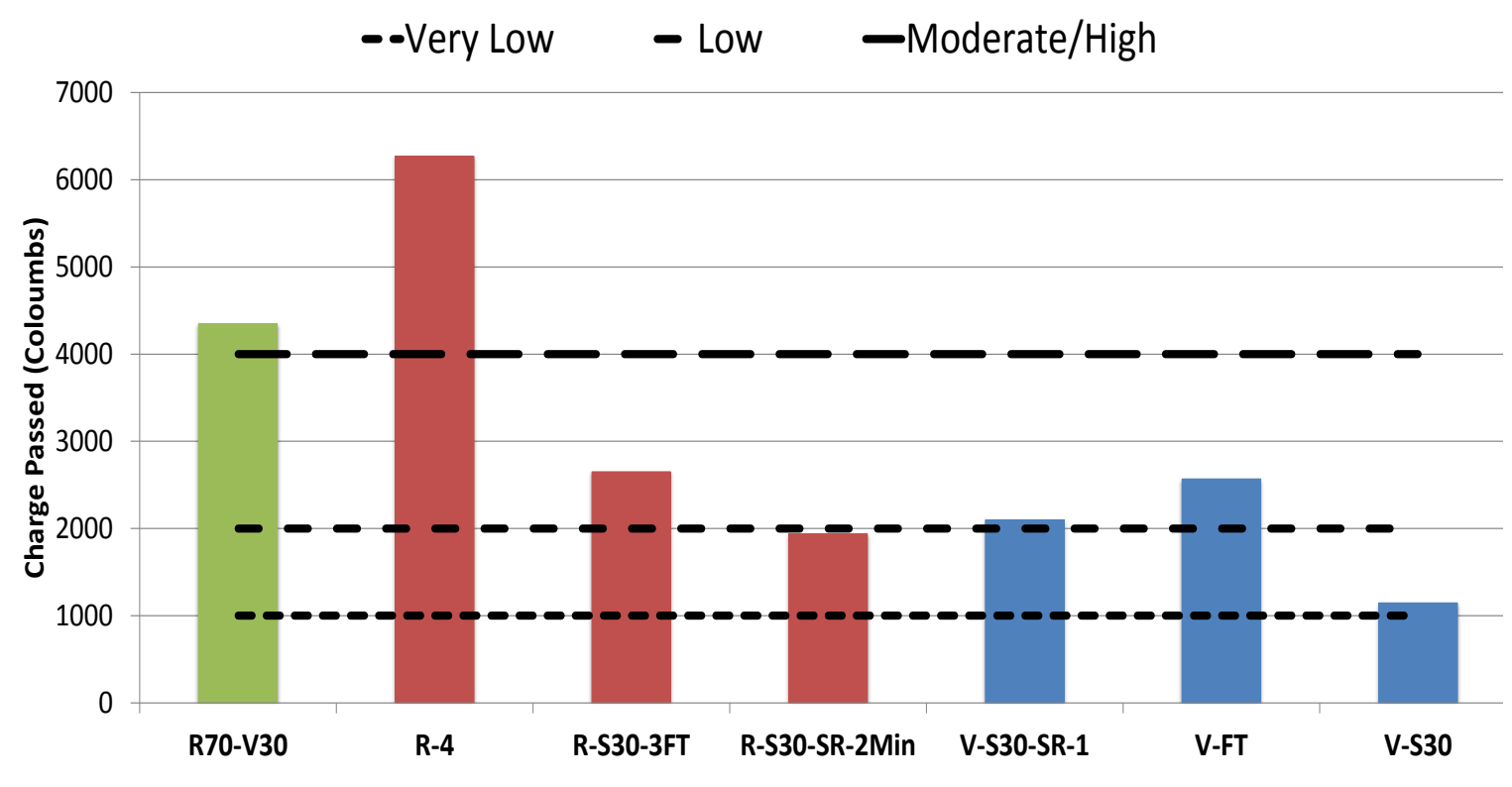

Figure 4.7-1 Charge passed on RCPT specimens 
Due to the highly porous nature of the residual mortar in RCA, the overall hardened density of the concrete mix is lowered, and thus experiences much lower resistivity to chloride ion penetration. This is evident by the high values observed by mix "R-4" containing $100 \%$ RCA as coarse aggregate. Though mix "R70-V30" exhibited a significant reduction in ion penetrability (30\%) due to the lowered RCA content to $70 \%$, it still achieved an overall high rating. It can thus be shown that due to the porous nature of the RCA, the chloride ion penetrability thus creates a direct linear correlation to the RCA content in the mix.

Shrinkage reducing admixture has displayed contradicting results in RCA and VA concrete, in terms of chloride penetrability. In the case of VA, the presence of SRA in the mix had a tendency of significantly increasing the ion penetrability of the mix to nearly double of the control mix V-S30. However, in the case of RCA concrete, the chloride ion penetrability of mix R-S30-SR, relative to the control mix R-S30-3FT, experienced an improvement, as a reduction of over $25 \%$ in chloride penetrability was observed. This finding repeats the improvement of RCA concrete mixtures once again with the addition of SRA and thus remains a topic requiring further study.

\subsection{Hydration Rate Testing of SRA Paste Samples using Loss on Ignition}

As SRA proved to be a vital constituent in complete mitigation of drying shrinkage when up to $100 \%$ coarse RCA is used, it was important to better understand the mechanism and behaviour of the admixture toward producing a more desirable concrete paste. In order to investigate the hydration rate of cement paste made using SRA, paste samples were cast with varying dosages of SRA, ranging from the minimum recommended manufacturer's dosage of $2.5 \mathrm{~L} / \mathrm{m}^{3}$ to $7.5 \mathrm{~L} / \mathrm{m}^{3}$. By elimination of the evaporable water content, through Loss on Ignition (LOI) testing, an accurate measure of the chemically bound water could be taken as an indicator of hydration rate within the cement paste. 
Figure 4.8-1 displays the various specimens cast for investigation of hydration rate. A control sample (CTR) comprised of Portland Cement (PC) and water at a w/cm ratio of 0.62 was taken as a standard and mixes with equivalent $\mathrm{w} / \mathrm{cm}$ ratio but varying levels of SRA and also a 30\% GGBS substitution.

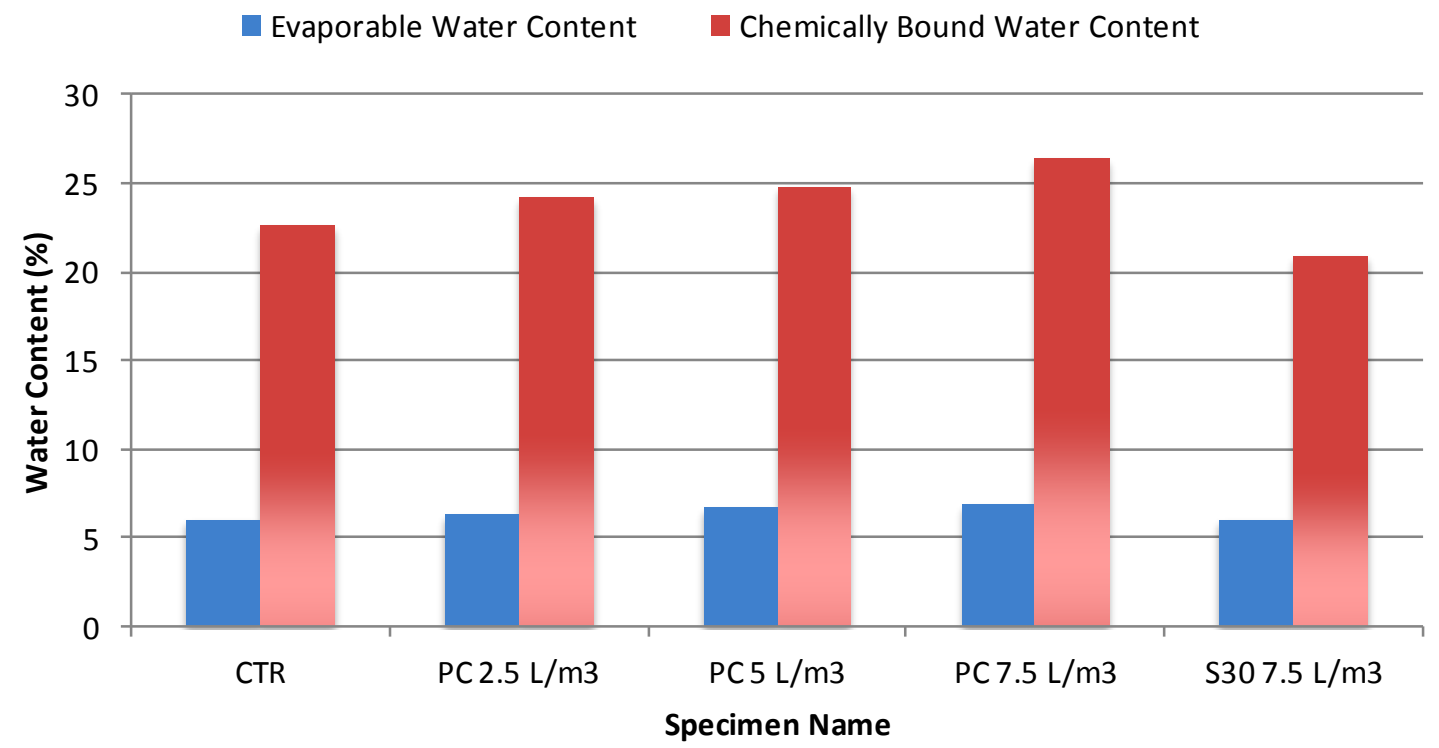

Figure 4.8-1 Loss on ignition of paste samples

A marginally increasing trend in chemically bound water is observed with an increase in the dosage of SRA in the cement paste. Assuming that the LOI is an indicator of the hydration rate of the paste, this may be linked back to the enhanced performance observed in both drying shrinkage and RCPT results. However, these results remain inconclusive, for the time being, as further in-depth research would be required to investigate whether the hydration products formed are in fact different enough to lead to these improved performance results. 


\section{Chapter 5}

\section{Summary, Conclusions and Recommendations for Future Work}

Many aspects of producing concrete containing RCA have been investigated in order to determine the feasibility of implementing high replacement levels of coarse RCA into the production of new concrete. Through evaluation of the mixes cast with a high $\mathrm{w} / \mathrm{cm}$ ratio and relatively low cementing materials content, a worst-case scenario was evaluated for relatively low performance concrete, and this feasibility was determined.

\subsection{Batching and Fresh Properties of RCA Concrete}

Due to its variant nature and composition, RCA required careful consideration in its preparation and use in design to ensure the desired fresh properties are achieved. Testing was conducted to determine: (a) the physical properties of the aggregate, (b) an optimal batching sequence and procedure, and (c) monitoring the slump and air stability of these mixes.

\subsubsection{Conclusions for Batching and Fresh Properties of RCA}

1. RCA has a relatively rapid absorption rate, relative to VA. Due to its tendency to absorb approximately $60 \%$ of its moisture limit within the first two minutes of batching, a pre-soaking procedure is required to avoid unworkable mixtures and low slump results at the batching point.

2. The suggested modifications to the TSMA originally proposed by Tam et al. (2005) allowed for proper mixing and obtained desired and consistent air content and slump results when the AEA was first dry mixed with the aggregates to avoid excessive air entrainment. 


\subsection{Hardened Properties of RCA Concrete}

All concrete mixes were required to meet the minimum compressive strength requirements of their exposure Class $\mathrm{R}$ and was thus evaluated for the various mixtures. Additional drying shrinkage testing was performed due to the nature of the coarse RCA containing a significant amount of residual mortar to promote drying shrinkage when used at such high replacement levels. The effects of incorporating different levels of coarse RCA, as well as addition of GGBS and chemical admixtures were evaluated.

\subsubsection{Conclusions for Hardened Properties of RCA Concrete}

1. Through slight modifications in mix design, such as the reduction in maximum w/cm ratio from 0.7 to 0.62 , the minimum requirements (compressive strength and air) of Class R concrete were easily satisfied, even when a coarse RCA replacement level of $100 \%$ was used.

2. As is standard practice in Ontario, incorporating a 30\% substitution of GGBS was able to improve environmental and economical feasibility of all mixes, while still maintaining the required compressive strength, and without negatively impacting the overall drying shrinkage of the mixtures.

3. It was observed that early drying shrinkage (up to 28 days) was lower than the control mixes containing only PC, it is suggested to ensure drying shrinkage of concrete containing RCA and SCMs to be tested at least to 90 days.

4. Relative to conventional (Class R) concrete, using VA, the trial mixtures displayed an increase of up to $50 \%$ in overall drying shrinkage when a substitution level of $100 \%$ coarse RCA was implemented.

5. It may be assumed that a non-linear relationship exists between the replacement level of RCA in RCA-concrete and its drying shrinkage. This was observed when reducing the replacement level from 100\% to $70 \%$ caused the increase in drying shrinkage (relative to VA) to decrease from $50 \%$ to approximately $20 \%$. 
6. An increase in compressive strength, and reduction in drying shrinkage, in both VA and RCA mixtures was observed for the use of WRA and SRA, respectively.

7. Water Reducer Admixture (WRA), when used to reduce cementing material content in the mix, did not have any impact on overall drying shrinkage, which is believed to be related to the fact that both the control mixture and reduced $\mathrm{CM}$ mixture had the same $\mathrm{w} / \mathrm{cm}$.

8. SRA proved to be a substantial contributor to mitigating the effects of drying shrinkage of high volume RCA concrete, when used at the correct dosage. In fact, when sufficient SRA was added, the effects of drying shrinkage were completely eliminated, even at $100 \%$ replacement.

\subsection{Durability of RCA Concrete}

In order to evaluate the durability of such a relatively weak concrete, when high replacement levels of coarse RCA are incorporated, testing was performed for AlkaliSilica Reactivity when used in combination with marginally reactive sand, freezing and thawing performance, and chloride ion ingression. The effects of various parameters such as RCA replacement level, cementing material composition, and admixture addition, were investigated.

\subsubsection{Conclusions for Durability of RCA Concrete}

1. In terms of alkali-silica reactivity, a replacement level of $100 \%$ coarse RCA did not display any tendency to promote further reaction when used with marginally reactive sand. This suggested that the reaction was perhaps limited to the amount of level of reactivity in the sand, and not to the amount of alkalis in the system. This is assuming that RCA releases alkalis to the mix (Shehata \& Thomas, 2010).

2. Alkali leaching tests have confirmed that the use of SCMs is able to effectively mitigate the reactivity of MRS when used in combination with RCA. The amount of available alkalis in the solution displayed a direct correlation to the observed expansion. 
3. As long as sufficient air entrainment is provided in the newly produced concrete, no major variations in terms of freezing and thawing resistance were observed in RCA concrete relative to its VA counterpart, even at $100 \%$ replacement. This is believed to be contributable to the fact that the RCA is mainly composed of air entrained residual mortar.

4. Some severe deterioration was observed during the freezing/thawing cycles when a single deleterious particle is present within the aggregate. Thus it is highly recommended to screen and separate the sources of the recycled concrete at the aggregate site to ensure such unwanted particles are removed prior to production.

5. The pulse-velocity method of measurement for the dynamic modulus of the specimens during freezing and thawing was found to create some inconsistent data in such relatively weak concrete specimens. When the direct transmission approach was taken at various points along the specimen, due to the variability of performance where minor deterioration is present such as pop-outs, the results may be not be representative of the whole specimen. It is thus suggested to perform testing on concrete, especially concrete made with RCA, using the impact-echo testing method to ensure better consistency in readings.

6. A linear trend displaying increasing chloride ion ingression with the increase of RCA content was observed. This phenomenon may be a direct result of the high porosity caused by the incorporation of the RCA due to its highly porous nature of the residual mortar. Incorporating GGBS at a replacement level of $30 \%$ into the mix, and thus forming a denser paste matrix to reduce the ingression of chloride ions was able to effectively mitigate this concern. 
Though many challenges are faced when using RCA in new concrete, it remains an alternative to conventional production that is well worth investigating. Overall, the study can conclude that viable options are available, in terms of mitigating the effects of RCA's drawbacks in concrete performance. RCA was able to meet the requirements of moderate strength concrete at replacement levels up to $100 \%$ and remains to be tested in higher performance applications. The study has provided a backbone for future developments incorporating high replacement levels of RCA by providing evidence of adequate performance, fresh and long-term behaviour, as well as several methods for addressing the most common issues.

\subsection{Recommendations for Future Research}

- As it was established that production of relatively low performance requirements concrete is possible (even at replacement levels of 100\%), further applications remain to be tested. Hence, it is recommended to test more applications.

- Further testing remains to be performed on higher requirement applications where RCPT or other requirements such as salt-scaling may be essential. Incorporation of mixes such as $\mathrm{C} 2$ sidewalks with high replacement levels may be a feasible next approach.

- As the European standards EN 206 have developed regulations in the use of higher coarse RCA replacement levels around 50\% in Class N (equivalent) exposure, such practice should be evaluated for the Canadian industry.

- Higher performance mixes containing higher cementing materials contents and super plasticizers remain yet to be evaluated at high replacement levels to see whether the suggested mitigation measures found in this study still apply at these higher performance levels.

- Due to the nature of the testing equipment used in the freezing/thawing cycles, the effectiveness of the pulse-velocity device should be investigated in comparison with the impact-echo method when a relatively weaker concrete is to be tested. 
- The use of shrinkage reducing admixture has proven to be very effective in mitigating drying shrinkage, as well as reducing the chloride ion intrusion of mixtures containing RCA. As such, it is highly recommended to perform a more in-depth study on the effects of SRA on RCA and concrete made with RCA to understand this relationship.

- As the alkali-leaching test had revealed a direct trend in relation to the expansion observed, further testing would be recommended by performing a leaching test on the aggregate itself and developing a correlation between the behaviour of alkalis from RCA obtained from various sources.

- By having proven that the major drawbacks of RCA can be mitigated through simple means such as proportioning of the mix, or incorporating common SCMs and admixtures, the opportunity remains for ready mix producers to investigate the use RCA in their value-added products such as self-consolidating concrete. Through proper batching protocol, and addition of admixtures, these mixes should be expected to perform well with RCA. 


\section{Appendix A - Alkali Leaching Test Calculations and Results}

Table A-1 - Outline of calculations for corrections of the alkali leaching test

\begin{tabular}{|c|c|c|}
\hline \# & Content & Description \\
\hline 1 & Label & Name \\
\hline 2 & Solution & Type of Solution \\
\hline 3 & Specimen ID & Name of Specimen \\
\hline 4 & Sample Data & \\
\hline 5 & Volume of Solution $( \pm 0.04 \mathrm{~mL})$ & $\begin{array}{l}\text { Volume of solution in } \\
\text { bottle }\end{array}$ \\
\hline 6 & Initial Mass of Powder (g) & $\begin{array}{l}\text { Mass of paste added to } \\
\text { bottle }\end{array}$ \\
\hline 7 & Solution Data & \\
\hline 8 & Initial $\mathrm{Na}^{+}$Concentration in Solution $(\mathrm{mol} / \mathrm{L})$ & $\begin{array}{l}\text { Initial Concentration of } \\
\mathrm{Na}^{+} \text {in Solution }\end{array}$ \\
\hline 9 & Final $\mathrm{Na}^{+}$Concentration in Solution $(\mathrm{mol} / \mathrm{L})$ & $\begin{array}{l}\text { Final Concentration of } \\
\mathrm{Na}^{+} \text {in Solution }\end{array}$ \\
\hline 10 & Initial $\mathrm{K}^{+}$Concentration in Solution (mol/L) & $\begin{array}{l}\text { Initial Concentration of } \mathrm{K}^{+} \\
\text {in Solution }\end{array}$ \\
\hline 11 & Final $\mathrm{K}^{+}$Concentration in Solution (mol/L) & $\begin{array}{l}\text { Final Concentration of } \mathrm{K}^{+} \\
\text {in Solution }\end{array}$ \\
\hline 12 & Evaporable Water Content & \\
\hline 13 & Mass of Dish (g) & Mass of measuring dish \\
\hline 14 & Mass of Dish + Powder $(g)$ & $\begin{array}{l}\text { Mass of measuring dish + } \\
\text { paste sample }\end{array}$ \\
\hline 15 & Mass of Dish + Powder (g) Oven Dry @ $105^{\circ} \mathrm{C}$ & $\begin{array}{l}\text { Mass of dish and powder } \\
\text { after drying }\end{array}$ \\
\hline 16 & Mass of Power (g) Oven Dry @ $105^{\circ} \mathrm{C}$ & \#15- \#13 \\
\hline
\end{tabular}




\begin{tabular}{|c|c|c|}
\hline 17 & Evaporable Water Content of Powder (\%) & $\begin{array}{l}100 \\
* \frac{((\# 14-\# 13)-\# 16)}{\# 16}\end{array}$ \\
\hline 18 & Dry Mass of Powder Sample (g) Oven Dry @ $105^{\circ} \mathrm{C}$ & $\frac{\# 6}{\left(1+\frac{\# 17}{100}\right)}$ \\
\hline 19 & Non-Evaporable Water Content & \\
\hline 20 & Mass of Crucible (g) & Mass of Crucible \\
\hline 21 & Mass of Crucible + Powder (g) Oven Dry @ $105^{\circ} \mathrm{C}$ & $\begin{array}{l}\text { Oven Dry Mass of } \\
\text { Crucible + Powder }\end{array}$ \\
\hline 22 & Mass of Crucible + Powder $(\mathrm{g}) @ 1050^{\circ} \mathrm{C}$ & $\begin{array}{l}\text { Ignited Mass of Crucible } \\
+ \text { Powder }\end{array}$ \\
\hline 23 & Mass of Powder $(\mathrm{g}) @ 1050^{\circ} \mathrm{C}$ & \#22- \#20 \\
\hline 24 & Non-Evaporable Water Content of Powder (\%) & $\begin{array}{l}100 \\
* \frac{((\# 21-\# 20)-\# 23)}{\# 23}\end{array}$ \\
\hline 25 & Ignited Mass of Powder Sample (g) @ $1050^{\circ} \mathrm{C}$ & $\frac{\# 18}{\left(1+\left(\frac{\# 24}{100}\right)\right)}$ \\
\hline 26 & Cementitious Material Properties & \\
\hline 27 & Cementitious Material Label & Name of CM \\
\hline 28 & Content $(\%)$ & $\%$ of respective $\mathrm{CM}$ \\
\hline 29 & Loss On Ignition (LOI) of Cementitious Material (\%) & LOI of respective CM \\
\hline 30 & Fractional LOI of Cementitious Material in Powder & $\# 29 * \frac{\# 28}{100}$ \\
\hline 31 & Total LOI of All Cementitious Materials (\%/100) & Sum of \#30 \\
\hline 32 & Total Mass Loss due to LOI Cementitious Materials (g) & $\# 31 * \# 25$ \\
\hline 33 & Mass of Powder $(\mathrm{g})$ - Corrected for LOI & $\# 32+\# 25$ \\
\hline
\end{tabular}




\begin{tabular}{|c|c|c|}
\hline 34 & Composition & Name of CM \\
\hline 35 & $\mathrm{Na}_{2} \mathrm{O}$ Content of Cementitious Material (wt \%) & $\begin{array}{l}\text { Initial } \mathrm{Na}_{2} \mathrm{O} \text { content of } \\
\mathrm{CM}\end{array}$ \\
\hline 36 & $\mathrm{~K}_{2} \mathrm{O}$ Content of Cementitious Material (wt \%) & Initial $\mathrm{K}_{2} \mathrm{O}$ content of $\mathrm{CM}$ \\
\hline 37 & $\Sigma \mathrm{Na}_{2} \mathrm{O}$ Content of Cementitious Materials & Sum of $\left(\# 35^{*} \# 28\right)$ \\
\hline 38 & $\Sigma \mathrm{K}_{2} \mathrm{O}$ Content of Cementitious Materials & Sum of $\left(\# 36^{*} \# 28\right)$ \\
\hline 39 & Original $\mathrm{Na}_{2} \mathrm{O}_{\mathrm{e}}$ Content of Cementitious Materials & $\# 37+(0.658 * \# 38)$ \\
\hline 40 & Total $\mathrm{Na}_{2} \mathrm{O}_{\mathrm{e}}$ as $\% \mathrm{Na}_{2} \mathrm{O}_{\mathrm{e}}$ in $\mathrm{SCMs}$ & \#50/ \#39 \\
\hline 41 & Final Concentrations & \\
\hline 42 & Corrected Final $\mathrm{Na}^{+}$Concentration in Solution $(\mathrm{mol} / \mathrm{L})$ & $\# 9 *\left(\frac{\left.\# 5+\frac{\# 17 * \# 18}{100}\right)}{\# 5}\right)$ \\
\hline 43 & Corrected Final $\mathrm{K}^{+}$Concentration in Solution (mol/L) & $\# 11 *\left(\frac{\left.\# 6+\frac{\# 17 * \# 18}{100}\right)}{\# 6}\right)$ \\
\hline 44 & $\Delta\left[\mathrm{Na}^{+}\right]$in Solution $(\mathrm{mol} / \mathrm{L})$ & \#42- \#8 \\
\hline 45 & $\Delta\left[\mathrm{K}^{+}\right]$in Solution $(\mathrm{mol} / \mathrm{L})$ & \#43- \#10 \\
\hline 46 & $\Sigma\left[\Delta \mathrm{Na}^{+}\right] \&\left[\Delta \mathrm{K}^{+}\right](\mathrm{mol} / \mathrm{L})$ & Sum of \#44+\#45 \\
\hline 47 & $\Sigma\left[\Delta \mathrm{Na}^{+}\right] \&\left[\Delta \mathrm{K}^{+}\right](\mathrm{mol})$ & $\frac{\# 46 * \# 5}{1000}$ \\
\hline 48 & $\Delta$ Alkalis as $\mathrm{Na}_{2} \mathrm{O}_{\mathrm{e}}(\mathrm{mol})$ & $\# 47 / 2$ \\
\hline 49 & Mass of $\Delta$ Alkalis as $\mathrm{Na}_{2} \mathrm{O}_{\mathrm{e}}(\mathrm{g})$ & \#48*61.9788 \\
\hline 50 & $\begin{array}{l}\sum \text { Alkalis in Sol'n from Sample (wt } \%{ }_{\mathrm{Na} 2 \mathrm{O}} / \text { Mass of } \\
\text { Solids) }\end{array}$ & $100 *(\# 49 / \# 33)$ \\
\hline 51 & Average & Average of \#50 \\
\hline
\end{tabular}


Table A-2 Alkali leaching results of Portland Cement paste control specimens

\begin{tabular}{|c|c|c|c|c|c|c|c|}
\hline \# & Content & & & & & & \\
\hline 1 & Label & \multicolumn{6}{|c|}{ CTR } \\
\hline 2 & Solution & \multicolumn{3}{|c|}{ DW } & \multicolumn{3}{|c|}{ Solution } \\
\hline 3 & Specimen ID & A & $\mathrm{B}$ & C & A & $\mathrm{B}$ & C \\
\hline 4 & Sample Data & & & & & & \\
\hline 5 & Volume of Solution $( \pm 0.04 \mathrm{~mL})$ & 24.0319 & 24.0125 & 24.0708 & 24.0319 & 24.0125 & 24.0708 \\
\hline 6 & Initial Mass of Powder $(\mathrm{g})$ & 1.9982 & 2.0012 & 2.0002 & 2.4018 & 2.4024 & 2.4084 \\
\hline 7 & Solution Data & & & & & & \\
\hline 8 & Initial $\mathrm{Na}^{+}$Concentration in Solution $(\mathrm{mol} / \mathrm{L})$ & 0 & 0 & 0 & 0.025857 & 0.025857 & 0.025857 \\
\hline 9 & Final $\mathrm{Na}^{+}$Concentration in Solution $(\mathrm{mol} / \mathrm{L})$ & 0.000536 & 0.000203 & 0.00087 & 0.075251 & 0.08009 & 0.070325 \\
\hline 10 & Initial $\mathrm{K}^{+}$Concentration in Solution $(\mathrm{mo} / \mathrm{L})$ & 0 & 0 & 0 & 0.09265 & 0.09265 & 0.09265 \\
\hline 11 & Final $\mathrm{K}^{+}$Concentration in Solution (mol/L) & 0.018066 & 0.017563 & 0.0185 & 0.174722 & 0.182399 & 0.17288 \\
\hline 12 & Evaporable Water Content & & & & & & \\
\hline 13 & Mass of Dish $(\mathrm{g})$ & \multicolumn{3}{|c|}{0} & \multicolumn{3}{|c|}{26.4251} \\
\hline 14 & Mass of Dish + Powder (g) & \multicolumn{3}{|c|}{1.9853} & \multicolumn{3}{|c|}{27.4646} \\
\hline 15 & Mass of Dish + Powder (g) Oven Dry @ $105^{\circ} \mathrm{C}$ & \multicolumn{3}{|c|}{1.9403} & \multicolumn{3}{|c|}{27.4243} \\
\hline 16 & Mass of Power (g) Oven Dry @ $105^{\circ} \mathrm{C}$ & \multicolumn{3}{|c|}{$\begin{array}{c}1.9403 \\
319228985\end{array}$} & \multicolumn{3}{|c|}{0.9992} \\
\hline 17 & Evaporable Water Content of Powder (\%) & \multicolumn{3}{|c|}{2.319228985} & \multicolumn{3}{|c|}{4.033226581} \\
\hline 18 & Dry Mass of Powder Sample (g) Oven Dry @ $105^{\circ} \mathrm{C}$ & 1.952908 & 1.95584 & 1.954862 & 2.308685 & 2.309262 & 2.31503 \\
\hline 19 & Non-Evaporable Water Content & & & & & & \\
\hline 20 & Mass of Crucible $(\mathrm{g})$ & \multicolumn{3}{|c|}{17.3092} & \multicolumn{3}{|c|}{26.4251} \\
\hline 21 & Mass of Crucible + Powder (g) Oven Dry @ $105^{\circ} \mathrm{C}$ & \multicolumn{3}{|c|}{19.246} & \multicolumn{3}{|c|}{27.4243} \\
\hline 22 & Mass of Crucible + Powder $(\mathrm{g}) @ 1050^{\circ} \mathrm{C}$ & \multicolumn{3}{|c|}{18.9545} & \multicolumn{3}{|c|}{27.2769} \\
\hline 23 & Mass of Powder $(\mathrm{g}) @ 1050^{\circ} \mathrm{C}$ & & 1.6453 & & & 0.8518 & \\
\hline 24 & Non-Evaporable Water Content of Powder (\%) & & 17.71713365 & & & 17.30453158 & \\
\hline 25 & Ignited Mass of Powder Sample (g) @ $1050^{\circ} \mathrm{C}$ & 1.658983 & 1.661474 & 1.660644 & 1.968113 & 1.968604 & 1.973521 \\
\hline 26 & Cementitious Material Properties & & & & & & \\
\hline 27 & Cementitious Material Label & PC & & & PC & 0 & 0 \\
\hline 28 & Content $(\%)$ & 100 & & & 100 & 0 & 0 \\
\hline 29 & Loss On Ignition (LOI) of Cementitious Material (\%) & 0.016 & & & 0.016 & 0 & 0 \\
\hline 30 & Fractional LOI of Cementitious Material in Powder & 0.016 & 0 & 0 & 0.016 & 0 & 0 \\
\hline 31 & Total LOI of All Cementitious Materials $(\% / 100)$ & & 0.016 & & & 0.016 & \\
\hline 32 & Total Mass Loss due to LOI Cementitious Materials (g) & 0.026544 & 0.026584 & 0.02657 & 0.026544 & 0.026584 & 0.02657 \\
\hline 33 & Mass of Powder (g) - Corrected for LOI & 1.685527 & 1.688058 & 1.687214 & 1.685527 & 1.688058 & 1.687214 \\
\hline 34 & Composition & \begin{tabular}{l|l} 
PC \\
\end{tabular} & 0 & 0 & & & \\
\hline 35 & $\mathrm{Na}_{2} \mathrm{O}$ Content of Cementitious Material (wt \%) & 0.24 & & & 0.24 & 0 & 0 \\
\hline 36 & $\mathrm{~K}_{2} \mathrm{O}$ Content of Cementitious Material (wt \%) & 1.2 & & & 1.2 & 0 & 0 \\
\hline 37 & $\Sigma \mathrm{Na}_{2} \mathrm{O}$ Content of Cementitious Materials & 24 & 24 & 24 & 24 & 24 & 24 \\
\hline 38 & $\Sigma \mathrm{K}_{2} \mathrm{O}$ Content of Cementitious Materials & 120 & 120 & 120 & 120 & 120 & 120 \\
\hline 39 & Original $\mathrm{Na}_{2} \mathrm{O}_{e}$ Content of Cementitious Materials & 102.96 & 102.96 & 102.96 & 102.96 & 102.96 & 102.96 \\
\hline 40 & Total $\mathrm{Na}_{2} \mathrm{O}_{\mathrm{e}}$ as $\% \mathrm{Na}_{2} \mathrm{O}_{\mathrm{e}}$ in SCMs & 0.008159 & 0.007777 & 0.008498 & 0.008159 & 0.007777 & 0.008498 \\
\hline 41 & Final Concentrations & & & & & & \\
\hline 42 & Corrected Final $\mathrm{Na}^{+}$Concentration in Solution $(\mathrm{mol} / \mathrm{L})$ & 0.000537 & 0.000203 & 0.00087 & 0.075543 & 0.08009 & 0.070325 \\
\hline 43 & Corrected Final $\mathrm{K}^{+}$Concentration in Solution $(\mathrm{mol} / \mathrm{L})$ & 0.018475 & 0.017961 & 0.01892 & 0.181496 & 0.189471 & 0.179583 \\
\hline 44 & $\Delta\left[\mathrm{Na}^{+}\right]$in Solution $(\mathrm{mol} / \mathrm{L})$ & 0.000537 & 0.000203 & 0.00087 & 0.049686 & 0.054233 & 0.044468 \\
\hline 45 & $\Delta\left[\mathrm{K}^{+}\right]$in Solution $(\mathrm{mol} / \mathrm{L})$ & 0.018475 & 0.017961 & 0.01892 & 0.088846 & 0.096821 & 0.086933 \\
\hline 46 & $\Sigma\left[\Delta \mathrm{Na}^{+}\right] \&\left[\Delta \mathrm{K}^{+}\right](\mathrm{mol} / \mathrm{L})$ & 0.019013 & 0.018164 & 0.01979 & 0.138532 & 0.151054 & 0.131401 \\
\hline 47 & $\Sigma\left[\Delta \mathrm{Na}^{+}\right] \&\left[\Delta \mathrm{K}^{+}\right](\mathrm{mol})$ & 0.000457 & 0.000436 & 0.000476 & 0.003329 & 0.003627 & 0.003163 \\
\hline 48 & $\Delta$ Alkalis as $\mathrm{Na}_{2} \mathrm{O}_{\mathrm{e}}(\mathrm{mol})$ & 0.000228 & 0.000218 & 0.000238 & 0.001665 & 0.001814 & 0.001581 \\
\hline 49 & Mass of $\Delta$ Alkalis as $\mathrm{Na}_{2} \mathrm{O}_{\mathrm{e}}(\mathrm{g})$ & 0.014159 & 0.013516 & 0.014762 & 0.103169 & 0.112404 & 0.098017 \\
\hline 50 & $\Sigma$ Alkalis in Sol'n from Sample (wt $\%_{\mathrm{Na} 2 \mathrm{Oe}} /$ Mass of Solids) & 0.840051 & 0.800693 & 0.874927 & 6.120892 & 6.658799 & 5.809417 \\
\hline 51 & Average & & .838557242 & & & 5.196369344 & \\
\hline
\end{tabular}


Table A-3 Alkali leaching results of 20\% Type F Fly Ash paste specimens

\begin{tabular}{|c|c|c|c|c|c|c|c|}
\hline \multirow{4}{*}{\begin{tabular}{|l|}
$\#$ \\
1 \\
2 \\
3
\end{tabular}} & \multirow{4}{*}{\begin{tabular}{|l|} 
Content \\
Label \\
Solution \\
Specimen ID
\end{tabular}} & \multirow{2}{*}{\multicolumn{6}{|c|}{ FFA 20}} \\
\hline & & & & & & & \\
\hline & & \multicolumn{3}{|c|}{ DW } & \multicolumn{3}{|c|}{ Solution } \\
\hline & & A & B & C & A & $\mathrm{B}$ & C \\
\hline \multicolumn{8}{|c|}{ Sample Data } \\
\hline 5 & Volume of Solution $( \pm 0.04 \mathrm{~mL})$ & 24.0319 & 24.0125 & 24.0708 & 24.0319 & 24.0125 & 24.0708 \\
\hline 6 & Initial Mass of Powder $(\mathrm{g})$ & 2.4007 & 2.4003 & 2.4045 & 2.4035 & 2.4031 & 2.4008 \\
\hline 7 & \multicolumn{7}{|l|}{ Solution Data } \\
\hline 8 & Initial $\mathrm{Na}^{+}$Concentration in Solution (mol/L) & 0 & 0 & 0 & 0.025857 & 0.025857 & 0.025857 \\
\hline 9 & Final $\mathrm{Na}^{+}$Concentration in Solution $(\mathrm{mol} / \mathrm{L})$ & 0.012614 & 0.013301 & 0.013223 & 0.05705 & 0.055551 & 0.05414 \\
\hline 10 & Initial $\mathrm{K}^{+}$Concentration in Solution $(\mathrm{mo} / \mathrm{L})$ & 0 & 0 & 0 & 0.09264 & 0.09264 & 0.09264 \\
\hline 11 & Final $\mathrm{K}^{+}$Concentration in Solution (mol/L) & 0.02415 & 0.024889 & 0.02498 & 0.163662 & 0.163667 & 0.162059 \\
\hline 12 & \multicolumn{7}{|l|}{ Evaporable Water Content } \\
\hline 13 & Mass of Dish $(\mathrm{g})$ & \multicolumn{3}{|c|}{10.1935} & \multicolumn{3}{|c|}{27.671} \\
\hline 14 & Mass of Dish + Powder $(\mathrm{g})$ & \multirow{2}{*}{\multicolumn{3}{|c|}{$\begin{array}{l}11.2118 \\
11.1969\end{array}$}} & \multicolumn{3}{|c|}{28.8843} \\
\hline 15 & Mass of Dish + Powder (g) Oven Dry @ $105^{\circ} \mathrm{C}$ & \multirow{2}{*}{\multicolumn{3}{|c|}{$\begin{array}{c}11.1969 \\
1.0034\end{array}$}} & \multicolumn{3}{|c|}{28.8566} \\
\hline 16 & Mass of Power (g) Oven Dry @ $105^{\circ} \mathrm{C}$ & & & & \multicolumn{3}{|c|}{1.1856} \\
\hline 17 & Evaporable Water Content of Powder (\%) & \multicolumn{3}{|c|}{1.484951166} & & 2.33636977 & \\
\hline 18 & Dry Mass of Powder Sample (g) Oven Dry @ $105^{\circ} \mathrm{C}$ & 2.365572 & 2.365178 & 2.369317 & 2.348627 & 2.348237 & 2.345989 \\
\hline 19 & \multicolumn{7}{|l|}{ Non-Evaporable Water Content } \\
\hline 20 & Mass of Crucible $(\mathrm{g})$ & \multicolumn{3}{|c|}{19.199} & & 27.671 & \\
\hline 21 & Mass of Crucible + Powder (g) Oven Dry @ $105^{\circ} \mathrm{C}$ & & 20.2007 & & & 28.8566 & \\
\hline 22 & Mass of Crucible + Powder $(\mathrm{g}) @ 1050^{\circ} \mathrm{C}$ & & 20.0669 & & & 28.7005 & \\
\hline 23 & Mass of Powder $(\mathrm{g}) @ 1050^{\circ} \mathrm{C}$ & & 0.8679 & & & 1.0295 & \\
\hline 24 & Non-Evaporable Water Content of Powder (\%) & & 15.4165226 & & & 15.1627003 & \\
\hline 25 & Ignited Mass of Powder Sample (g) @ $1050^{\circ} \mathrm{C}$ & 2.049596 & 2.049254 & 2.05284 & 2.039399 & 2.03906 & 2.037108 \\
\hline 26 & Cementitious Material Properties & & & & & & \\
\hline 27 & Cementitious Material Label & PC & FFA & & PC & FFA & 0 \\
\hline 28 & Content (\%) & 80 & 20 & & 80 & 20 & 0 \\
\hline 29 & Loss On Ignition (LOI) of Cementitious Material (\%) & 0.016 & 0.02 & & 0.016 & 0.02 & 0 \\
\hline 30 & Fractional LOI of Cementitious Material in Powder & 0.0128 & 0.004 & 0 & 0.0128 & 0.004 & 0 \\
\hline 31 & Total LOI of All Cementitious Materials (\%/100) & & 0.0168 & & & 0.0168 & \\
\hline 32 & Total Mass Loss due to LOI Cementitious Materials (g) & 0.034433 & 0.034427 & 0.034488 & 0.034433 & 0.034427 & 0.034488 \\
\hline 33 & Mass of Powder (g) - Corrected for LOI & 2.084029 & 2.083682 & 2.087328 & 2.084029 & 2.083682 & 2.087328 \\
\hline 34 & Composition & PC & F FA & 0 & & & \\
\hline 35 & $\mathrm{Na}_{2} \mathrm{O}$ Content of Cementitious Material (wt \%) & 0.24 & 0.44 & & 0.24 & 0.44 & 0 \\
\hline 36 & $\mathrm{~K}_{2} \mathrm{O}$ Content of Cementitious Material (wt \%) & 1.2 & 2.29 & & 1.2 & 2.29 & 0 \\
\hline 37 & $\Sigma \mathrm{Na}_{2} \mathrm{O}$ Content of Cementitious Materials & 28 & 28 & 28 & 28 & 28 & 28 \\
\hline 38 & $\Sigma \mathrm{K}_{2} \mathrm{O}$ Content of Cementitious Materials & 141.8 & 141.8 & 141.8 & 141.8 & 141.8 & 141.8 \\
\hline 39 & Original $\mathrm{Na}_{2} \mathrm{O}_{\mathrm{e}}$ Content of Cementitious Materials & 121.3044 & 121.3044 & 121.3044 & 121.3044 & 121.3044 & 121.3044 \\
\hline 40 & Total $\mathrm{Na}_{2} \mathrm{O}_{\mathrm{e}}$ as $\% \mathrm{Na}_{2} \mathrm{O}_{\mathrm{e}}$ in SCMs & 0.01094 & 0.01135 & 0.011362 & 0.01094 & 0.01135 & 0.011362 \\
\hline 41 & Final Concentrations & & & & & & \\
\hline 42 & Corrected Final $\mathrm{Na}^{+}$Concentration in Solution $(\mathrm{mol} / \mathrm{L})$ & 0.012633 & 0.013301 & 0.013223 & 0.05718 & 0.055551 & 0.05414 \\
\hline 43 & Corrected Final $\mathrm{K}^{+}$Concentration in Solution $(\mathrm{mo} / \mathrm{L})$ & 0.024503 & 0.025253 & 0.025345 & 0.167398 & 0.167404 & 0.165759 \\
\hline 44 & $\Delta\left[\mathrm{Na}^{+}\right]$in Solution $(\mathrm{mol} / \mathrm{L})$ & 0.012633 & 0.013301 & 0.013223 & 0.031323 & 0.029694 & 0.028283 \\
\hline 45 & $\Delta\left[\mathrm{K}^{+}\right]$in Solution $(\mathrm{mol} / \mathrm{L})$ & 0.024503 & 0.025253 & 0.025345 & 0.074758 & 0.074764 & 0.073119 \\
\hline 46 & $\Sigma\left[\Delta \mathrm{Na}^{+}\right] \&\left[\Delta \mathrm{K}^{+}\right](\mathrm{mol} / \mathrm{L})$ & 0.037136 & 0.038554 & 0.038569 & 0.106082 & 0.104458 & 0.101402 \\
\hline 47 & $\Sigma\left[\Delta \mathrm{Na}^{+}\right] \&\left[\Delta \mathrm{K}^{+}\right](\mathrm{mol})$ & 0.000892 & 0.000926 & 0.000928 & 0.002549 & 0.002508 & 0.002441 \\
\hline 48 & $\Delta$ Alkalis as $\mathrm{Na}_{2} \mathrm{O}_{\mathrm{e}}(\mathrm{mol})$ & 0.000446 & 0.000463 & 0.000464 & 0.001275 & 0.001254 & 0.00122 \\
\hline 49 & Mass of $\Delta$ Alkalis as $\mathrm{Na}_{2} \mathrm{O}_{\mathrm{e}}(\mathrm{g})$ & 0.027657 & 0.028689 & 0.02877 & 0.079003 & 0.07773 & 0.07564 \\
\hline 50 & $\Sigma$ Alkalis in Sol'n from Sample (wt $\%_{\mathrm{Na} 2 \mathrm{Oe}} /$ Mass of Solids) & 1.32707 & 1.376844 & 1.37831 & 3.790862 & 3.730431 & 3.623756 \\
\hline 51 & Average & & 1.36074099 & & & 3.71501635 & \\
\hline
\end{tabular}


Table A-4 Alkali leaching results of 30\% GGBS paste specimens

\begin{tabular}{|c|c|c|c|c|c|c|c|}
\hline \multirow{3}{*}{$\begin{array}{l}\# \\
1 \\
2\end{array}$} & \multicolumn{7}{|l|}{ Content } \\
\hline & Label & \multicolumn{6}{|c|}{ S 30} \\
\hline & Solution & \multicolumn{3}{|c|}{ DW } & \multicolumn{3}{|c|}{ Solution } \\
\hline 3 & Specimen ID & A & B & C & A & B & C \\
\hline 4 & Sample Data & & & & & & \\
\hline 5 & Volume of Solution $( \pm 0.04 \mathrm{~mL})$ & 24.0319 & 24.0125 & 24.0708 & 24.0319 & 24.0125 & 24.0708 \\
\hline 6 & Initial Mass of Powder $(\mathrm{g})$ & 2.4022 & 2.4003 & 2.4058 & 2.4106 & 2.4091 & 2.4083 \\
\hline 7 & Solution Data & & & & & & \\
\hline 8 & Initial $\mathrm{Na}^{+}$Concentration in Solution $(\mathrm{mol} / \mathrm{L})$ & 0 & 0 & 0 & 0.033905 & 0.033905 & 0.033905 \\
\hline 9 & Final $\mathrm{Na}^{+}$Concentration in Solution $(\mathrm{mo} / \mathrm{L})$ & 0.000773 & 0.000793 & 0.000657 & 0.082617 & 0.088987 & 0.090814 \\
\hline 10 & Initial $\mathrm{K}^{+}$Concentration in Solution $(\mathrm{mol} / \mathrm{L})$ & 0 & 0 & 0 & 0.088785 & 0.088785 & 0.088785 \\
\hline 11 & Final $\mathrm{K}^{+}$Concentration in Solution $(\mathrm{mol} / \mathrm{L})$ & 0.022161 & 0.021649 & 0.021166 & 0.163974 & 0.175137 & 0.178695 \\
\hline 12 & Evaporable Water Content & & & & & & \\
\hline 13 & Mass of Dish $(\mathrm{g})$ & \multicolumn{3}{|c|}{10.1943} & \multicolumn{3}{|c|}{27.6559} \\
\hline 14 & Mass of Dish + Powder (g) & \multicolumn{3}{|c|}{11.1965} & \multicolumn{3}{|c|}{28.6782} \\
\hline 15 & Mass of Dish + Powder (g) Oven Dry @ $105^{\circ} \mathrm{C}$ & \multirow{2}{*}{\multicolumn{3}{|c|}{\begin{tabular}{|c|}
11.1709 \\
0.9766
\end{tabular}}} & \multicolumn{3}{|c|}{28.654} \\
\hline 16 & Mass of Power $(\mathrm{g})$ Oven Dry $@ 105^{\circ} \mathrm{C}$ & & & & \multicolumn{3}{|c|}{0.9981} \\
\hline 17 & Evaporable Water Content of Powder (\%) & \multicolumn{3}{|c|}{$\frac{0.9766}{2.621339341}$} & \multicolumn{3}{|c|}{2.424606753} \\
\hline 18 & Dry Mass of Powder Sample (g) Oven Dry @ $105^{\circ} \mathrm{C}$ & 2.340839 & 2.338987 & 2.344347 & 2.353536 & 2.352072 & 2.35129 \\
\hline 19 & Non-Evaporable Water Content & & & & & & \\
\hline 20 & Mass of Crucible $(\mathrm{g})$ & \multicolumn{3}{|c|}{19.1988} & \multicolumn{3}{|c|}{27.6559} \\
\hline 21 & Mass of Crucible + Powder (g) Oven Dry @ $105^{\circ} \mathrm{C}$ & \multicolumn{3}{|c|}{20.1842} & \multicolumn{3}{|c|}{28.654} \\
\hline 22 & Mass of Crucible + Powder $(\mathrm{g}) @ 1050^{\circ} \mathrm{C}$ & & 20.0487 & & & 28.523 & \\
\hline 23 & Mass of Powder (g) @ $1050^{\circ} \mathrm{C}$ & & 0.8499 & & & 0.8671 & \\
\hline 24 & Non-Evaporable Water Content of Powder (\%) & & 15.94305212 & & & 15.1078307 & \\
\hline 25 & Ignited Mass of Powder Sample (g) @ $1050^{\circ} \mathrm{C}$ & 2.018956 & 2.017359 & 2.021981 & 2.044636 & 2.043364 & 2.042685 \\
\hline 26 & Cementitious Material Properties & & & & & & \\
\hline 27 & Cementitious Material Label & PC & Slag & & PC & Slag & 0 \\
\hline 28 & Content (\%) & 70 & 30 & & 70 & 30 & 0 \\
\hline 29 & Loss On Ignition (LOI) of Cementitious Material (\%) & 0.016 & 0.42 & & 0.016 & 0.42 & 0 \\
\hline 30 & Fractional LOI of Cementitious Material in Powder & 0.0112 & 0.126 & 0 & 0.0112 & 0.126 & 0 \\
\hline 31 & Total LOI of All Cementitious Materials (\%/100) & & 0.1372 & & & 0.1372 & \\
\hline 32 & Total Mass Loss due to LOI Cementitious Materials (g) & 0.277001 & 0.276782 & 0.277416 & 0.277001 & 0.276782 & 0.277416 \\
\hline 33 & Mass of Powder (g) - Corrected for LOI & 2.295956 & 2.29414 & 2.299397 & 2.295956 & 2.29414 & 2.299397 \\
\hline 34 & Composition & PC & Slag & 0 & & & \\
\hline 35 & $\mathrm{Na}_{2} \mathrm{O}$ Content of Cementitious Material (wt \%) & 0.24 & 0.37 & & 0.24 & 0.37 & 0 \\
\hline 36 & $\mathrm{~K}_{2} \mathrm{O}$ Content of Cementitious Material (wt \%) & 1.2 & 0.54 & & 1.2 & 0.54 & 0 \\
\hline 37 & $\Sigma \mathrm{Na}_{2} \mathrm{O}$ Content of Cementitious Materials & 27.9 & 27.9 & 27.9 & 27.9 & 27.9 & 27.9 \\
\hline 38 & $\Sigma \mathrm{K}_{2} \mathrm{O}$ Content of Cementitious Materials & 100.2 & 100.2 & 100.2 & 100.2 & 100.2 & 100.2 \\
\hline 39 & Original $\mathrm{Na}_{2} \mathrm{O}_{\mathrm{e}}$ Content of Cementitious Materials & 93.8316 & 93.8316 & 93.8316 & 93.8316 & 93.8316 & 93.8316 \\
\hline 40 & Total $\mathrm{Na}_{2} \mathrm{O}_{\mathrm{e}}$ as $\% \mathrm{Na}_{2} \mathrm{O}_{\mathrm{e}}$ in $\mathrm{SCMs}$ & 0.008124 & 0.007949 & 0.007732 & 0.008124 & 0.007949 & 0.007732 \\
\hline 41 & Final Concentrations & & & & & & \\
\hline 42 & Corrected Final $\mathrm{Na}^{+}$Concentration in Solution $(\mathrm{mol} / \mathrm{L})$ & 0.000775 & 0.000793 & 0.000657 & 0.082813 & 0.088987 & 0.090814 \\
\hline 43 & Corrected Final $\mathrm{K}^{+}$Concentration in Solution $(\mathrm{mol} / \mathrm{L})$ & 0.022727 & 0.022202 & 0.021707 & 0.167856 & 0.179283 & 0.182925 \\
\hline 44 & $\Delta\left[\mathrm{Na}^{+}\right]$in Solution $(\mathrm{mol} / \mathrm{L})$ & 0.000775 & 0.000793 & 0.000657 & 0.048908 & 0.055082 & 0.056909 \\
\hline 45 & $\Delta\left[\mathrm{K}^{+}\right]$in Solution $(\mathrm{mol} / \mathrm{L})$ & 0.022727 & 0.022202 & 0.021707 & 0.079071 & 0.090498 & 0.09414 \\
\hline 46 & $\Sigma\left[\Delta \mathrm{Na}^{+}\right] \&\left[\Delta \mathrm{K}^{+}\right](\mathrm{mol} / \mathrm{L})$ & 0.023502 & 0.022995 & 0.022364 & 0.127979 & 0.14558 & 0.151049 \\
\hline 47 & $\Sigma\left[\Delta \mathrm{Na}^{+}\right] \&\left[\Delta \mathrm{K}^{+}\right](\mathrm{mol})$ & 0.000565 & 0.000552 & 0.000538 & 0.003076 & 0.003496 & 0.003636 \\
\hline 48 & $\Delta$ Alkalis as $\mathrm{Na}_{2} \mathrm{O}_{\mathrm{e}}(\mathrm{mol})$ & 0.000282 & 0.000276 & 0.000269 & 0.001538 & 0.001748 & 0.001818 \\
\hline 49 & Mass of $\Delta$ Alkalis as $\mathrm{Na}_{2} \mathrm{O}_{\mathrm{e}}(\mathrm{g})$ & 0.017503 & 0.017111 & 0.016682 & 0.095311 & 0.108331 & 0.112674 \\
\hline 50 & $\Sigma$ Alkalis in Sol'n from Sample (wt $\%_{\mathrm{Na} 2 \mathrm{Oe}} /$ Mass of Solids) & 0.762329 & 0.745864 & 0.725502 & 4.151238 & 4.722075 & 4.900139 \\
\hline 51 & Average & & 0.74456497 & & & 4.59115066 & \\
\hline
\end{tabular}




\section{Appendix B - Drying Shrinkage Prism Results}

Table B-1 Sample of data worksheet for recording drying shrinkage results

\begin{tabular}{|c|c|c|c|c|c|c|c|c|c|c|}
\hline \multirow{3}{*}{$\begin{array}{l}\text { Time } \\
\text { Days } \\
\text { Cast }\end{array}$} & \multicolumn{5}{|c|}{ Specimen A } & \multicolumn{5}{|c|}{ Specimen B } \\
\hline & \multicolumn{3}{|c|}{ Reading (mm) } & \multirow{2}{*}{$\begin{array}{c}\text { Shrinkage } \\
\text { (\%) }\end{array}$} & \multirow{2}{*}{$\begin{array}{c}\text { Corrected } \\
\text { Shrinkage } \\
(\%)\end{array}$} & \multicolumn{3}{|c|}{ Reading (mm) } & \multirow{2}{*}{$\begin{array}{c}\text { Shrinkage } \\
\text { (\%) }\end{array}$} & \multirow{2}{*}{$\begin{array}{c}\text { Corrected } \\
\text { Shrinkage } \\
(\%)\end{array}$} \\
\hline & Low & High & $\Delta$ & & & Low & High & $\Delta$ & & \\
\hline 1 & 1.714 & 1.716 & 0.002 & 0.000 & 0.000 & 2.058 & 2.058 & 0.000 & 0.000 & 0.000 \\
\hline 4 & 1.742 & 1.744 & 0.002 & 0.011 & 0.011 & 2.092 & 2.092 & 0.000 & 0.013 & 0.013 \\
\hline 7 & 1.738 & 1.738 & 0.000 & 0.000 & 0.000 & 2.086 & 2.086 & 0.000 & 0.000 & 0.000 \\
\hline 14 & 1.716 & 1.718 & 0.002 & 0.001 & -0.008 & 2.066 & 2.066 & 0.000 & 0.003 & -0.008 \\
\hline 18 & 1.698 & 1.700 & 0.002 & -0.006 & -0.015 & 2.056 & 2.056 & 0.000 & -0.001 & -0.012 \\
\hline 23 & 1.684 & 1.684 & 0.000 & -0.013 & -0.021 & 2.036 & 2.036 & 0.000 & -0.009 & -0.020 \\
\hline 28 & 1.67 & 1.670 & 0.000 & -0.018 & -0.027 & 2.028 & 2.028 & 0.000 & -0.012 & -0.023 \\
\hline 56 & 1.63 & 1.630 & 0.000 & -0.034 & -0.043 & 1.986 & 1.986 & 0.000 & -0.028 & -0.040 \\
\hline 70 & 1.584 & 1.584 & 0.000 & -0.052 & -0.061 & 1.94 & 1.940 & 0.000 & -0.046 & -0.058 \\
\hline 106 & 1.558 & 1.558 & 0.000 & -0.062 & -0.072 & 1.916 & 1.916 & 0.000 & -0.056 & -0.068 \\
\hline 150 & 1.536 & 1.536 & 0.000 & -0.071 & -0.083 & 1.888 & 1.888 & 0.000 & -0.067 & -0.081 \\
\hline 176 & 1.536 & 1.536 & 0.000 & -0.071 & -0.084 & 1.892 & 1.892 & 0.000 & -0.065 & -0.080 \\
\hline \multirow{2}{*}{ Time } & \multicolumn{5}{|c|}{ Specimen C } & & \multicolumn{2}{|c|}{ Specimen Average } & \multicolumn{2}{|c|}{ Calibration } \\
\hline & \multicolumn{3}{|c|}{ Reading (mm) } & \multirow{2}{*}{$\begin{array}{c}\text { Shrinkage } \\
(\%)\end{array}$} & \multirow{2}{*}{$\begin{array}{c}\text { Corrected } \\
\text { Shrinkage } \\
\text { (\%) }\end{array}$} & & \multirow{2}{*}{$\begin{array}{c}\text { Average } \\
\text { Shrinkage } \\
\text { (\%) }\end{array}$} & \multirow{2}{*}{$\begin{array}{l}\text { Corrected } \\
\text { Average } \\
\text { Shrinkage }\end{array}$} & \multirow{2}{*}{$\begin{array}{c}\text { Correction } \\
\text { Value } \\
(\mathrm{mm})\end{array}$} & \multirow{2}{*}{$\begin{array}{c}\text { Invar Bar } \\
\text { Reading } \\
\text { (mm) }\end{array}$} \\
\hline $\begin{array}{l}\text { Days } \\
\text { Cast }\end{array}$ & Low & High & $\Delta$ & & & & & & & \\
\hline 1 & 1.362 & 1.362 & 0.000 & 0.000 & 0.000 & & 0.000 & 0.000 & -0.0015366 & -0.076 \\
\hline 4 & 1.38 & 1.380 & 0.000 & 0.007 & 0.007 & & 0.010 & 0.010 & -0.0015366 & -0.076 \\
\hline 7 & 1.376 & 1.376 & 0.000 & 0.000 & 0.000 & & 0.000 & 0.000 & -0.0015366 & -0.076 \\
\hline 14 & 1.352 & 1.352 & 0.000 & -0.004 & -0.010 & & 0.000 & -0.008 & -0.0013659 & -0.076171 \\
\hline 18 & 1.346 & 1.346 & 0.000 & -0.006 & -0.012 & & -0.004 & -0.013 & -0.0012683 & -0.076268 \\
\hline 23 & 1.328 & 1.328 & 0.000 & -0.013 & -0.019 & & -0.012 & -0.020 & -0.0011463 & -0.07639 \\
\hline 28 & 1.314 & 1.314 & 0.000 & -0.019 & -0.025 & & -0.016 & -0.025 & -0.0010244 & -0.076512 \\
\hline 56 & 1.274 & 1.274 & 0.000 & -0.035 & -0.041 & & -0.032 & -0.041 & -0.0003415 & -0.077195 \\
\hline 70 & 1.238 & 1.238 & 0.000 & -0.049 & -0.055 & & -0.049 & -0.058 & 0.0000000 & -0.077537 \\
\hline 106 & 1.214 & 1.214 & 0.000 & -0.058 & -0.065 & & -0.059 & -0.069 & 0.0021139 & -0.07965 \\
\hline 150 & 1.19 & 1.190 & 0.000 & -0.068 & -0.076 & & -0.069 & -0.080 & 0.0063857 & -0.083922 \\
\hline 176 & 1.188 & 1.188 & 0.000 & -0.069 & -0.078 & & -0.068 & -0.081 & 0.0089100 & -0.086447 \\
\hline
\end{tabular}


Table B-2 Average drying shrinkage of Class R mixtures (\%)

\begin{tabular}{|cc|}
\hline Days & $\mathrm{V}-1$ \\
\hline 1 & 0.000 \\
4 & 0.005 \\
7 & 0.000 \\
14 & -0.011 \\
26 & -0.028 \\
28 & -0.031 \\
58 & -0.042 \\
78 & -0.049 \\
158 & -0.057 \\
197 & -0.053 \\
& \\
& \\
\hline
\end{tabular}

\begin{tabular}{|cc|}
\hline Days & $\mathrm{V}-2$ \\
\hline 1 & 0.000 \\
4 & -0.001 \\
7 & 0.000 \\
14 & -0.016 \\
20 & -0.022 \\
25 & -0.028 \\
29 & -0.030 \\
56 & -0.044 \\
72 & -0.049 \\
152 & -0.056 \\
178 & -0.057 \\
& \\
\hline
\end{tabular}

\begin{tabular}{|cc|}
\hline Days & V-S30-1 \\
\hline 1 & 0.000 \\
4 & 0.008 \\
7 & 0.000 \\
14 & -0.006 \\
26 & -0.025 \\
28 & -0.027 \\
31 & -0.029 \\
58 & -0.040 \\
78 & -0.045 \\
158 & -0.056 \\
197 & -0.050 \\
& \\
\hline
\end{tabular}

\begin{tabular}{|cc|}
\hline Days & V-3 \\
\hline 1 & 0.000 \\
4 & 0.920 \\
7 & 0.000 \\
10 & -0.010 \\
14 & -0.019 \\
18 & -0.023 \\
21 & -0.026 \\
84 & -0.052 \\
110 & -0.051 \\
145 & -0.052 \\
152 & -0.051 \\
159 & -0.050 \\
\hline
\end{tabular}

\begin{tabular}{|cc|}
\hline Days & R-1 \\
\hline 1 & 0.000 \\
4 & 0.000 \\
7 & 0.000 \\
16 & -0.021 \\
28 & -0.032 \\
62 & -0.049 \\
125 & -0.056 \\
205 & -0.060 \\
231 & -0.056 \\
& \\
& \\
\end{tabular}

\begin{tabular}{|cc|}
\hline Days & $\mathrm{R}-2$ \\
\hline 1 & 0.000 \\
2 & 0.000 \\
7 & 0.000 \\
14 & -0.014 \\
28 & -0.029 \\
48 & -0.042 \\
64 & -0.045 \\
111 & -0.053 \\
191 & -0.062 \\
217 & -0.056 \\
& \\
& \\
\hline
\end{tabular}

\begin{tabular}{|cc|}
\hline Days & $\mathrm{R}-4$ \\
\hline 1 & 0.000 \\
4 & 0.006 \\
7 & 0.000 \\
14 & -0.024 \\
19 & -0.035 \\
24 & -0.044 \\
28 & -0.051 \\
71 & -0.082 \\
103 & -0.084 \\
151 & -0.094 \\
191 & -0.089 \\
& \\
\hline
\end{tabular}

\begin{tabular}{|cc|}
\hline Days & R-5 \\
\hline 1 & 0.000 \\
4 & 0.929 \\
7 & 0.000 \\
10 & -0.015 \\
14 & -0.025 \\
18 & -0.035 \\
21 & -0.041 \\
84 & -0.075 \\
110 & -0.079 \\
145 & -0.078 \\
152 & -0.077 \\
159 & -0.077 \\
\hline
\end{tabular}


Table B-3 Average drying shrinkage of Class R mixtures (\%)

\begin{tabular}{|cc|}
\hline Days & $\begin{array}{c}\text { R70-V30- } \\
\text { S30-2 }\end{array}$ \\
\hline 1 & 0.000 \\
4 & 0.008 \\
7 & 0.000 \\
15 & -0.012 \\
27 & -0.034 \\
63 & -0.054 \\
107 & -0.064 \\
133 & -0.067 \\
168 & -0.067 \\
175 & -0.067 \\
182 & -0.068 \\
& \\
\end{tabular}

\begin{tabular}{|cc|}
\hline Days & R70-V30 \\
\hline 1 & 0.000 \\
4 & 0.006 \\
7 & 0.000 \\
15 & -0.019 \\
27 & -0.040 \\
63 & -0.058 \\
107 & -0.064 \\
133 & -0.065 \\
168 & -0.064 \\
175 & -0.063 \\
182 & -0.064 \\
& \\
\hline
\end{tabular}

\begin{tabular}{|cc|}
\hline Days & R-S30-3 \\
\hline 1 & 0.000 \\
4 & 0.917 \\
7 & 0.000 \\
10 & -0.008 \\
14 & -0.021 \\
18 & -0.028 \\
21 & -0.034 \\
40 & -0.054 \\
84 & -0.075 \\
110 & -0.078 \\
145 & -0.080 \\
152 & -0.078 \\
159 & -0.081 \\
\hline
\end{tabular}

\begin{tabular}{|cc|}
\hline Days & R-S30-2Min \\
\hline 1 & 0.000 \\
5 & 0.012 \\
7 & 0.000 \\
14 & -0.015 \\
21 & -0.025 \\
38 & -0.042 \\
57 & -0.053 \\
101 & -0.070 \\
127 & -0.073 \\
162 & -0.074 \\
169 & -0.074 \\
176 & -0.074 \\
180 & -0.073 \\
\hline
\end{tabular}

\begin{tabular}{|cc|}
\hline Days & V-S30-2 \\
\hline 1 & 0.000 \\
4 & 0.014 \\
7 & 0.000 \\
14 & -0.016 \\
25 & -0.024 \\
28 & -0.028 \\
57 & -0.043 \\
77 & -0.054 \\
157 & -0.066 \\
183 & -0.068 \\
& \\
& \\
\hline
\end{tabular}

\begin{tabular}{|cc|}
\hline Days & V-S30-SR \\
\hline 1 & 0.000 \\
4 & 0.008 \\
7 & 0.000 \\
14 & 0.000 \\
26 & -0.015 \\
28 & -0.016 \\
58 & -0.027 \\
78 & -0.033 \\
158 & -0.045 \\
197 & -0.041 \\
& \\
& \\
\hline
\end{tabular}

\begin{tabular}{|cc|}
\hline Days & V-S30-WR \\
\hline 1 & 0.000 \\
4 & 0.011 \\
7 & 0.000 \\
14 & -0.009 \\
26 & -0.029 \\
28 & -0.030 \\
58 & -0.040 \\
78 & -0.046 \\
158 & -0.055 \\
197 & -0.050 \\
& \\
& \\
\hline
\end{tabular}

\begin{tabular}{|cc|}
\hline Days & R-S30-1 \\
\hline 1 & 0.000 \\
4 & 0.005 \\
7 & 0.000 \\
14 & -0.015 \\
18 & -0.021 \\
23 & -0.029 \\
28 & -0.035 \\
56 & -0.054 \\
70 & -0.066 \\
102 & -0.076 \\
150 & -0.086 \\
190 & -0.082 \\
\hline
\end{tabular}


Table B-4 Average drying shrinkage of Class R mixtures (\%)

\begin{tabular}{|cc|}
\hline Days & R-S30-3Max \\
\hline 1 & 0.000 \\
7 & 0.000 \\
7 & 0.000 \\
14 & -0.012 \\
19 & -0.017 \\
36 & -0.028 \\
55 & -0.039 \\
99 & -0.050 \\
138 & -0.052 \\
160 & -0.056 \\
167 & -0.054 \\
174 & -0.055 \\
180 & -0.055 \\
\hline
\end{tabular}

\begin{tabular}{|cc|}
\hline Days & R70-V30-S30 \\
\hline 1 & 0.000 \\
4 & 0.007 \\
7 & 0.000 \\
15 & -0.018 \\
21 & -0.026 \\
28 & -0.034 \\
60 & -0.055 \\
96 & -0.065 \\
140 & -0.072 \\
166 & -0.072 \\
& \\
& \\
\end{tabular}

\begin{tabular}{|cc|}
\hline Days & V-S50 \\
\hline 1 & 0.000 \\
4 & 0.014 \\
7 & 0.000 \\
14 & -0.005 \\
28 & -0.016 \\
66 & -0.040 \\
98 & -0.046 \\
146 & -0.058 \\
185 & -0.054 \\
& \\
& \\
& \\
\end{tabular}

\begin{tabular}{|cc|}
\hline Days & R-S30-WR \\
\hline 1 & 0.000 \\
4 & 0.002 \\
7 & 0.000 \\
14 & -0.019 \\
19 & -0.029 \\
28 & -0.040 \\
66 & -0.067 \\
98 & -0.074 \\
146 & -0.085 \\
185 & -0.080 \\
& \\
& \\
\hline
\end{tabular}

\begin{tabular}{|cc|}
\hline Days & R-S30-SR \\
\hline 1 & 0.000 \\
4 & 0.010 \\
7 & 0.000 \\
14 & -0.008 \\
18 & -0.013 \\
23 & -0.020 \\
28 & -0.025 \\
56 & -0.041 \\
70 & -0.058 \\
106 & -0.069 \\
150 & -0.080 \\
176 & -0.081 \\
\hline
\end{tabular}




\section{Appendix C - Freeze/Thaw Durability Results}

Table C-1 Sample of data worksheet for recording freeze-thaw results

\begin{tabular}{|c|c|c|c|c|c|c|c|c|c|c|c|c|c|c|}
\hline \multirow{3}{*}{$\begin{array}{l}\text { Time } \\
\text { Cycles }\end{array}$} & \multicolumn{7}{|c|}{ Specimen D } & \multicolumn{7}{|c|}{ Specimen E } \\
\hline & \multicolumn{3}{|c|}{ Velocity $(\mathrm{m} / \mathrm{s})$} & \multirow{2}{*}{$\begin{array}{c}\text { Average } \\
\text { Velocity } \\
(\mathrm{m} / \mathrm{s})\end{array}$} & \multirow{2}{*}{ Mass (kg) } & \multirow{2}{*}{$\rho(\mathrm{kg} / \mathrm{m} 3)$} & \multirow{2}{*}{$\mathbf{E}$} & \multicolumn{3}{|c|}{ Velocity $(\mathrm{m} / \mathrm{s})$} & \multirow{2}{*}{$\begin{array}{c}\text { Average } \\
\text { Velocity } \\
(\mathrm{m} / \mathrm{s})\end{array}$} & \multirow{2}{*}{ Mass (kg) } & \multirow{2}{*}{$\rho(\mathrm{kg} / \mathrm{m} 3)$} & \multirow{2}{*}{$\mathbf{E}$} \\
\hline & A & B & C & & & & & A & B & C & & & & \\
\hline 0 & 4810 & 4840 & 4662 & 4771 & 3.906 & 2300 & $5.235 \mathrm{E}+10$ & 4691 & 4662 & 4810 & 4721 & 3.976 & 2400 & $5.349 E+10$ \\
\hline 30 & 4840 & 5033 & 4662 & 4845 & 3.908 & 2300 & $5.399 \mathrm{E}+10$ & 4810 & 4662 & 4967 & 4813 & 3.982 & 2400 & $5.560 \mathrm{E}+10$ \\
\hline 60 & 4810 & 4810 & 4497 & 4706 & 3.906 & 2300 & $5.093 \mathrm{E}+10$ & 4779 & 4444 & 4935 & 4719 & 3.977 & 2400 & $5.345 \mathrm{E}+10$ \\
\hline 90 & 4816 & 4662 & 4691 & 4723 & 3.894 & 2300 & $5.131 \mathrm{E}+10$ & 4662 & 4662 & 5000 & 4775 & 3.969 & 2400 & $5.471 \mathrm{E}+10$ \\
\hline 120 & 4634 & 4691 & 4523 & 4616 & 3.886 & 2300 & $4.901 \mathrm{E}+10$ & 4634 & 4523 & 4935 & 4697 & 3.949 & 2400 & $5.296 \mathrm{E}+10$ \\
\hline 150 & 4662 & 4691 & 4662 & 4672 & 3.897 & 2300 & $5.020 \mathrm{E}+10$ & 4662 & 4550 & 4662 & 4625 & 3.959 & 2400 & $5.133 \mathrm{E}+10$ \\
\hline 180 & 4550 & 4523 & 4393 & 4489 & 3.885 & 2300 & $4.634 \mathrm{E}+10$ & 4523 & 4523 & 4550 & 4532 & 3.944 & 2400 & $4.929 E+10$ \\
\hline 210 & 4591 & 4506 & 4345 & 4481 & 3.851 & 2300 & $4.618 E+10$ & 4345 & 4171 & 4562 & 4359 & 3.896 & 2400 & $4.561 E+10$ \\
\hline 270 & 4634 & 4810 & 4470 & 4638 & 3.848 & 2300 & $4.948 \mathrm{E}+10$ & 4523 & 4342 & 4634 & 4500 & 3.893 & 2400 & $4.859 \mathrm{E}+10$ \\
\hline 300 & 4634 & 4662 & 4606 & 4634 & 3.845 & 2300 & $4.939 E+10$ & 4606 & 4342 & 4606 & 4518 & 3.888 & 2400 & 4.899E+10 \\
\hline \multirow{2}{*}{ Time } & \multicolumn{7}{|c|}{ Specimen F } & & & & \multicolumn{2}{|c|}{ Specimen Average } & & \\
\hline & \multicolumn{3}{|c|}{ Velocity (m/s) } & \multirow{2}{*}{$\begin{array}{c}\text { Average } \\
\text { Velocity } \\
(\mathrm{m} / \mathrm{s})\end{array}$} & \multirow[b]{2}{*}{ Mass (kg) } & \multirow[b]{2}{*}{$\rho(\mathrm{kg} / \mathrm{m} 3)$} & \multirow[b]{2}{*}{$\mathbf{E}$} & & & & \multirow[b]{2}{*}{ Average $\mathrm{E}$} & \multirow[b]{2}{*}{$\%$ Change } & & \\
\hline Cycles & A & B & C & & & & & & & & & & & \\
\hline 0 & 4810 & 4810 & 4840 & 4820 & 3.911 & 2320 & $5.390 \mathrm{E}+10$ & & & & $5.325 E+10$ & 10.872 & & \\
\hline 30 & 4840 & 4810 & 5000 & 4883 & 3.916 & 2320 & $5.532 \mathrm{E}+10$ & & & & $5.497 \mathrm{E}+10$ & 14.463 & & \\
\hline 60 & 4810 & 4810 & 4903 & 4841 & 3.915 & 2320 & $5.437 E+10$ & & & & $5.292 E+10$ & 10.189 & & \\
\hline 90 & 4840 & 4691 & 4662 & 4731 & 3.908 & 2320 & $5.193 \mathrm{E}+10$ & & & & $5.265 E+10$ & 9.629 & & \\
\hline 120 & 4779 & 4779 & 4779 & 4779 & 3.898 & 2320 & $5.299 \mathrm{E}+10$ & & & & $5.165 E+10$ & 7.549 & & \\
\hline 150 & 4691 & 4550 & 4779 & 4673 & 3.908 & 2320 & $5.067 \mathrm{E}+10$ & & & & $5.073 E+10$ & 5.637 & & \\
\hline 180 & 4662 & 4523 & 4523 & 4569 & 3.898 & 2320 & $4.844 \mathrm{E}+10$ & & & & $4.802 E+10$ & 0.000 & & \\
\hline 210 & 4591 & 4345 & 4451 & 4462 & 3.884 & 2320 & $4.620 \mathrm{E}+10$ & & & & $4.599 E+10$ & -4.228 & & \\
\hline 270 & 4523 & 4634 & 4662 & 4606 & 3.869 & 2320 & $4.923 \mathrm{E}+10$ & & & & $4.910 \mathrm{E}+10$ & 2.236 & & \\
\hline 300 & 4606 & 4606 & 4470 & 4561 & 3.864 & 2320 & $4.826 \mathrm{E}+10$ & & & & $4.888 \mathrm{E}+10$ & 1.778 & & \\
\hline
\end{tabular}


Table C-2 Durability factor results of freeze-thaw specimens

\begin{tabular}{|c|ccc|c|}
\hline \multirow{2}{*}{ Cycles } & \multicolumn{4}{|c|}{ R-CTR-5FT } \\
\cline { 2 - 5 } & $\% \mathrm{D}$ & $\% \mathrm{E}$ & $\% \mathrm{~F}$ & Average \\
\hline 30 & 100.00 & 100.00 & 100.00 & 100.00 \\
\cline { 1 - 3 } & 92.86 & 96.19 & 98.48 & 95.84 \\
\hline 90 & 90.70 & 90.89 & 96.49 & 92.70 \\
\hline 120 & 95.20 & 91.65 & 93.27 & 93.38 \\
\hline 150 & 90.69 & 90.97 & 92.85 & 91.51 \\
\hline 180 & 89.08 & 89.60 & 89.47 & 89.38 \\
\hline 210 & 87.44 & 84.07 & 84.86 & 85.45 \\
\hline 270 & 94.03 & 90.72 & 90.23 & 91.66 \\
\hline 300 & 90.13 & 87.06 & 82.05 & 86.41 \\
\hline
\end{tabular}

\begin{tabular}{|c|c|c|c|c|}
\hline \multirow{2}{*}{ Cycles } & \multicolumn{4}{|c|}{ R-CTR-S30-3FT } \\
\hline & $\% \mathrm{D}$ & $\% \mathrm{E}$ & $\% \mathrm{~F}$ & Average \\
\hline 30 & 92.35 & 100.00 & 100.00 & 97.45 \\
\hline 60 & 88.82 & 92.06 & 91.68 & 90.86 \\
\hline 90 & 90.07 & 90.21 & 86.89 & 89.06 \\
\hline 120 & 88.69 & 88.10 & 84.84 & 87.21 \\
\hline 150 & 86.67 & 91.13 & 86.52 & 88.11 \\
\hline 180 & 81.46 & 80.56 & 76.09 & 79.37 \\
\hline 210 & 80.40 & 80.53 & 79.78 & 80.24 \\
\hline 270 & 83.38 & 88.46 & 81.18 & 84.34 \\
\hline 300 & 84.55 & 87.75 & 82.07 & 84.79 \\
\hline
\end{tabular}

\begin{tabular}{|c|ccc|c|}
\hline \multirow{2}{*}{ Cycles } & \multicolumn{4}{|c|}{ V-CTR-3FT } \\
\cline { 2 - 5 } & $\% \mathrm{D}$ & $\% \mathrm{E}$ & $\% \mathrm{~F}$ & Average \\
\hline 30 & 100.00 & 100.00 & 100.00 & 100.00 \\
\hline 60 & 94.33 & 96.15 & 98.27 & 96.25 \\
\hline 90 & 95.03 & 98.41 & 93.86 & 95.77 \\
\hline 120 & 90.77 & 95.25 & 95.77 & 93.93 \\
\hline 150 & 92.97 & 92.33 & 91.58 & 92.29 \\
\hline 180 & 85.83 & 88.66 & 87.55 & 87.35 \\
\hline 210 & 85.53 & 82.04 & 83.50 & 83.69 \\
\hline 270 & 91.64 & 87.40 & 88.98 & 89.34 \\
\hline 300 & 91.48 & 88.12 & 87.22 & 88.94 \\
\hline
\end{tabular}




\section{Appendix D - RCA Absorption Rate Results}

Table D-1 Absorption Rate of 14 mm - 19 mm RCA

\begin{tabular}{|c|c|c|c|c|c|c|c|c|c|}
\hline \multirow{4}{*}{$\begin{array}{c}\text { Weight of Dish (g) } \\
12.5 \\
\end{array}$} & \multicolumn{9}{|c|}{ Specimen A (14 mm - $19 \mathrm{~mm})$} \\
\hline & \multicolumn{9}{|c|}{ Time (Minutes) } \\
\hline & \multicolumn{3}{|c|}{1} & \multicolumn{3}{|c|}{4} & \multicolumn{3}{|c|}{7} \\
\hline & Specimen 1 & Specimen 2 & Specimen 3 & Specimen 1 & Specimen 2 & Specimen 3 & Specimen 1 & Specimen 2 & Specimen 3 \\
\hline Mass of SSD Agg. + Dish (g) & 312.900 & 267.900 & 367.800 & 323.800 & 381.900 & 392.900 & 226.100 & 266.930 & 324.600 \\
\hline Mass of OD Agg. + Dish (g) & 304.300 & 260.800 & 357.100 & 313.100 & 368.100 & 378.700 & 217.900 & 256.900 & 314.400 \\
\hline Mass of OD AGG. (g) & 291.800 & 248.300 & 344.600 & 300.600 & 355.600 & 366.200 & 205.400 & 244.400 & 301.900 \\
\hline Mass of Water (g) & 8.600 & 7.100 & 10.700 & 10.700 & 13.800 & 14.200 & 8.200 & 10.030 & 10.200 \\
\hline Absorption (\%) & 2.947 & 2.859 & 3.105 & 3.560 & 3.881 & 3.878 & 3.992 & 4.104 & \\
\hline Average Absorption (\%) & \multicolumn{3}{|c|}{2.971} & \multicolumn{3}{|c|}{3.773} & \multicolumn{3}{|c|}{4.048} \\
\hline Percentage of Maximum (\%) & 53.918 & 52.313 & 56.806 & & 70.997 & 70.941 & 73.036 & 75.080 & \\
\hline Average \% of Maximum (\%) & \multicolumn{3}{|c|}{54.346} & \multicolumn{3}{|c|}{70.969} & \multicolumn{3}{|c|}{74.058} \\
\hline & \multicolumn{3}{|c|}{15} & \multicolumn{3}{|c|}{30} & \multicolumn{3}{|c|}{45} \\
\hline Parameter & Specimen 1 & Specimen 2 & Specimen 3 & Specimen 1 & Specimen 2 & Specimen 3 & Specimen 1 & Specimen 2 & Specimen 3 \\
\hline Mass of SSD Agg. + Dish (g) & 343.600 & 309.800 & 376.600 & 285.800 & 284.100 & 447.300 & 207.700 & 259.500 & 248.300 \\
\hline Mass of OD Agg. + Dish (g) & 330.300 & 299.100 & 361.900 & 273.100 & 273.300 & 426.200 & 198.000 & 248.600 & 236.700 \\
\hline Mass of OD AGG. (g) & 317.800 & 286.600 & 349.400 & 260.600 & 260.800 & 413.700 & 185.500 & 236.100 & 224.200 \\
\hline Mass of Water (g) & 13.300 & 10.700 & 14.700 & 12.700 & 10.800 & 21.100 & 9.700 & 10.900 & 11.600 \\
\hline Absorption (\%) & 4.185 & & 4.207 & 4.873 & & 5.100 & 5.229 & & 5.174 \\
\hline Average Absorption (\%) & \multicolumn{3}{|c|}{4.196} & \multicolumn{3}{|c|}{4.987} & \multicolumn{3}{|c|}{5.202} \\
\hline Percentage of Maximum (\%) & 76.564 & & 76.970 & 89.157 & & 93.309 & 95.665 & & 94.656 \\
\hline \multirow[t]{2}{*}{ Average $\%$ of Maximum (\%) } & \multicolumn{3}{|c|}{76.767} & \multicolumn{3}{|c|}{91.233} & \multicolumn{3}{|c|}{95.160} \\
\hline & \multicolumn{3}{|c|}{ Maximum (Post 24 Hours) } & & & & & & \\
\hline Parameter & Specimen 1 & Specimen 2 & Specimen 3 & & & & & & \\
\hline Mass of SSD Agg. + Dish (g) & 313.720 & 373.310 & 266.440 & & & & & & \\
\hline Mass of OD Agg. + Dish (g) & 296.300 & 356.200 & 253.700 & & & & & & \\
\hline Mass of OD AGG. (g) & 283.800 & 343.700 & 241.200 & & & & & & \\
\hline Mass of Water (g) & 17.420 & 17.110 & 12.740 & & & & & & \\
\hline Absorption (\%) & 6.138 & 4.978 & 5.282 & & & & & & \\
\hline Average Absorption (\%) & & 5.466 & & & & & & & \\
\hline Percentage of Maximum (\%) & 112.295 & 91.074 & 96.631 & & & & & & \\
\hline Average $\%$ of Maximum (\%) & & 100.000 & & & & & & & \\
\hline
\end{tabular}


Table D-2 Absorption Rate of 10 mm- 14 mm RCA

\begin{tabular}{|c|c|c|c|c|c|c|c|c|c|}
\hline \multirow{3}{*}{$\begin{array}{c}\text { Weight of Dish (g) } \\
12.5\end{array}$} & \multicolumn{9}{|c|}{ Specimen A (10 mm - $14 \mathrm{~mm})$} \\
\hline & \multicolumn{9}{|c|}{ Time (Minutes) } \\
\hline & \multicolumn{3}{|c|}{1} & \multicolumn{3}{|c|}{4} & \multicolumn{3}{|c|}{7} \\
\hline Parameter & Specimen 1 & Specimen 2 & Specimen 3 & Specimen 1 & Specimen 2 & Specimen 3 & Specimen 1 & Specimen 2 & Specimen 3 \\
\hline Mass of SSD Agg. + Dish (g) & 283.600 & 294.600 & 263.600 & 248.600 & 334.700 & 287.800 & 253.200 & 257.300 & 249.500 \\
\hline Mass of OD Agg. + Dish (g) & 274.400 & 290.800 & 254.200 & 240.100 & 323.600 & 276.600 & 243.500 & 248.600 & 240.900 \\
\hline Mass of OD AGG. (g) & 261.900 & 278.300 & 241.700 & 227.600 & 311.100 & 264.100 & 231.000 & 236.100 & 228.400 \\
\hline Mass of Water (g) & 9.200 & 3.800 & 9.400 & 8.500 & 11.100 & 11.200 & 9.700 & 8.700 & 8.600 \\
\hline Absorption (\%) & 3.513 & & 3.889 & 3.735 & 3.568 & 4.241 & 4.199 & 3.685 & 3.765 \\
\hline Average Absorption (\%) & \multicolumn{3}{|c|}{3.701} & \multicolumn{3}{|c|}{3.848} & \multicolumn{3}{|c|}{3.883} \\
\hline Percentage of Maximum (\%) & 65.331 & & 72.330 & 69.457 & 66.357 & 78.871 & 78.096 & 68.531 & 70.028 \\
\hline \multirow[t]{2}{*}{ Average $\%$ of Maximum (\%) } & \multicolumn{3}{|c|}{68.830} & \multicolumn{3}{|c|}{71.562} & \multicolumn{3}{|c|}{72.218} \\
\hline & \multicolumn{3}{|c|}{15} & \multicolumn{3}{|c|}{30} & \multicolumn{3}{|c|}{45} \\
\hline Parameter & Specimen 1 & Specimen 2 & Specimen 3 & Specimen 1 & Specimen 2 & Specimen 3 & Specimen 1 & Specimen 2 & Specimen 3 \\
\hline Mass of SSD Agg. + Dish (g) & 309.200 & 299.300 & 450.100 & 218.400 & 283.900 & 318.500 & 220.000 & 199.000 & 216.600 \\
\hline Mass of OD Agg. + Dish (g) & 297.100 & 286.800 & 431.500 & 209.200 & 272.000 & 305.300 & 211.300 & 190.200 & 207.140 \\
\hline Mass of OD AGG. (g) & 284.600 & 274.300 & 419.000 & 196.700 & 259.500 & 292.800 & 198.800 & 177.700 & 194.640 \\
\hline Mass of Water (g) & 12.100 & 12.500 & 18.600 & 9.200 & 11.900 & 13.200 & 8.700 & 8.800 & 9.460 \\
\hline Absorption (\%) & 4.252 & 4.557 & 4.439 & 4.677 & 4.586 & 4.508 & & 4.952 & 4.860 \\
\hline Average Absorption (\%) & \multicolumn{3}{|c|}{4.416} & \multicolumn{3}{|c|}{4.590} & \multicolumn{3}{|c|}{4.906} \\
\hline Percentage of Maximum (\%) & 79.071 & 84.752 & 82.559 & 86.986 & 85.286 & 83.844 & & 92.101 & 90.391 \\
\hline \multirow[t]{2}{*}{ Average $\%$ of Maximum (\%) } & \multicolumn{3}{|c|}{82.128} & \multicolumn{3}{|c|}{85.372} & \multicolumn{3}{|c|}{91.246} \\
\hline & \multicolumn{3}{|c|}{ Maximum (Post 24 Hours) } & & & & & & \\
\hline Parameter & Specimen 1 & Specimen 2 & Specimen 3 & & & & & & \\
\hline Mass of SSD Agg. + Dish (g) & 329.900 & 356.800 & 297.600 & & & & & & \\
\hline Mass of OD Agg. + Dish (g) & 313.000 & 340.100 & 282.970 & & & & & & \\
\hline Mass of OD AGG. (g) & 300.500 & 327.600 & 270.470 & & & & & & \\
\hline Mass of Water (g) & 16.900 & 16.700 & 14.630 & & & & & & \\
\hline Absorption (\%) & 5.624 & 5.098 & 5.409 & & & & & & \\
\hline Average Absorption (\%) & \multicolumn{3}{|c|}{5.377} & & & & & & \\
\hline Percentage of Maximum (\%) & 104.595 & 94.807 & 100.599 & & & & & & \\
\hline Average $\%$ of Maximum (\%) & \multicolumn{3}{|c|}{100.000} & & & & & & \\
\hline
\end{tabular}


Table D-3 Absorption Rate of $5 \mathrm{~mm}-10 \mathrm{~mm}$ RCA

\begin{tabular}{|c|c|c|c|c|c|c|c|c|c|}
\hline \multirow{3}{*}{$\begin{array}{c}\text { Weight of Dish (g) } \\
12.5 \\
\end{array}$} & \multicolumn{9}{|c|}{ Specimen B (5 mm - $10 \mathrm{~mm})$} \\
\hline & \multicolumn{9}{|c|}{ Time (Minutes) } \\
\hline & \multicolumn{3}{|c|}{1} & \multicolumn{3}{|c|}{4} & \multicolumn{3}{|c|}{7} \\
\hline Parameter & Specimen 1 & Specimen 2 & Specimen 3 & Specimen 1 & Specimen 2 & Specimen 3 & Specimen 1 & Specimen 2 & Specimen 3 \\
\hline Mass of SSD Agg. + Dish (g) & 243.800 & 252.800 & 198.500 & 242.200 & 198.830 & 183.600 & 219.500 & 293.600 & 271.700 \\
\hline Mass of OD Agg. + Dish (g) & 235.500 & 244.300 & 191.450 & 233.300 & 191.600 & 176.600 & 211.800 & 282.800 & 261.300 \\
\hline Mass of OD AGG. (g) & 223.000 & 231.800 & 178.950 & 220.800 & 179.100 & 164.100 & 199.300 & 270.300 & 248.800 \\
\hline Mass of Water (g) & 8.300 & 8.500 & 7.050 & 8.900 & 7.230 & 7.000 & 7.700 & 10.800 & 10.400 \\
\hline Absorption (\%) & 3.722 & 3.667 & 3.940 & 4.031 & 4.037 & 4.266 & 3.864 & 3.996 & 4.180 \\
\hline Average Absorption (\%) & \multicolumn{3}{|c|}{3.776} & \multicolumn{3}{|c|}{4.111} & \multicolumn{3}{|c|}{4.013} \\
\hline Percentage of Maximum (\%) & 74.720 & 73.615 & 79.090 & 80.920 & 81.041 & & & 80.212 & 83.916 \\
\hline \multirow[t]{2}{*}{ Average $\%$ of Maximum (\%) } & \multicolumn{3}{|c|}{75.808} & \multicolumn{3}{|c|}{80.980} & \multicolumn{3}{|c|}{82.064} \\
\hline & \multicolumn{3}{|c|}{15} & \multicolumn{3}{|c|}{30} & \multicolumn{3}{|c|}{45} \\
\hline Parameter & Specimen 1 & Specimen 2 & Specimen 3 & Specimen 1 & Specimen 2 & Specimen 3 & Specimen 1 & Specimen 2 & Specimen 3 \\
\hline Mass of SSD Agg. + Dish (g) & 278.900 & 288.700 & 354.900 & 167.800 & 248.000 & 244.500 & 176.000 & 195.200 & 243.700 \\
\hline Mass of OD Agg. + Dish (g) & 267.700 & 277.200 & 340.600 & 161.400 & 237.900 & 234.300 & 168.900 & 187.300 & 233.520 \\
\hline Mass of OD AGG. (g) & 255.200 & 264.700 & 328.100 & 148.900 & 225.400 & 221.800 & 156.400 & 174.800 & 221.020 \\
\hline Mass of Water (g) & 11.200 & 11.500 & 14.300 & 6.400 & 10.100 & 10.200 & 7.100 & 7.900 & 10.180 \\
\hline Absorption (\%) & 4.389 & 4.345 & 4.358 & 4.298 & 4.481 & 4.599 & 4.540 & 4.519 & 4.606 \\
\hline Average Absorption (\%) & \multicolumn{3}{|c|}{4.364} & \multicolumn{3}{|c|}{4.459} & \multicolumn{3}{|c|}{4.555} \\
\hline Percentage of Maximum (\%) & 88.105 & 87.218 & 87.497 & 86.287 & 89.956 & 92.321 & 91.135 & 90.729 & 92.465 \\
\hline \multirow[t]{2}{*}{ Average $\%$ of Maximum (\%) } & \multicolumn{3}{|c|}{87.607} & \multicolumn{3}{|c|}{89.522} & \multicolumn{3}{|c|}{91.443} \\
\hline & \multicolumn{3}{|c|}{ Maximum (Post 24 Hours) } & & & & & & \\
\hline Parameter & Specimen 1 & Specimen 2 & Specimen 3 & & & & & & \\
\hline Mass of SSD Agg. + Dish (g) & 319.900 & 259.800 & 251.700 & & & & & & \\
\hline Mass of OD Agg. + Dish (g) & 305.200 & 247.900 & 240.600 & & & & & & \\
\hline Mass of OD AGG. (g) & 292.700 & 235.400 & 228.100 & & & & & & \\
\hline Mass of Water (g) & 14.700 & 11.900 & 11.100 & & & & & & \\
\hline Absorption (\%) & 5.022 & 5.055 & 4.866 & & & & & & \\
\hline Average Absorption (\%) & \multicolumn{3}{|c|}{4.981} & & & & & & \\
\hline Percentage of Maximum (\%) & 100.822 & 101.485 & 97.692 & & & & & & \\
\hline Average $\%$ of Maximum (\%) & \multicolumn{3}{|c|}{100.000} & & & & & & \\
\hline
\end{tabular}


Table D-4 Absorption Rate of Graded Mixture

\begin{tabular}{|c|c|c|c|c|c|c|c|}
\hline \multirow{3}{*}{ Weight Percentage (\%) } & \multirow{3}{*}{ Gradation } & \multicolumn{6}{|c|}{ Graded Mixture } \\
\hline & & \multicolumn{6}{|c|}{ Time (Minutes) } \\
\hline & & 1 & 4 & 7 & 15 & 30 & 45 \\
\hline 62.50 & A & 54.346 & 70.969 & 74.058 & 76.767 & 91.233 & 95.160 \\
\hline 30.00 & B & 68.830 & 71.562 & 72.218 & 82.128 & 85.372 & 91.246 \\
\hline 7.50 & $\mathrm{C}$ & 75.808 & 80.980 & 82.064 & 87.607 & 89.522 & 91.443 \\
\hline 100.00 & Mix & 60.301 & 71.898 & 74.107 & 79.188 & 89.346 & 93.707 \\
\hline Weighted Mix Absorption (\%) & 5.403 & & & & & & \\
\hline
\end{tabular}




\section{Appendix E - LOI Testing Results}

Table E-1 Loss on Ignition (LOI) of Paste Samples

\begin{tabular}{|c|c|c|c|c|c|c|c|}
\hline & & \multicolumn{3}{|c|}{ CTR } & \multicolumn{3}{|c|}{$\mathrm{PC}\left(2.5 \mathrm{~L} / \mathrm{m}^{3} \mathrm{SRA}\right)$} \\
\hline Description & Units & A & B & C & A & B & C \\
\hline Mass of Pan & $\mathrm{g}$ & 15.0761 & 15.2105 & 15.2668 & 6.2357 & 6.1704 & 6.1757 \\
\hline Mass of Pan + Air-Dry Sample & $\mathrm{g}$ & 20.5197 & 20.148 & 20.1708 & 11.729 & 12.0724 & 11.4303 \\
\hline Mass of Pan + Oven-Dry Sample & $\mathrm{g}$ & 20.2097 & 19.8683 & 19.8952 & 11.4061 & 11.7236 & 11.1207 \\
\hline Mass of Oven-Dry Sample & $\mathrm{g}$ & 5.1336 & 4.6578 & 4.6284 & 5.1704 & 5.5532 & 4.945 \\
\hline Mass of Water & $\mathrm{g}$ & 0.31 & 0.2797 & 0.2756 & 0.3229 & 0.3488 & 0.3096 \\
\hline Evaporable Water Content & $\%$ & 6.038647343 & 6.004980892 & 5.954541526 & 6.245164784 & 6.281063171 & 6.260869565 \\
\hline Mass of Crucible & $\mathrm{g}$ & 26.4247 & 26.8957 & 27.1166 & 26.4269 & 26.8998 & 27.1185 \\
\hline Mass of Crucible + Oven-Dry Sample & $\mathrm{g}$ & 31.5908 & 31.5738 & 31.772 & 31.682 & 32.481 & 32.1457 \\
\hline Mass of Crucible + Ignited Sample & $\mathrm{g}$ & 30.6378 & 30.7072 & 30.9163 & 30.6535 & 31.4044 & 31.1613 \\
\hline Mass of Ignited Sample & $\mathrm{g}$ & 4.2131 & 3.8115 & 3.7997 & 4.2266 & 4.5046 & 4.0428 \\
\hline Mass of Chemically Bound Water & $\mathrm{g}$ & 0.953 & 0.8666 & 0.8557 & 1.0285 & 1.0766 & 0.9844 \\
\hline Chemically Bound Water Content & $\%$ & 22.61992357 & 22.73645546 & 22.52019896 & 24.33398003 & 23.90001332 & 24.34946077 \\
\hline Average Evaporable Water Content & $\%$ & \multicolumn{3}{|c|}{\begin{tabular}{|l|}
5.99938992 \\
\end{tabular}} & \multicolumn{3}{|c|}{\begin{tabular}{|r|}
6.26236584 \\
\end{tabular}} \\
\hline Average Chemically Bound Water Content & $\%$ & \multicolumn{3}{|c|}{22.625526} & \multicolumn{3}{|c|}{24.19448471} \\
\hline
\end{tabular}

\begin{tabular}{|c|c|c|c|c|c|c|c|}
\hline & & \multicolumn{3}{|c|}{ PC (5 L/m $\mathrm{m}^{3}$ SRA) } & \multicolumn{3}{|c|}{$\mathrm{PC}\left(7.5 \mathrm{~L} / \mathrm{m}^{3} \mathrm{SRA}\right)$} \\
\hline Description & Units & A & B & $\mathrm{C}$ & A & B & $\mathrm{C}$ \\
\hline Mass of Pan & $\mathrm{g}$ & 15.2792 & 15.3814 & 15.4491 & 6.1673 & 6.09 & 6.1844 \\
\hline Mass of Pan + Air-Dry Sample & $\mathrm{g}$ & 20.0945 & 20.1729 & 20.3218 & 11.3954 & 11.0588 & 11.2261 \\
\hline Mass of Pan + Oven-Dry Sample & $\mathrm{g}$ & 19.795 & 19.8687 & 20.0146 & 11.0623 & 10.7413 & 10.9058 \\
\hline Mass of Oven-Dry Sample & $\mathrm{g}$ & 4.5158 & 4.4873 & 4.5655 & 4.895 & 4.6513 & 4.7214 \\
\hline Mass of Water & $\mathrm{g}$ & 0.2995 & 0.3042 & 0.3072 & 0.3331 & 0.3175 & 0.3203 \\
\hline Evaporable Water Content & $\%$ & 6.632268922 & 6.779132218 & 6.728726317 & 6.804902962 & 6.826048632 & 6.784004744 \\
\hline Mass of Crucible & $\mathrm{g}$ & 26.4284 & 26.8991 & 27.1179 & 26.4312 & 27.6747 & 27.12 \\
\hline Mass of Crucible + Oven-Dry Sample & $\mathrm{g}$ & 31.0002 & 31.4607 & 31.749 & 31.2662 & 32.4482 & 31.9564 \\
\hline Mass of Crucible + Ignited Sample & $\mathrm{g}$ & 30.1005 & 30.5543 & 30.8198 & 30.2701 & 31.4422 & 30.948 \\
\hline Mass of Ignited Sample & $\mathrm{g}$ & 3.6721 & 3.6552 & 3.7019 & 3.8389 & 3.7675 & 3.828 \\
\hline Mass of Chemically Bound Water & $\mathrm{g}$ & 0.8997 & 0.9064 & 0.9292 & 0.9961 & 1.006 & 1.0084 \\
\hline Chemically Bound Water Content & $\%$ & 24.50096675 & 24.7975487 & 25.100624 & 25.94753705 & 26.70205707 & 26.34273772 \\
\hline Average Evaporable Water Content & $\%$ & \multicolumn{3}{|c|}{6.713375819} & \multicolumn{3}{|c|}{6.804985446} \\
\hline Average Chemically Bound Water Content & $\%$ & \multicolumn{3}{|c|}{24.79971315} & \multicolumn{3}{|c|}{26.33077728} \\
\hline
\end{tabular}

\begin{tabular}{|c|c|c|c|c|}
\hline & & \multicolumn{3}{|c|}{$\mathrm{S} 30\left(7.5 \mathrm{~L} / \mathrm{m}^{3} \mathrm{SRA}\right)$} \\
\hline Description & Units & A & B & C \\
\hline Mass of Pan & $\mathrm{g}$ & 27.7188 & 27.6278 & 27.5574 \\
\hline Mass of Pan + Air-Dry Sample & g & 33.1754 & 33.15 & 33.5041 \\
\hline Mass of Pan + Oven-Dry Sample & $\mathrm{g}$ & 32.87 & 32.8404 & 33.1662 \\
\hline Mass of Oven-Dry Sample & $\mathrm{g}$ & 5.1512 & 5.2126 & 5.6088 \\
\hline Mass of Water & $\mathrm{g}$ & 0.3054 & 0.3096 & 0.3379 \\
\hline Evaporable Water Content & $\%$ & 5.928715639 & 5.939454399 & 6.02446156 \\
\hline Mass of Crucible & $\mathrm{g}$ & 26.4308 & 26.9025 & 27.1188 \\
\hline Mass of Crucible + Oven-Dry Sample & $\mathrm{g}$ & 31.5312 & 32.0825 & 32.7015 \\
\hline Mass of Crucible + Ignited Sample & $\mathrm{g}$ & 30.6474 & 31.1859 & 31.7363 \\
\hline Mass of Ignited Sample & g & 4.2166 & 4.2834 & 4.6175 \\
\hline Mass of Chemically Bound Water & $\mathrm{g}$ & 0.8838 & 0.8966 & 0.9652 \\
\hline Chemically Bound Water Content & $\%$ & 20.96001518 & 20.93196993 & 20.90308609 \\
\hline Average Evaporable Water Content & $\%$ & \multicolumn{3}{|c|}{5.964210533} \\
\hline Average Chemically Bound Water Content & $\%$ & \multicolumn{3}{|c|}{20.9316904} \\
\hline
\end{tabular}




\section{References}

Abbas, A., Fathifazl, G., Isgor, O. B., Razaqpur, A. G., Fournier, B., \& Foo, S. (2009). Durability of Recycled Aggregate Concrete Designed with Equivalent Mortar Volume Method. Cement and Concrete Composites, 31(8), 555-563.

American Concrete Pavement Association. (2010). American Concrete Pavement Association. Retrieved July 2012, from Properties and Characteristics of RCA: http://www.pavement.com/Downloads/TS/EB043P/TS043.3P.pdf

American Concrete Pavement Association. (2010). Properties of Concrete Containing RCA. Retrieved 2012, from Concrete Pavement Technology Series: www.acpa.org

American Concrete Pavement Association. (2010). Uses of RCA. Retrieved 2012, from Concrete Pavement Technology Series: www.acpa.org

ASTM C1202. (2012). Standard Test Method for Electrical Indication of Concrete's Ability to Resist Chloride Ion Penetration. West Conhohocken: ASTM.

ASTM C127. (2007). Standard Test Method for Densities, Relative Density (SPecific Gravity), and Absorption of Coarse Aggregate. West Conshohocken: ASTM.

ASTM C157. (2008). Standard Test Method for Length Change of Hardened HydraulicCement Mortar and Concrete. West Conhohocken: ASTM.

ASTM C260. (2010). Standard Specification for Air-Entraining Admixtures for Concrete. West Conshohocken: ASTM.

ASTM C39. (2012). Standard Test Method for Compressive Strength of Cylindrical Concrete Specimens. West Conhohocken: ASTM. 
ASTM C597. (2009). Standard Test Method for Pulse Velocity Through Concrete. West Conhohocken: ASTM.

ASTM C666. (2008). Standard Test Method for Resistance of Concrete to Rapid Freezing and Thawing. West Conhohocken: ASTM.

ASTM D6928. (2010). Standard Test Method for Resistance of Coarse Aggregate to Degradation by Abrasion in the Micro-Deval Apparatus. West Conhohocken: ASTM.

Berndt, M. L. (2009). Properties of Sustainable Concrete Containing Fly Ash, Slag and Recycled Concrete Aggregate. Construction and Building Materials, 23(7), 26062613.

Canadian Standards Association. (2009). Concrete materials and methods of concrete construction/Test methods and standard practices for concrete. Canadian Standards Association. CSA.

Corinaldesi, V. (2011). Structural Concrete Prepared with Coarse Recycled Concrete Aggregate: From Investigation to Design. (P. Monteiro, Ed.) Advances in Civil Engineering, 2011(10.1155), p. 6 Pages.

Corinaldesi, V., \& Moriconi, G. (2010). Recycling of rubble from building demolition for low-shrinkage concrete. Waste Management, 30(4), 655-659.

CSA 23.1. (2000). Concrete Materials and Methods of Concrete Construction/Methods of Test for Concrete. Toronto: Canadian Standards Association.

CSA 23.2-14A. (2009). Potential Expansivity of Aggregates; Procedure for Length Change Due to Alkali-Aggregate Reaction in Concrete Prisms. Toronto: Canadian Standards Association. 
European Committee for Standardization. (2012). EN 206 - Concrete - Specification, performance, production and conformity. European Committee for Standardization. Brussels: European Committee for Standardization.

Fontana, P. (2013). Damage Mechanisms and Protective Measures - Degradation of concrete by alkali silica reaction (ASR). Retrieved June 20, 2013, from BAM Federal Institute for Materials Research and Testing: http://www.bam.de/en/kompetenzen/fachabteilungen/abteilung_7/fg71/fg71_ag2c .htm

Hansen, T. C. (1986). Recycled aggregates and recycled aggregate concrete second stateof-the-art report developments 1945-1985. Materials and Structures, 19(3), 201246.

Hooton, R. D., Stanish, K., \& Prusinski, J. (2004). The Effect of Ground, Granulated Blast Furnace Slag (Slag Cement) on the Drying Shrinkage of Concrete - A Critical Review of the Literature. Eighth CANMET/ACI International Conference on Fly Ash, Silica Fume, Slag and Natural Pozzolans in Concrete. American Concrete Institute.

Konin, A., \& Kouadio, D. M. (2011). Influence of Cement Content on Recycled Aggregates Concrete Properties. Modern Applied Science, 5(1), 23-31.

Kosmatka, S. H., Kerkhoff, B., Hooton, R. D., \& McGrath, R. J. (2011). Design and Control of Concrete Mixtures. Ottawa: Cement Association of Canada.

Kosmatka, S. H., Kerkhoff, B., Panarese, W. C., MacLeod, N. F., \& McGrath, R. J. (2002). Design and Control of Concrete Mixtures (7th Canadian Edition). Ottawa, ON, Canada: Cement Association of Canada. 
Limbachiya, M. C., Koulouris, A., Roberts, J. J., \& Fried, A. N. (2004). Performance of Recycled Aggregate Concrete. In N. Kashino, \& O. Y. (Ed.), RILEM International Symposium on Environmental-Conscious Materials and Systems for Sustainable Development (pp. 127-136). RILEM Publications SARL.

Mehta, P. K., \& Monteiro, P. J. (1993). Concrete: Structure, properties, and materials (Vol. 2). Englewood Cliffs, New Jersey, USA: Prentice Hall Canada.

Mindess, S., Young, J., \& Darwin, D. (2003). Concrete (2nd Edition). New Jersey, USA: Pearson Education Ltd.

Moser, R. D., Jayapalan, A. R., Garas, V. Y., \& Kurtis, K. E. (2010). Assessment of binary and ternary blends of metakaolin and Class $\mathrm{C}$ fly ash for alkali-silica reaction mitigation in concrete. Cement \& Concrete Research, 40(12), 1664-1672.

Oikonomou, N. D. (2005). Recycled concrete aggregates. Cement \& Concrete Composites, 27(2), 315-318.

Poon, C. S., Shui, Z. H., Lam, L., Fok, H., \& Kou, S. C. (2004). Influence of Moisture States of Natural and Recycled Aggregates on the Slump and Compressive Strength of Concrete. Cement and Concrete Research, 34(1), 31-36.

Rahman, I. A., Hamdam, H., \& Ahmad Zaidi, A. M. (2009, October). Assesment of Recylced Aggregate Concrete. Modern Applied Science, 3(10), 47-54.

Ryu, J. S. (2002). Improvement on strength and impermeability of recycled concrete made from crushed concrete coarse aggregate. Journal of Material Science, 21(20), 1565-1567.

Sagoe-Crentsil, K. K., Brown, T., \& Taylor, A. H. (2001). Performance of Concrete Made With Commercially Produced Coarse Recycled Concrete Aggregate. Cement and Concrete Research, 31(5), 707-712. 
Shehata, M. H., \& Thomas, M. (2010). The Role of Alkali Content of Portland Cement on the Expansion of Concrete Prisms Containing Reactive Aggregates and Supplementary Cementing Materials. Cement and Concrete Research, 40(4), 569574.

Shehata, M., \& Thomas, M. (2006). Alkali Release Characteristics of Blended Cements. Cement and Concrete Research, 36(6), 1166-1175.

Sriravindrajah, R., Loo, Y. H., \& Tam, C. T. (1988). Strength evaluation of recycledaggregate concrete by in-situ tests. Materials \& Structures, 21(4), 289-295.

Stark, D. (1996). The Use of Recycled-Concrete Aggregate from Concrete Exhiniting Alkali-Silica Reactivity. Skokie, IL, USA: Portland Cement Association.

Tam, V. W., \& Tam, C. M. (2007). Assessment of durability of recycled aggregate concrete produced by two-stage mixing approach. Journal of Materials Science, 42(10), 3592-3602.

Tam, V. W., Gao, X. F., \& Tam, C. M. (2005). Microstructural analysis of recycled aggregate concrete produced from two-stage mixing approach. Cement and Concrete Research, 35(6), 1195-1203.

Tavakoli, M., \& Soroushian, P. (1996). Drying Shrinkage Behaviour of Recycled Aggregate Concrete. Concrete International, pp. 58-61.

The Constructor. (2012). Ultrasonic Pulse Velocity (UPV) Test. Retrieved February 2013, from The Constructor - Civil Engineering Home: http://theconstructor.org/concrete/ultrasonic-pulse-velocity-upv-test/2847/

Wang, K., \& Steffes, B. (2009). Investigation into Freezing-Thawing Durability of Low Permeability Concrete with and without Air Entraining Agent. Retrieved from Iowa State University - Institute for Transportation: http://www.intrans.iastate.edu/research/projects/detail/?projectID=-370307518 
Zhang, W., \& Ingham, J. M. (2010). Using Recycled Concrete Aggregates in New Zealand Ready-Mix Concrete Production. Journal of Materials in Civil Engineering, 22(5), 443-450. 